Portland State University

PDXScholar

$5-1977$

\title{
An exploratory study of adolescent perceptions of communication behavior
}

\author{
Pat Adams \\ Portland State University \\ Marion Summers \\ Portland State University
}

Follow this and additional works at: https://pdxscholar.library.pdx.edu/open_access_etds

Part of the Interpersonal and Small Group Communication Commons, and the Social Work Commons Let us know how access to this document benefits you.

\section{Recommended Citation}

Adams, Pat and Summers, Marion, "An exploratory study of adolescent perceptions of communication behavior" (1977). Dissertations and Theses. Paper 1904.

https://doi.org/10.15760/etd.1903

This Thesis is brought to you for free and open access. It has been accepted for inclusion in Dissertations and Theses by an authorized administrator of PDXScholar. Please contact us if we can make this document more accessible: pdxscholar@pdx.edu. 
AN EXPLORATORY STUDY OF ADOLESCENT PERCEPTIONS

$\mathrm{OF}$

COMMUNICATION BEHAVIOR

by

PAT ADAMS AND MARION SUMMERS

A report submitted in partial fulfillment of the requirements for the degree of

MASTER OF

SOCIAL WORK

Portland State University

19.77 
This Practicum for the

Master of Social Work Degree

by

Pat Adams and Marion Summers

has been approved

May 1977

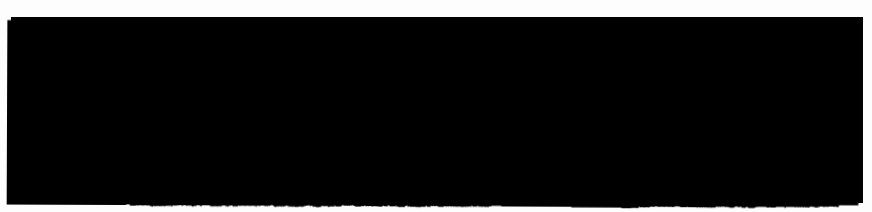

Lewis H. Curtis, Practicum Advisor 


\section{ACKNOWLEDGMENTS}

The researchers wish to express their appreciation to the administrative personnel at The Bridge for giving us permission to conduct this research project within their program. Their suggestions and encouragement during the course of our study were also greatly appreciated.

We particularly want to thank Phyllis Koch, the social worker at The Bridge, for her support and cooperation in administering our questionnaire. This research project would have been very difficult to complete without her help. We would also like to thank the girls at The Bridge for their willingness and cooperation in filling out our questionnaire.

We are grateful to Dr. Frank Miles for his knowledge and guidance. His patience with our attempts at statistical analysis and his enthusiasm for what we were trying to accomplish helped to make this project a reality.

Finally, the researchers especially want to convey their appreciation and gratitude to Mr. Lewis Curtis. Not only did he contribute time and effort in his role as our advisor, he also served as an invaluable source of information and knowledge about the field under investigation. His guidance in helping us define the scope of our study and his support in facilitating its completion are greatly valued. 
TABLE OF CONTENTS

Page

LIST OF TABLES ............................... vi

LIST OF FIGURES . . . . . . . . . . . . . . . ix

Chapter

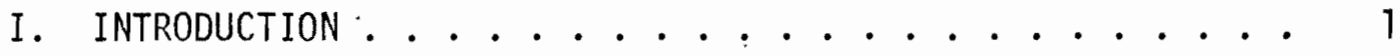

II. REVIEW OF THE LITERATURE . . . . . . . . . . . . 6

General Adolescent Development . . . . . . . . 6

Parent-Child Relationships ........... 13

Studies of Relationship Dimensions ......... 22

Interlocking crises ............ 31

Runaways ................ 36

Communication ................ 41

Family Therapy ............... . . 70

Milieu Treatment ............... 78

III. METHODOLOGY . . . . . . . . . . . . . 87

Introduction .............. . . 87

Measurement Scale ............ 87

Administration of Questionnaire ......... 89

IV. PRESENTATION AND EVALUATION OF DATA ........ 92

Coding, Tabulation, and Scoring of Data . . . . . 93

Population Perceptions of the Communication

Process .......................... 100 
Chapter

Population Characteristics .......... 100

Perception Scores Before Program Involvement ............... 110

Perception Scores After Program Involvement ............... 116

Comparison of Before and After Perception Scores ............. 121

Population Perceptions of Communication Content . . 126

Process Areas from a Content Perspective .. . . . . . . . . . 126

Basic Content Areas ............. 141

V. CONCLUSIONS AND RECOMMENDATIONS . . . . . . . . 169

Limitations . . . . . . . . . . . . 169

Conclusions . . . . . . . . . . . . . 170

Implications for Program Development . . . . . . 182

Implications for Future Studies . . . . . . . 186

VI. EPILOGUE . . . . . . . . . . . . . . . . . . 189

LIST OF WORKS CONSLILTED . . . . . . . . . . . . . . . 190

APPENDIX A: DEMOGRAPHIC FACE SHEET . . . . . . . . . . . . 201

APPENDIX B: QUESTION CONTENT AND PROCESS

CATEGORIES .................... 204

APPENDIX C: COVER SHEETS AND QUESTIONNAIRE . . . . . . . . 210

APPENDIX D: DEFINITIONS OF STATISTICAL MEASURES . . . . . . . 219 
LIST OF TABLES

TABLE

Page

I. A Replica of Becker's Dimension Combinations . . . . 18

II. Interactions in the Consequences of Warmth vs. Hostility and Restrictiveness vs. Permissiveness . . . 20

III. Number and. Program Involvement of Girls Completing Questionnaires............ 90

IV. Scale Used in Rating Responses . . . . . . . . . 94

V. Questions Within the Category of Sending Information ................ 95

VI. Questions Within the Category of Receiving Information .............. 96

VII. Questions Within the Category of Sending Feelings................. . . 97

VIII. Questions Within the Category of Receiving

Feelings................. 98

IX. Hedian Scores by Category and Population Group . . . . 102

X. Length of Stay in Total Weeks .......... . 103

XI. Age of Girls at Intake............. 103

XII. Marital Status of Natural Parents ........ 104

XIII. Most Recent Family Setting . . . . . . . . . 105

XIV. Length of Time in Most Recent Family Setting . . . . . 106

XV. Last Grade Completed .............. . 106

XVI. Current Educational Status Prior to Bridge . . . . . . 107

XVII. Prior Involvenent with Juvenile Justice System . . . 107

XVIII. Place to Which Girl Initially Ran ......... 108 
XIX. Number of Times Previously Run .......... 108

XX. Disposition from Bridge . . . . . . . . . . 109

XXI. Summary of Test Results for Perception Scores Before Program Involvement: Population

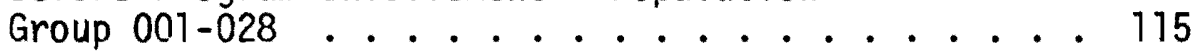

XXII. Summary of Test Results for Perception Scores After Program Involvement: Population Group 001-008..................... 120

XXIII. Summary of Test Results for Perception Scores Before and After Program Involvement: Population Group 001-008 ........... 125

XXIV. Questions Receiving Lowest Ratio Scores for Parents: Sending Information ......... 128

XXV. Questions Receiving Lowest Ratio Scores for Parents: Receiving Information . . . . . . 129

XXVI. Questions Receiving Lowest Ratio Scores for Parents: Sending Feelings ........... 130

XXVII: Questions Receiving Lowest Ratio Scores for

Parents: Receiving Feelings.......... 131

XXVIII. Questions Receiving Lowest Ratio Scores for Adults: Sending Information ........ 132

XXIX. Questions Receiving Lowest Ratio Scores for Adults: Receiving Information......... 133

$X X X$. Questions Receiving Lowest Ratio Scores for Adults: Sending Feelings .......... 134

XXXI. Questions Receiving Lowest Ratio Scores for Adults: Receiving Feelings ........... 135

XXXII. Questions Receiving Lowest Ratio Scores by Content Area and Process Area Before and After Program Involvement . . . . . . . 139

XXXIII. Ratio, Scores for Content Areas: Parents . . . . . 142 XXXIV. Ratio Scores for Content Areas: Adults . . . . . . 143 XXXV. Summary of Test Results for Content Ratio Scores . . 146 
TABLE

Page

XXXVI. Parent and Adult Ratio Scores for Anger Before and After Program Involvement ... . . . . . 148

XXXVII. Rank of Content Areas for Parents Before Program Involvement: Highest to Lowest . . . . . . . . . . . . . 164

XXXVIII. Rank of Content Areas for Parents After Program Involvement: Highest to Lowest . . . . . . . 165

XXXIX. Rank of Content Areas for Adults Before Program Involvement: Highest to Lowest . . . . . . . 166

$X L$. Rank of Content Areas for Adults After Program Involvement: Highest to Lowest ........... 
1. A Replica of Schaefer's (1959) Hypothetical Circumplex Model for Maternal Behavior . . . . . 15

2. A Replica of Roe's Model for Parent Behavior . . . . 16

3. A Replica of Becker's Hypothetical Model for Parental Behavior ............. 17

4. A Replica of Slater's Model for Parent Behavior . . . 18

5. A Replica of Gordon's "You" Message--"I" Message Dichotomy 
Chapter I

\section{INTRODUCTION}

The interaction between troubled adolescents and the adult world is generally characterized as laden with ambiguity and conflict, and is rarely seen as productive or mutually satisfying. This research project is an attempt to study the way in which this interaction is perceived by a group of female adolescents involved in The Bridge, a short-term residential program for girls in a state of early crisis as demonstrated by runaway behavior. This study specifically focuses on communication behaviors of parents and of adults other than parents as perceived by the adolescent upon her entry into The Bridge and at her release from the program.

The impact of communication cannot be underrated. Problems in the communication process contribute to the need for intervention into the adolescent's social network and also make the success of that intervention more difficult. Both authors have had prior involvement with adolescents in various treatment settings and have heard again and again the lament of the adolescent that "nobody understands me," "nobody listens,". and "nobody cares." Unless the adolescent receives messages that enhance her. sense of self, her adaptation to her present world and her move into the adult world of the future will be impaired.

While the primary source for meeting or not meeting the adolescent's interpersonal needs of affection, inclusion, and autonomy is the parent- 
adolescent relationship, other sources can also influence or address these needs. As the adolescent moves toward adulthood, she is increasingly involved with adults other than her parents--particularly if she engages in runaway or delinquent behavior. These adults vary widely and may include teachers, policemen, juvenile court personnel, judges, probation officers, case workers, social workers, group workers, etc. The adolescent's exposure to these adults can have either positive or negative effects, depending upon the adolescent's perception of the messages conveyed.

Therefore, our research study will attempt to explore and further develop the following assumptions:

1. Symptoms expressed by a family member may signify or represent a dysfunctional family system--one that is not meeting the needs of family members and promoting growth.

2. The adolescent's perception of the behavior of others is more important in determining her adjustment than is the actual behavior of others.

3. The adolescent's perception of parent-adolescent communication is a contributing factor in her decision to run away.

4. The adolescent engages in perception generalization in that she assumes that other adults will relate to her in the same manner that her parents relate to her.

5. Therapeutic intervention into the family system has an impact on the adolescent's perception of parental communication behaviors.

6. Therapeutic exposure to adult role models who communicate functionally enables the adolescent to perceive adults other than her parents in a more favorable light.

\section{Setting}

Our source of data. and information is the treatment population involved in The Bridge program. This experimental program was begun in 
1976 and is short-term with the maximum stay for a girl being two months. The Bridge provides residential milieu care for the girls and intensive therapy with their families as part of treatment. The expressed goal of The Bridge is to "stabilize the family system, thus preventing long-term, out-of-home placements." When this is not possible or feasible, program efforts are directed toward stabilizing the individual girl to enable her to accept responsibility and make decisions about herself and her future.

In an attempt to foster the goal of stabilizing individual girls, The Bridge also provides emergency shelter care to runaways who are actively seeking shelter or who have refused to return home once apprehended. The Bridge evaluates their situations and makes recommendations for future service such as referral to another social service agency, continued care at The Bridge, etc.

A professional team at The Bridge is responsible for the diagnostic assessment of the adolescent's problem situation, formulation of problemsolving goals and methods, and the provision of treatment services to those girls in residence. The program administrator fills dual roles: she is responsible for program management and policy-making, and is also supervisor of the child care staff. The social worker is responsible for therapy with families, provides consultation to the child care staff and teachers, and is available for screening and intake. She is assisted by a part-time social work intern. The child care workers are responsible for the supervision of daily living activities, on-the-spot therapeutic interventions, and management of three group living meetings per week. The teacher is responsible for the girls in residence from 9:00 a.m. to 
1:00 p.m. each weekday and provides them with individualized educational material. As these descriptions indicate, the girls at The Bridge are exposed to a number of adults performing various professional functions during the course of their program involvement.

\section{$\underline{\text { Subjects }}$}

The subjects of our study were drawn from The Bridge population. In order to clarify certain factors about these subjects, some information on referral and intake procedures at The Bridge is necessary.

Referrals to The Bridge come from a variety of sources including the police, youth service centers, Children's Services Division, and juvenile courts. Referrals which are appropriate for the program meet the following criteria: 1) the adolescent is a female between the ages of 12 and 18;2) she has exhibited runaway behavior and has preferably run away only one or two times; and 3) her family resides in the tricounty (Multnomah, Washington, and Clackamas) area. "Family" here is defined to mean an intact or partially intact natural family, although a long-term committed foster family will also be considered. Inappropriate referrals to The Bridge are those in which the adolescent demonstrates a severe emotional disturbance or severe learning deficiencies. Adolescents who are or who have been in substitute care such as group homes, child care centers, and institutions are also not acceptable referrals.

Once referral criteria have been met, admission to the program is contingent upon a verbal commitment made by both the parents and the adolescent to participate in treatment with the intent of working toward the return of the adolescent to her family. (Criteria for referral to 
emergency shelter care are the same as those for program referral with the exception that adolescents and parents are not required to make a commitment for treatment at The Bridge.) During an initial screening interview at The Bridge which includes both the adolescent and her family, the adolescent is informed that her participation in the program is entirely voluntary: she may at any time express to a staff member her desire to terminate involvement in the program. If this occurs, the staff member will then take appropriate action on her decision, which may range from actually returning the girl to her family to helping her to evaluate and reconsider the consequences of her decision.

The actual subjects of our study include two groups of adolescents: those girls who were involved in the intake procedure, and those girls who were accepted into and officially completed the program. "Girls involved in intake" includes those who met the referral criteria and who may or may not have been in emergency shelter and who may or may not have been accepted into The Bridge program. "Girls officially completing the program" refers to those girls who were released from the program on the basis of mutual agreement between the girl and the staff that treatment efforts had progressed as far as possible. In these cases, termination occurred via a planned transition rather than through runaway behavior or an abrupt decision to leave. 
Chapter II

REVIEW OF THE LITERATURE

\section{General Adolescent Development}

Adolescence is as confusing to those who try to define it as it is to those who are experiencing it. The definitions given of adolescence are varied, and problems often arise due to ambiguous terninology. Basic assumptions as to what actually constitutes adolescence differ with differing schools of thought. Sociological definitions see adolescence as a transition period from dependent childhood to self-sufficient adulthood. Psychological definitions, on the other hand, see this period as a marginal situation in which new adjustments have to be made to distinguish child behavior from adult behavior.

Both these views have a common factor: a distinction is made between the status or role of the child and the status or role of the adult. This distinction is readily apparent in terms of physique, clothing, recreation, cultural customs, ways of behaving and being treated, and formalized legal codes. However, between the child-adult dichotomy occurs a grey period known as adolescence. For the adolescent is simultaneously partly in and partly out of the child world, and partly in and partly out of the adult world. Adolescence overlaps both childhood and adulthood, and therein lies the difficulty.

Wattenburg (116) points out some of the consequences of being in an overlapping situation. The adolescent tends to have stronger social 
and identity needs than a person not in an overlapping situation. Sensitive to the issues relating to the content of the overlapping (i.e. age), the adolescent often behaves in a vacillating manner in which she alternates between childlike and adultlike behavior. With the onslaught of puberty, the adolescent is physically no longer a child, but psychologically is not yet an adult. Her attempts to reconcile her ambiguous position generally result in a period of crisis.

Controversy exists in the literature as to the extent and intensity of this crisis. Representing one side of the controversy surrounding adolescent turmoil are the findings of offer and 0ffer (86). In a longitudinal follow-up study, the authors selected a group of nonpatient adolescents whose adaptation to their environment was not seen as deviant by parents, teachers, or psychological tests. They found that their sample of "normal" adolescents adequately coped with crises and stresses through using appropriate defense mechanisms and an action orientation. As a result; Offer and offer see adolescence as a period of successful adaptation for the majority of adolescents rather than a time of painful fluctuation.

Representing the other side of the controversy are authors such as Peter BJos (27) and Anna Freud (48). Blos sees the adolescent as passing through stages of self-consciousness and fragmented existence which are accompanied by feelings of isolation, loneliness, and confusion. Adolescent individuation is indeed a time of crisis according to the following statement: "the realization of the finality of the end of childhood, of the binding nature of commitments, of the definite limitation to individual existence itself--this realization creates a 
sense of urgency, fear, and panic" (27, p. 19). Anna Freud sees adolescent reactions as a developmental disturbance. She agrees with Blos in seeing adolescence as a time of upheaval in character and personality. The disturbances are often so sweeping that the picture of the former child becomes wholly submerged in the newly evolving image of the adolescent. Part of the difference between this view and the view presented by Offer and Offer lies in the relative populations examined. While Offer and Offer examined non-deviant adolescents, Blos and Freud draw on an adolescent patient population.

Most other authors fa11 somewhere between these two yiews $(11,74$, 83, 104). Despite their various positions on the continuum of "adaptation vs. turmoil" in adolescence, a11 authors do agree that certain changes in the areas of biology, cognition, interpersonal relations, and identity occur in adolescence. These changes are given different emphasis by different authors.

In the area of biological and sexual changes, psychoanalytic theory plays a predominant role. Muuss (85), for example, sees the stages of psycho-sexual development as genetically determined and relatively independent of environmental factors. Al1 adolescents experience the seemingly sudden physical changes of puberty--body image becomes radically different, sexual tensions increase, and reproduction is now possible. With the increase in libido or sexual impulses, the main task of adolescence according to psychoanalytic theory becomes the attainment of genital primacy in the definitive completion of the process of nonincestuous object-finding. These changes and tasks tend to be unsettling to the adolescent due to her lack of understanding about the nature of 
her developing sexuality, the influences of the peer group and the mass media in promoting an unrealistic physical ideal, and the fact that the individual matures at her own rate irrespective of social standards.

Another area of major change for the adolescent is in her cognitive functioning. Piaget is largely responsible for the development of theory in this area and assigns it primary importance:

Consciousness, judgment, and reasoning--in fact, a11 attributes of personality--depend primarily upon the evolving intellectual capacity of the individual to organize his experience (75, p. 85). He delineates the forms that thinking assumes at various developmental levels. In adolescence, hypothetico-deductive thinking becomes possible in which common principles can be derived from specific instances, and specific instances can be placed into general systems and theories. The adolescent becomes able to think and reason beyond the realities of her own world and her own beliefs. She enters the world of ideas and finds pleasure in the new power of manipulating ideas without seriously committing herself to any one idea. Her cognitive striving to find an equilibrium between herself and her environment depends on two interrelated processes: 1) assimilation in which the individual subjectively experiences an event as she conceives it, and 2) accommodation in which she conceives of and incorporates the experience as it truly is. Empowered with a new kind of reasoning, the adolescent perceives her capacity to explore as both exciting and frustrating.

A number of authors have contributed to the study of interpersonal relations in adolescence. According to Wenar (117), the main task of the adolescent in this area is to re-do the contingencies upon which valuing of self is based. In childhood, the granting or withholding of parental 
love results in either a feeling of "I am loveworthy" (self-satisfaction) or "I am not loveworthy" (guilt). However, in adolescence, the source of satisfaction is shifted from parents to peers: the granting or withholding of esteem by peers results in either a feeling of "I am esteemworthy" (self-esteem) or "I am not esteemworthy" (inferiority). In addition to this primary role, peer groups also perform a number of other important social functions for the adolescent. As Mays (81) indicates, the peer group offers opportunities for exploration and experimentation in new social situations away from the scrutiny and control of parents and adults. The group becomes the source of emotional support by promoting a sense of belonging and providing clear guides to behavior. In this way the group helps the adolescent to master her uncertainty and establish self-control without having to rely on old forms of parental discipline. Despite the rigidity, absolutism, and demands for conformity which characterize the adolescent group, it does serve as a bridge to the future for the adolescent as she moves from egocentrism to reciprocity.

The last major area of change, and perhaps the one most commonly associated with adolescence, is that of the "identity crisis." Here the dominant theorist is Erikson $(42,43)$. In Identity, Youth and Crisis, he describes the eight stages of man and their accompanying tasks. The fifth stage occurs at adolescence and the critical task is to acquire a sense of identity while overcoming a sense of identity diffusion. The formation of identity occurs during a psychosocial moratorium--a period of delay granted to the adolescent who is not yet ready to meet the obligations of adult society. During this period, the adolescent 
examines previously resolved issues in order to integrate them into a new sense of personal identity. Erikson lists seven dimensions of this task: 1) time perspective vs, time diffusion in which the adolescent must be able to see her life in a definite framework; 2) self-certainty vs. apathy in which the awareness of self and the presentation of self must coincide; 3 ) role experimentation vs. negative identity in which opportunities for successful experimentation with a wide range of roles must be provided; 4) anticipation of achievement vs. work paralysis in which the sense of industry must be brought together in a persistent pattern rather than to unrelated situational opportunities; 5) sexual identity vs. bisexual diffusion in which the adolescent must see himself or herself as wholly male or female and experience comfort in a range of contacts with the opposite sex; 6) leadership polarization vs. authority diffusion in which the adolescent must have a realistically clear appraisal of authority and a readiness to be in authority if necessary; and 7) ideological polarization vs. diffusion of ideals in which the adolescent must select a basic philosophy, ideology, or religion to provide an anchoring trust in her life and in society. Successful resolution of these dimensions and crises result in a sense of inner continuity and interpersonal mutuality for the adolescent. While the individual must make choices compatible with herself and with the opportunities of her society, her society must also adapt to the crises of this phase. On the one hand, society must extend sufficient time, space, and social freedom to the adolescent. But on the other hand, it cannot deny its ultimate range of control and guidance over her. In summary, identity, interpersonal relations, cognition, and 
physiology are areas of major change in adolescence. How much and what kind of crisis occurs as a result of these changes depends on the particular focus of the author's orientation. One way of integrating these perspectives is to view the adolescent crisis on a continuum. For some adolescents, this period can be extremely traumatic while others seem to pass through adolescence with a minimum of discomfort. One of the keys to understanding this individual variation during the period of time which occurs between childhood and adulthood lies in parent-child relationships, the subject of the next section. 
Parent-Child Relationships

Parent-child relationships occur within the context of the family, which makes an understanding of the family crucial. Andrews (9) has described the family as a number of differing systems. The family as an emotional system gains intensity from the repetitious and close proximity of daily living together. The family as a living system promotes growth and change as part of its natural development. And in the family as a social system, behavior results from both forces within and without the individual.

Within these family systems, Stachowiak (108) proposes four major factors in family effectiveness. To maintain family productivity or efficiency, a balance is needed between task-oriented activities and attending to family members' emotional needs. Leadership patterns should include a moderate tendency toward a matriarchal or patriarchal structure (as opposed to an autocratic or leaderless equalitarian style) and allow for different family members to take a leadership role at different times. Expression of conflict should occur appropriately (neither too much nor too little) and clarity of communication should be present. In somewhat more detail, Glasser and Glasser (53) define five criteria of adequate family functioning. The first criteria is internal role consistency: in order to behave appropriately in a way which contributes to the solution of family problems, each member must understand what is expected of herself and others. The second criteria is consistency between family roles and norms and actual role performance: to maintain consistent expectations and norms within the group, it is necessary that the members carry out their roles in the way anticipated. 
The third criteria is compatibility of family roles and norms with societal norms: external systems need to view the family as functioning appropriately in meeting community standards. The fourth criteria is the meeting of psychological needs of family members: a member must perform roles that are not only consistent with her own expectations and the expectations of other group members but also meet her socioemotional needs. The fifth criteria of adequate family functioning is the ability of the family group to respond to change: to maintain itself, the family must be in a state of dynamic equilibrium, responding appropriately to the demands of role flexibility, unanticipated situational changes, and environmental pressures for change.

Within the framework presented above, families can be further characterized in terms of family atmosphere. Wattenberg (116) presents the following dimensions of family atmosphere: 1) morale and emotional climate, 2) knittedness, 3) routines, 4) discipline, and 5) decisionmaking. For example, families can be either easy-going or suspicious, either tight-knit or fragmented, either integrated or disorganized, either over-controlling or lacking in control, and either authoritarian or democratic.

Various attempts have been made to present these characteristics in a conceptual form. Most models examine dimensions of the relationship between parent and child rather than dimensions of the family as a whole. Schaefer's Hypothetical Circumplex Model for Maternal Behavior places these characteristics on intersecting continuums as illustrated in the following diagram (101, p. 131). 


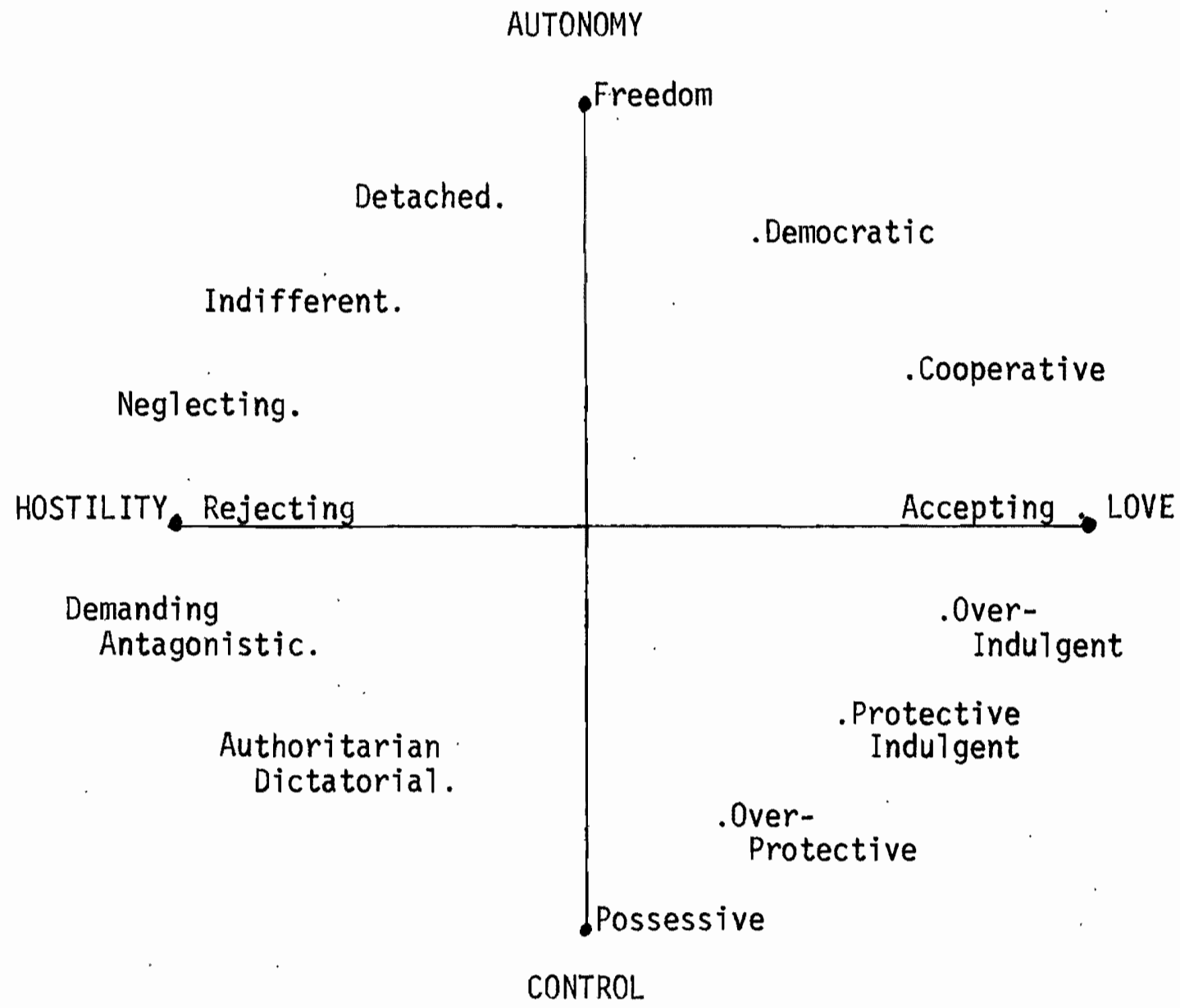

Figure 1. A replica of Schaefer's (1959) Hypothetical Model for Maternal Behavior.

Along the dimension of love-hostility, both maternal behavior and the child's need for love are seen as being relatively stable over time. Along the dimension of autonomy-control, however, maternal behavior is often inconsistent over time as the child's need for autonomy changes greatly from infancy to adolescence.

Roe's Mode1 for Parent Behavior presents the dimensions in the form of concentric circles (101, p. 134). 


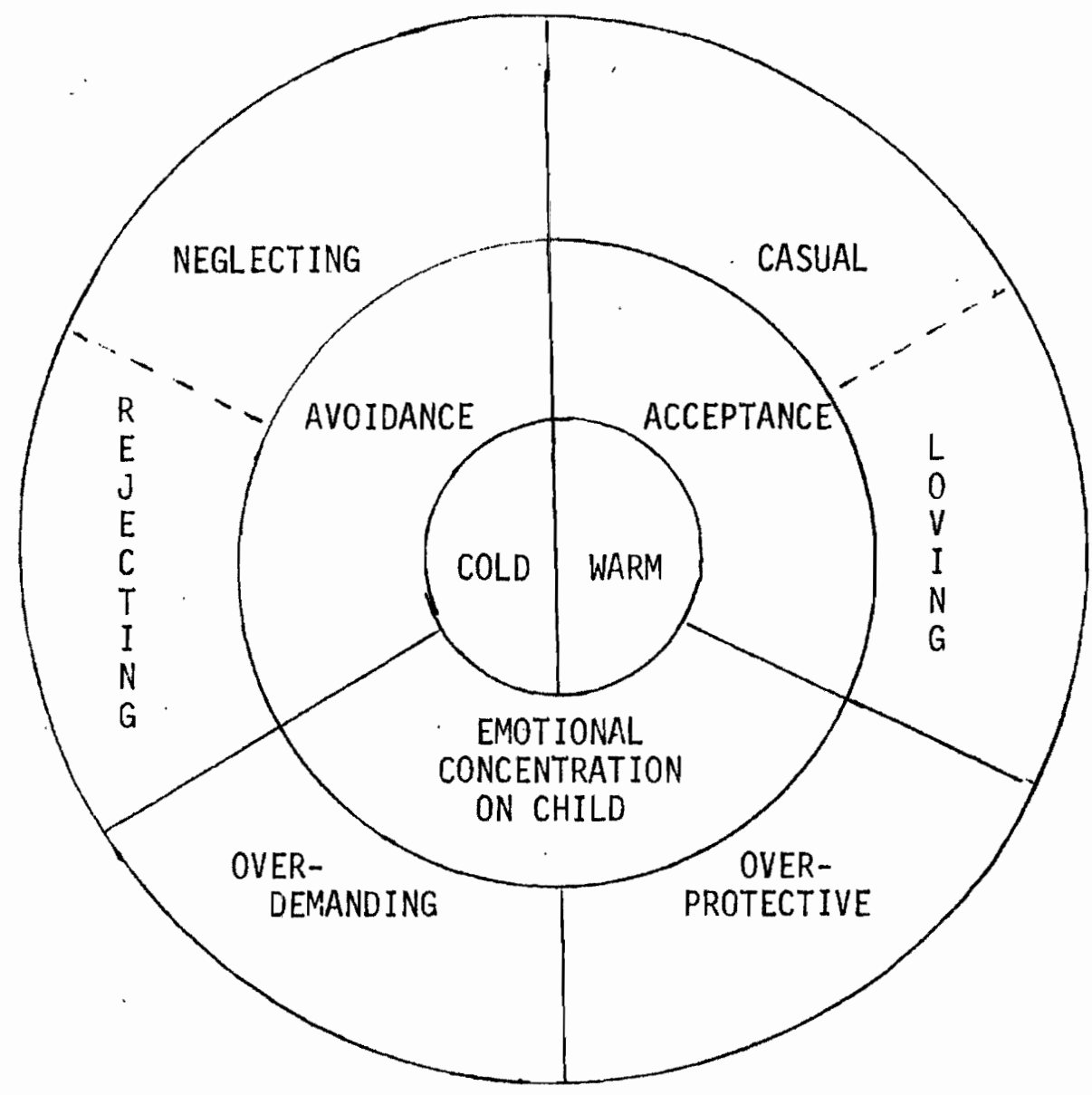

Figure 2. A replica of Roe's Model for Parent Behavior

His basic dichotomy is between the warm and cold parent. Although his model is not as specific as Schaefer's, he does place a greater emphasis on the importance of emotional concentration of the parent on the child.

Becker's Hypothetical Model for Parental Behavior is similar to Roe's model in that he also proposes three significant dimensions in parental behavior (15, p. 175). 


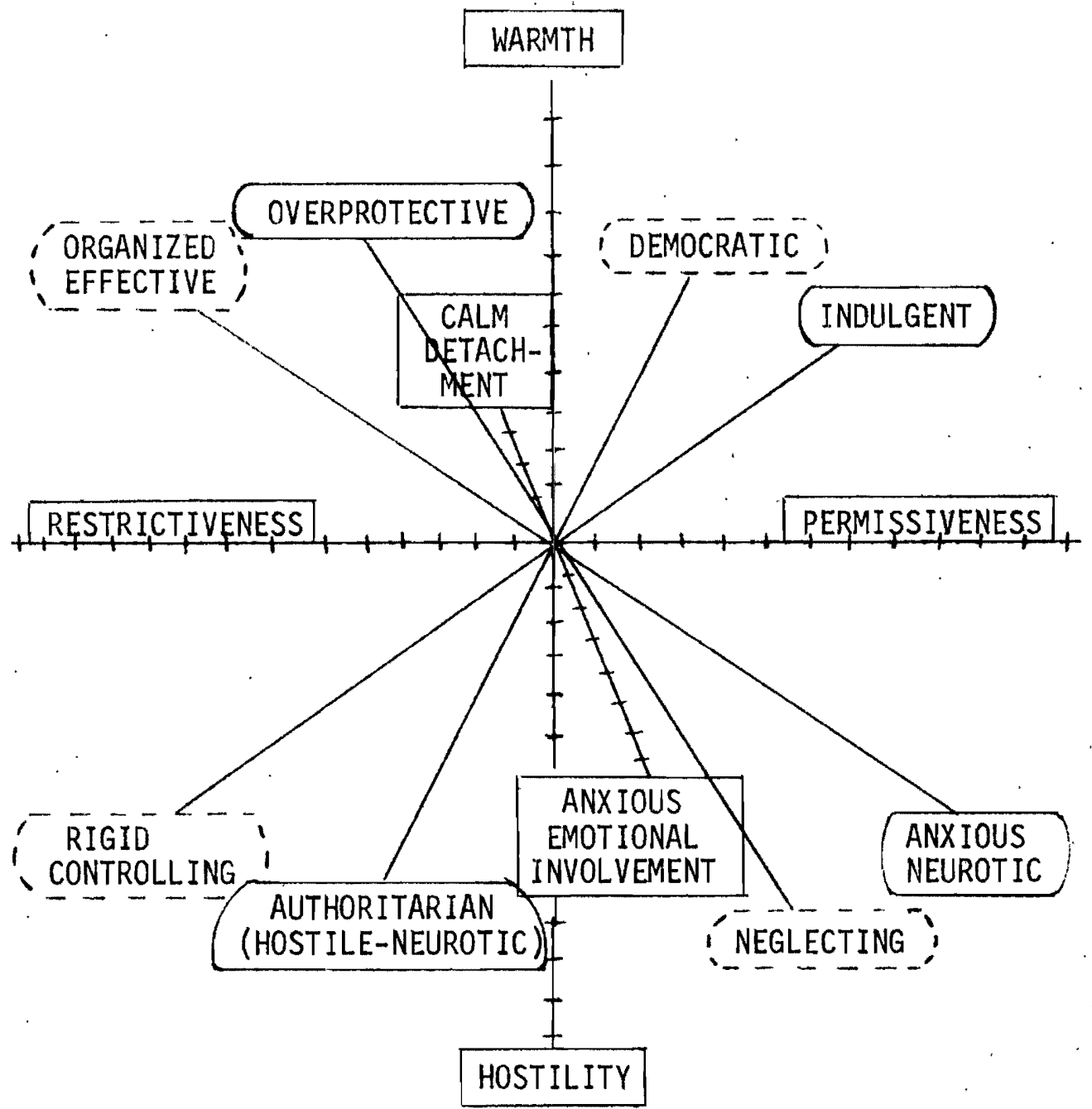

Figure 3. A replica of Becker's Hypothetical Model for Parental Behavior

He subdivides Schaefer's control vs, autonomy dimension into restrictiveness vs. permissiveness and anxious-emotional involvement vs. calmdetachment. These coupled with the dimension of warmth-hostility enable various types of parents to be defined according to dimension combinations as illustrated below (15, p. 176). 
TABLE I

A REPLICA OF BECKER'S DIMENSION COMBINATIONS

\begin{tabular}{|l|l|l|l|}
\hline \multirow{2}{*}{ TYPE OF PARENT } & & \multicolumn{3}{|c|}{ DIMENSIONS } \\
\cline { 2 - 4 } & WARMTH & PERMISSIVENESS & $\begin{array}{c}\text { EMOTIONAL } \\
\text { INVOLVEMENT }\end{array}$ \\
\hline \hline Democratic & High & High & Low \\
\hline Indulgent & High & High & High \\
\hline Organized Effective & High & Low & Low \\
\hline Over-Protective & High & Low & High \\
\hline
\end{tabular}

Although his concepts appear to be valid when presented in the form of a chart, Becker's three dimensional model is somewhat confusing to the eye.

Slater's Model for Parent Behavior is similar to Schaefer's model presented on page 15 (101, p. 134).

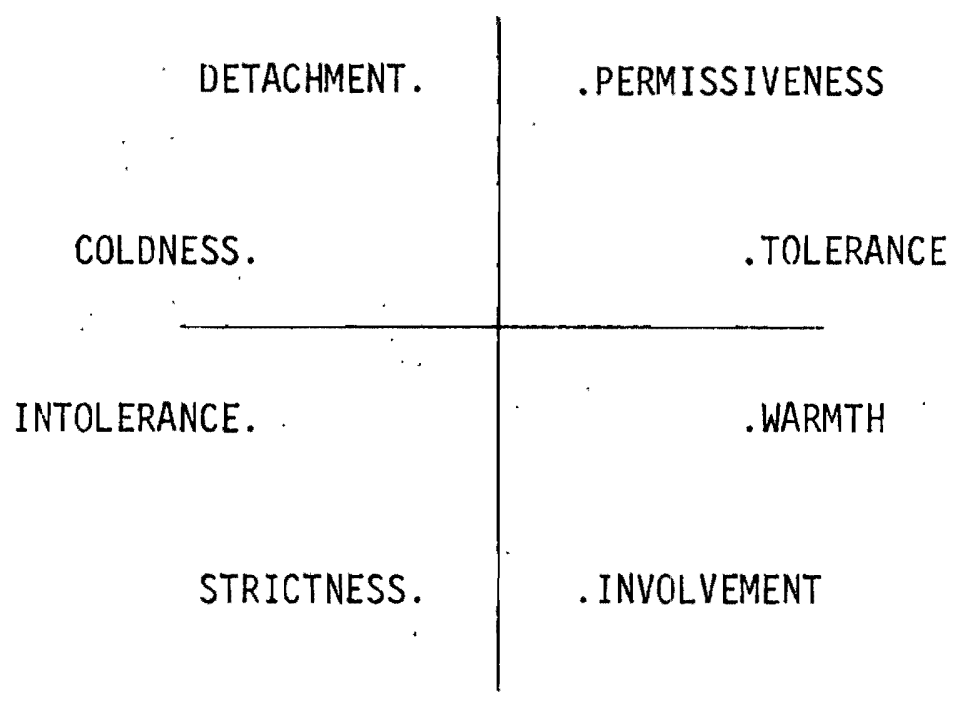

Figure 4. A replica of Slater's Model for Parent Behavior.

He contrasts the parental behaviors of warmth and involvement with coldness 
and detachment, and the behaviors of tolerance and permissiveness with intolerance and strictness.

From these models, the two most basic dimensions of parent-child relationships are love-hostility and control-autonomy. The third dimension proposed by Roe and Becker is subsumed under the two more basic dimensions. Anxious emotional involvement or a high emotionality in relation to the child resulting in babying, protectiveness, and solicitousness for the child's welfare contains elements found in love vs. hostility and control vs, autonomy.

The dimension of love vs. hostility is generally defined in terms of opposites. For example, "love" may be described as warmth, acceptance, affectionate, approving, understanding, child-centered, frequent use of explanations, positive response to dependency behavior, high use of reasons in discipline, high use of praise in discipline, and low use of physical punishment. Hostility would be described in opposite terminology. The dimension of control vs. autonomy is defined somewhat differently. Most definitions focus on: 1) where control is centered, i.e. the parent, the child, or some combination; 2) how it is managed or what style of transmission is operating, i.e. the style may be forcefur, punitive, tolerant, respecting, etc.; and 3) the degree of separateness that the parent allows the child, i.e. the parent may keep the child enmeshed in a symbiotic relationship, he may take no responsibility for the child, or he may lie somewhere between these two extremes.

While these two dimensions may be separated for definitional understanding and research purposes, it is important to remember that in reality they cannot be separated, for the interaction of these dimensions 
is the crucial variable in parent-child relationships. Becker presents a summary of salient findings relating to the importance of this interaction (15, p. 198).

TABLE II

INTERACTIONS IN THE CONSEQUENCE OF WARMTH VS. HOSTILITY

AND RESTRICTIVENESS vs. PERMISSIVENESS

\begin{tabular}{|c|c|c|}
\hline & RESTRICTIVENESS & PERMISS IVENESS \\
\hline WARMTH & $\begin{array}{l}\text { Submissive, dependent, } \\
\text { polite, neat, obedient } \\
\text { (Levy) } \\
\text { Minimal aggression } \\
\text { (Sears) } \\
\text { Maximum rule enforcement, } \\
\text { boys (Maccoby) } \\
\text { Dependent, not friendly, } \\
\text { not creative (Watson) } \\
\text { Maximal compliance } \\
\text { (Meyers) }\end{array}$ & $\begin{array}{l}\text { Active, socially out- } \\
\text { going, creative, suc- } \\
\text { cessfully aggressive } \\
\text { (Baldwin) } \\
\text { Minimal rule enforce- } \\
\text { ment, boys (Maccoby) } \\
\text { Facilitates adult role } \\
\text { taking (Levin) } \\
\text { Minimal self-aggression, } \\
\text { boys (Sears) } \\
\text { Independent, friendly, } \\
\text { creative, low projec- } \\
\text { tive hostility } \\
\text { (Watson) }\end{array}$ \\
\hline HOSTILITY & $\begin{array}{l}\text { "Neurotic" problems } \\
\text { (clinical studies) } \\
\text { More quarreling and shy- } \\
\text { ness with peers } \\
\text { (Watson) } \\
\text { Socially withdrawn } \\
\text { (Baldwin) } \\
\text { Low in adult role } \\
\text { taking (Levin) } \\
\text { Maximal self-aggression, } \\
\text { boys (Sears) }\end{array}$ & $\begin{array}{l}\text { Del inquency (Gluecks, } \\
\text { Bandura and Walters) } \\
\text { Noncompliance } \\
\text { (Meyers) } \\
\text { Maximal aggression } \\
\text { (Sears) }\end{array}$ \\
\hline
\end{tabular}

These findings seem to indicate that the combinations of warmth (love) and permissiveness (autonomy) substantiate the recommendations of childspecialists and promote the idealized result of successful child-rearing. 
A number of research studies will be examined further in the next section to give substance to the models and relationship dimensions just presented. 
Studies of Relationship Dimensions

A number of studies seem to uphold the findings presented in the preceding section. Elder's approach (28) to the interaction effects of love-hostility and control-autonomy was to examine the kinds of social structures in child-rearing relationships. He identified seven types of parental styles: autocratic, authoritarian, democratic, equalitarian, permissive, laissez-faire, and ignoring. Moving along the continuum from autocratic to ignoring involves a gradual increase in the participation of the adolescent in self-direction and a concurrent decrease in the participation of her parents in making decisions concerning her. These structures also represent different patterns of communication. Communication is primarily from parent to child in the autocratic structure and from child to parent in the permissive structure. Elder's investigation also evaluated the structural effects upon the affective relations between parent and adolescent, and the adolescent's attitude toward parental child-rearing policy. He found that the likelihood of mutual rejection in parent-adolescent relations and unfavorable evaluations of parental policy was greatest in autocratically structured relationships. Scheafer and Bayley (116) approached this area from a different direction but obtained similar results. Retrospective reports of maternal behavior during early adolescence were gathered and their study concluded that parental over-involvement during early adolescence was either experienced by the adolescent as hostile rejection or led to conflict between the parent and child.

A study by Stinnett, Farris, and Walters (110) collected 
retrospective reports from adolescents concerning parental behavior of both mother and father. They reported the following: 1) twice as many males as females reported father to be the primary source of parental discipline during childhood; 2) more than twice as many females than males reported they received praise often during their childhood;

3) more males than females perceived mother to be the source of most affection during childhood, while more females than males reported both mother and father about equally as the source of most affection during childhood; 4) more females than males indicated that mother very often found time to do things together with them as a child, while more males than females reported that mother rarely found time to do things together with them as a child; and 5) more than twice as many males as females reported that father was the greatest parental influence in determining the kind of person they are, while more females than males perceived mother as the greatest source of parental influence. Duncan (38) found similar results in her study. Fathers were seen as: 1) advocating more use of authority; 2) being more restrictive in the area of control; 3) demanding more conformity; 4) allowing the child more freedom to interact with the environment; and 5) demonstrating less affection to his child. In summary, parents have a decidedly different effect on the lives of their sons and daughters, and mothers have a greater influence than do fathers upon the children.

A more concrete way of examining structure is to determine who actually makes decisions. The study done by Johannes and Rollins (116) examined family decision-making. When asked the question "who generally makes decisions in your family?" adolescents reported the following 
(116, p. 132):

$\begin{array}{lr}\text { Father and mother jointly } & 63 \% \\ \text { Father, mother, and children jointly } & 11 \% \\ \text { Father alone } & 15 \% \\ \text { Mother alone } & 10 \% \\ \text { Children alone } & 0.3 \% \\ \text { No one in family } & 16 \%\end{array}$

They conclude that the existence of the ideal democratic family decisionmaking team (composed of father, mother, and older children) is not supported by the data on who is to accomplish specific activities. It is interesting to note that although the father-mother team is responsible for decision-making in almost two-thirds of the families, the next largest group is the "laissez-faire" situation where no one seems to make family decisions.

In addition to examining the effects of structure and the centering of authority on parent-child relationships, studies have also examined how authority is managed and transmitted. Hoffman (63) has developed a theoretical framework to explain the impact of various forms of parental authority on the behavior of the child. The author views the parent-child relationship as one in which the parent potentially has complete power in all areas of the child's life. Because of this strong position, the parent is free to choose influence techniques which, in varying degrees, either assert power or attempt to induce the child to change her behavior voluntarily. The author defines unqualified power assertion as "the most power assertive technique that might be used, which, without qualificatịon, puts direct coercive pressure on the child to change her entire ongoing pattern of behavior immediately and is accomplished through direct commands, threats, deprivation and physical force" (63, p. 130). 
Opposite this are techniques which do not assert power but rely instead for their effectiveness primarily on the child's own internalized standards and good judgment. The author hypothesized on the basis of this theory that the parent's use of unqualified power assertive techniques, initial or reactive, would relate positively to the following characteristics of the child: hostility toward other children; power assertiveness toward them; and resistance to their influence attempts. This hypothesis was supported by the data collected, particularly when unqualified power assertion was used by the mother.

Hoffman's findings have been supported by other sources. In reviewing such authors as Bandura and Walters, Sears, and Unger, Becker (15) found that the nature of affectional relations was significantly correlated with the use of certain kinds of discipline. Research comparing love-oriented and power-assertive techniques suggests that discipline which uses the love relationship with the child as a way to shape her behavior is more likely to be related to internalized reactions to transgressions (e.g. feelings of guilt, self-responsibility, confession) and to nonaggressive or cooperative social relationships. This occurs primarily because of certain characteristics of parental behavior: 1) warmth makes the parent important to the child and therefore reduces the need for more severe forms of discipline to gain compliance; 2) the parent provides a model of controlled behavior for the child; and 3) the parent provides verbal cues which facilitate the child's understanding of expectations and her anticipation of consequences. On the other hand, power-assertive techniques are more likely to be correlated with externalized reactions to transgressions 
(e.g. fear of punishment, projected hostility) and with non-copoperative, aggressive behaviors. Power-assertive techniques often induce further aggression in the child for a number of reasons: 1) power-assertion occurs in a hostile context and is likely to further frustrate the child and lead to a counter-aggressive anger reaction; 2) the aggressive behavior modeled by the parent shows the child how to be aggressive as well as providing an implicit sanction for it; and 3) some hostilepunitive parents directly reinforce or encourage aggressive behaviors to others.

This perspective is further supported by Chorost (30). He investigated child-rearing attitudes of authoritarian control and parental warmth, and their correlates in adolescent hostility. He found that parental attitudes of authoritarian control are positively related to overt adolescent hostility and that attitudes of parental warmth are negatively related to overt adolescent hostility.

A third group of studies examines the degree of separateness allowed in the parent-child relationship. Some research efforts describe parental attributes and hypothesize the effects of these attributes on the child. In "Parental Power Legitimation and Its Effect on the Adolescent," Elder (40) examined the relation between autocratic, democratic, and permissive parental practices and adolescent autonomy. Autonomy was indicated by 1) the adolescent's confidence in her own values and goals, and her awareness of rules, and 2) her independence or her desire to make up her own mind with or without listening to other's ideas. The study found that adolescent confidence and independence occurred most frequently among the children 
of democratic and permissive parents who also frequently provided parental explanations. Lack of confidence and dependence occurred most frequently among autocratic parents who infrequently provided parental explanations of rules of conduct and expectations; they occurred least frequently among democratic, explaining parents.

An important qualification to Elder's conclusions is presented by Baumrind (14) who distinguishes between the "authoritarian" parent and the "authoritative" parent. The authoritarian parent is one who attempts to shape, control, and evaluate the behavior and attitudes of the child in accordance with an absolute standard of conduct, who values obedience as a virtue, and who favors punitive, forceful measures to curb selfwill, with no encouragement of give-and-take with the child. In contrast, the authoritative parent attempts to direct the child's activities in a rational, issue-oriented manner, encourages verbal give-and-take with the child, and shares with the child the reasoning behind the policy.

Baumrind also points out that during early years, the exercise of power is a legitimate right of parents and serves to legitimate authority in the mind of the child. By early adolescence, however, power cannot be used to legitimize authority and the parent must be prepared to defend rationally a directive with which the adolescent disagrees. This distinction supports Schaefer's model for maternal behavior: both agree that while warmith must be consistent over time, the degrees of control and authority must be altered over time to allow for expanding separateness. Another way of viewing this issue of separateness is to examine adolescent characteristics and to look for their determinants in parental behavior. Murphy's study (116) examined the relationship between degrees 
of autonomy in adolescents and parental characteristics. Parents with adolescents rated high in autonomy were characterized as follows:

1) they possessed stable and consistent values; 2) they could communicate these values to their children; and 3) they demonstrated congruence between their beliefs and actions in their everyday lives and acted as consistent models. In sum, these parents behaved as autonomous people with inner-directed standards of behavior. In contrast, the parents with adolescents rated low in autonomy were characterized differently: 1) they lacked confidence in their child's ability to achieve autonomy; 2) their children experienced less clarity about parental yalues; 3) there was more often a discrepancy between stated parental values and parental behavior; and 4) these parents were unable to respond to their child's growth by shifting their own images from that of "dependent child" to "young adult."

Thomas, Gecas, Weigart, and Rooney (113) attempt to establish a relationship between the adolescent's self-concept, conformity, religiosity, and identification with a counter culture, and between parental support and control. In this study, support is defined as the quality perceived by the adolescent which emerges from a positive affective relationship established by significant others with her (love-hostility). Control is defined as the quality of interaction perceived as constraining him to do what the significant other wants (control-autonomy). The authors found that parental support or love is related to 1) feelings of self-esteem, power, worth, and happiness; 2) a positive family identity; 3) conformity to authoritative others; 4) religiosity; and 5) a lack of identification with counter culture values and attitudes. 
The authors also found no clear and central thrust in terms of control and feel that control must be considered in connection with support.

This concept was more specifically examined by Jourard and Remy (67). In studying the relationship between the perceived parental attitudes, the self, and security, the following results were obtained: 1) the adolescent's self-rated valuations of "self" correlated with the perceived parental valuations; 2) parental valuation also correlated with adolescent security-insecurity (i.e. the lower the valuation, the lower the feelings of security); and 3) negative self-appraisal by the adolescent and perceived negative parental appraisals of "self" are correlates of psychological insecurity.

The previous studies indicate the need for a balance along the continuums of love-hostility and control-autonomy if the adolescent is to make a successful transition through this stage and achieve mature adul thood. Parents who are too restrictive may attempt to keep the adolescent in a child state, while parents who are too permissive may force the adolescent into the adult world before she is ready. Parents who accept the adolescent's dependency but encourage her separateness appear to be authoritative rather than authoritarian, congruent in their beliefs and actions, and confident in the adolescent's ability to achieve maturity. Despite these characteristics, parents generally find that maintaining an appropriate, workable balance between lovehostility and control-autonomy is, at best, difficult. And during adolescence when the need for this balance is most critical, parents may find themselves least able to provide it.' For during this time, a number of other factors impinge upon the parent-child relationship-- 
not the least of which is the parent's own sense of personal crisis. The nature and impact of these interlocking crises will be the subject of the next section. 
Interlocking Crises

The balance between love-hostility and control-autonomy in parentadolescent relationships does not always occur easily, if it even occurs at a11. While the adolescent is struggling with her developmental tasks, her parents are also faced with the developmental tasks of the middle years as a number of sources indicate $(10,60,72,74,104)$. As Scherz has so succinctly stated: "families with adolescents can be described as living in a stage of transitional crisis characterized by confusion" (103, p. 209). Confusion arises out of the interplay of generational tasks in the areas of sexuality, vocation, and separation.

The developing sexuality of the adolescent may trigger fears and conflicts in the parent about approaching menopause and changes in sexual vigor and activity. As the parent feels his sexual youth slipping away, he may provoke the adolescent to act out some of his own urgent repressed fantasies, and at the same time punish her for attempting to do so. A normal increase in adolescent seductiveness occurs as the adolescent experiments with new ways of relating to the opposite sex. This often creates difficulties for the parent since the very individual toward whom she was able to show overt signs of love during childhood has now become a sexually stimulating but taboo subject. This situation can become exacerbated if marital difficulties or dissatisfactions exist. The "sexual malaise of middle age" is often temporary but can become a significant factor in the sexual tug-of-war with the adolescent unless parents resolve the difficulty in the marriage. As one author states, "the parents need to support each other against 
undue sexual competitiveness, stimulation, and seductiveness with the adolescent" (103, p. 102). Parents must come to terms with their own changing sexuality so that the normal anxieties elicited by the adolescent's emerging sexual behavioral expression can be dealt with appropriately rather than leading to parental intrusiveness and spying or resignation and abandonment of the adolescent and her fluctuating sexual impulses.

A similar pattern exists in the area of vocation. The adolescent's struggle with determining a vocation and assuming responsibility for her own achievements is characterized by alternating spurts of growth and regression. This struggle often coincides with the parent's own conflicts in regard to achievement and career success. At this period of time, the parent begins to re-examine and re-evaluate not only his vocational performance but his choice of vocation. The "results" of this survey may place the parent in an ambivalent position with regard to the adolescent's developmental tasks. On the one hand, the parent may sincerely want the adolescent to achieve more than he did in an area both gratifying and fulfilling. On the other hand, the parent may be envious of the numerous opportunities and potentials for success open to the adolescent. Parents may convey this ambivalence to the adolescent by sending double or contradictory messages--yerbally pushing the adolescent to succeed but subtly giving her the message that they expect her to fail or at least not succeed to the point of passing parental achievements. Because the adolescent is often uncertain at this time about vocational commitments, she needs support rather than competition from her parents, and permission to explore and experiment 
rather than exhortations to succeed.

Potentially the most explosive issue faced by the adolescent and her parents is that of separation. The adolescent is beginning to test out her own sense of autonomy and move away from family members. The adolescent is torn between letting go and holding on. She wants parental limits on behavior but fights against being controlled; she wants assurances of parental love but is fearful of emotional dependency; and she wants to maintain her identity as a family member but also wants to establish an identity as an individual apart from the family. The adolescent's ambivalence around these issues often leads to behavior fluctuations and mood swings which her parents find difficult to deal with, particularly since they are also trving to resolve their own conflicts and feelings about the separation. Parents come to the realization that they are no longer the most important people in their child's life. Their control and authority over the child is being challenged, and their position as the source of all love for the child is threatened as her move toward other love objects occurs. The parents may experience a sense of emptiness and an absence of goals that had motivated them so strongly throughout the child-rearing years. This can be extremely difficult for a mother who has based. her whole identity on the raising of her children. As her children leave her sphere of influence, she may find herself with no sense of structure or purpose in her life. The loss of task organization around child-rearing may also have an effect on the marital relationship. Parents must restructure the marriage to accommodate to this loss and find new ways of meeting their needs. Unless parents move to "fill in the gaps" left by the 
adolescent, the marriage itself may face dissolution.

Resolution of the developmental tasks around sexuality, vocation, and separation for the adolescent and her parents reflects the pattern established throughout the parent-child relationship. As Covar (71) states, a girl is confirmed by her family in a certain fashion and she continues to affirm herself in the manner in which she was confirmed. That is, if the family has conveyed love and acceptance to the girl and has appropriately allowed her increasing amounts of self-direction and self-control, then her transition from childhood to adulthood will be accomplished with a minimum of discomfort. If, on the other hand, hostility and rejection have been conveyed and an inappropriate balance of control and autonomy has been maintained, then the adolescent period is likely to be painfully difficult.

The adolescent girl who is confirmed by her family in negative ways or who experiences gaps or inconsistencies in areas of confirmation will affirm herself in negative ways $(28,69,70)$. A lack of preparation for the onset of puberty and the establishment of sexual identity may result in fear, resentment, disgust, and/or experimentation with her own or the opposite sex. Parental characteristics such as a brutal or absent father and a weak or competitive mother may make the identification process difficult and lead to a rejection of femininity. Little tradition of learning and preparation for employment and limited vocational choice may compound this and lead to school failure, resentment of work, and a turning to "being supported" as a way out. The doublestandards around male-female roles may produce resentment and a violation of these standards in an attempt to gain revenge. The girl may find 
herself trapped in a vicious circle. Her excessive loneliness, low self-image, estrangement from adult society, and incapacity for intimate friendships leads to her losing herself in the crowd and a frantic search for romantic involvement. This in turn generally leads to a rejection by society which further confirms her as "alienated" or "delinquent" and leads to a final crystallization of her negative personification. Whether this circle is completed in full measure or whether the adolescent only begins to become enmeshed in it, she finds herself with only a limited number of options. One response which is becoming more frequent among adolescents will be discussed in the next section. 
Runaways

One of the most common reactions of the adolescent girl involved in the previously described situation is to run away from home. 1

Because female runaway behavior is such a recent phenomenon, there are onty a linited number of studies which focus on this area. Most of these studies have either been descriptive or have examined the previously discussed themes of sexuality, affective relationships, separation, and/or conflict.

The classic study of Robey, Rosenwald, Snell, and Lee (95) emphasizes that running away is almost always indicative of some severe individual or family pathology. The cause most frequently observed was the unconscious threat of an incestuous relationship with the father, the fear of the resultant dissolution of the family, and the concurrent depression. The pattern of family interaction included the following: 1) a disturbed marital relationship; 2) poor control by parents over their own impulses; 3) an equal inability of the parents to control the girl's impulses; 4) a mother-child relationship lacking any real maternal warmth; and 5) unconscious pressure by the mother on the girl to take over the maternal role. In the eyes of the adolescent, the "pressure-cooker" atmosphere surrounding sexuality appears to make running away her only healthy alternative.

Another perspective on running away is gained from studying the affective relationships between the adolescent and her parents.

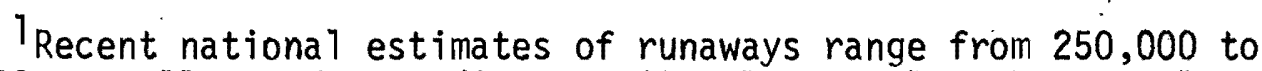
500,000 annual1y, and according to D'Angelo, et al., the actual numbers are probably five to ten times the reported figures (36). 
Foster (45) compared runaway and non-runaway delinquents and found several significant factors that differentiate the two groups: 1) almost sixty percent of all runaways had experienced abandonment by the father during childhood; 2) families of the runaway displayed a much greater incidence of physical aggression and open sexual activity in the home; 3) the runaway's parents almost universally exhibited a marked and overt rejection of the child; and 4) parents of runaways expected their children to become aggressive and dangerous upon entering adolescence. In essence, the parents set up and operated on the basis of a negative affective relationship which was then confirmed by the adolescent's running away. These conclusions are further supported by Riemer (93) whose study describes lack of parental love as one of the basic factors in creating the runaway.

Stierl in (109) has also characterized runaways in terms of emotional involvement with parents and feels that a major factor in the adolescent's running away from home is a painful and difficult home life. Runaways with strong but ambivalent psychological ties to the family are labelled "abortive" or "lonely schizoid" runaways: their attempt to run away precipitously fails and their bizarre and selfdestructive behavior usually results in institutionalization. "Crisis" runaways also have strong psychological ties to the family but their runaway attempts usually reflect a crisis in family life rather than an ongoing intrapsychic disturbance. Their stay in the runaway culture is usually temporary and they covertly make sure they are "rescued" by their parents. Stierlin's third group is labelled "casual" runaways. In response to rejecting parents, the object relations of these 
adolescents are typically transient, shallow, and exploitive, and they experience no qualms or difficulties in separating from their families.

On the basis of his descriptive study, Stiel in has proposed a linking system between the affective component operating in families of runaways and transactional modes reflecting the degree of separateness between parent and child. The interactions in the family of the "abortive" runaway are described as "binding" and reflect a view of the outside world as hostile. In such a family, the parent "binds" the adolescent by 1) infantilizing the child through excessive gratification, 2) interfering with the child's differentiated self-awareness and self-determination, and 3) exploiting the child's loyalty to the family.

The families of the "crisis" runaway make use of "delegating modes" of interaction. In these families, parents are reacting to their own developmental crisis with ambivalence and conflict, and they recruit their child in order to meet their own needs. Stierlin describes the runaway episodes as "missions" which serve to externalize the parents' need for 1) vicarious thrills, 2) support in doing something the parent feels too afraid or embarrassed to do himself, and 3) alleviation of the parents' conscience and guilt feelings.

Parents of "casual" runaways are rejecting of their children and Stierlin labels this the "expelling mode." The parents, in solving their own crises, come to view their adolescent children as hindrances and in response to this neglect, the adolescent runs away early and casual1y.

The fourth major area of focus in studies of runaways is 
parent-child conflict. The most extensive study here was conducted by the Ohio State University School of Social Work $(26,37)$. A preliminary study compared the perception of family conflicts between runaways and non-runaways. They found that conflict perceived by the runaways included a broader range of issues and was more intense than that perceived by non-runaways. The major portion of the study explored and described a variety of variables to distinguish the runaway from the non-runaway. In examining the home environment of runaways, the following findings are reported (37, p. 60):

1. Runaways reported their parents didn't get along about two and one-half times more than the controls (non-runaways).

2. Runaways indicated their parents argued more than other parents at three times the rate of controls.

3. Runaways reported their parents used indirect means of settling disputes one and one-third times the rate of controls.

4. Runaways reported they were given a chance to explain themselves in disputes with parents at three-fourths the rate of the controls.

5. Runaways experienced physical abuse from narents three times as much as controls.

6. Runaways reported their fathers were unfair twice as often as controls; mothers were unfair three times more than the figure reported by controls.

7. One-half as many runaways indicated a willingness to consult their parents when in trouble as did the controls.

8. Runaways indicated they had poor relationships with mothers twice as often as controls; poor relationships with fathers three times as often as controls.

From the runaways' reports of the parental relationship, the arguments, and the communication between their parents, it can be hypothesized that these parents acted as poor models in resolving conflicts. This 
coupled with the report of runaways that they experienced less chance to explain themselves to parents and more physical abuse from parents can be viewed as contributing to the runaways' feelings of parental unfairness, an unwillingness to consult parents, and a generally poor relationship with parents. This disruptive family atmosphere and lack of trust made itself felt on the runaways' self-images: the study found that twice as many controls as runaways had "high" self-acceptance scores.

In summary, the descriptive data presented above indicates that conflict occurs more frequently, is more disruptive, and is handled more ineffectively in families of runaways, with definite negative effects on the adolescent's self-image. The authors propose that one of the keys to understanding the conflict in such families is the issue of communication. This area of communication will be examined more closely in the following section. 
Communication

Before communication in families with adolescents can be discussed, some general information on the communication process is necessary. Communication refers to nonverbal as well as verbal behavior within a social context and includes interactions, transactions, symbols, and clues used by persons in giving and receiving meaning. Communication has been labeled as "the pipeline to human relationships," "the index of family operations whereby the family transacts the business of life," and "the blueprint by which the child grows from infancy to maturity" (24, p. 117). A11 individuals experience the following basic interpersonal needs: 1) affection or the need to feel that the self is lovable; 2) inclusion or the need to feel that the self is significant and worthwhile; and 3) control or the need to feel that the self is responsible and successfully coming to grips with the environment (118). Another way of viewing these interpersonal needs is offered by Wynne (121). When relatedness is experienced primarily as a goal in its own right, the relationship meets expressive needs: meaningful feelings are sought directly, immediately, and spontaneously. When relatedness is experienced more as a means for some other task or objective, the relationship meets instrumental needs: tasks and the foci of attention are external to the participants and the interpersonal relationship is not valued anart from its utility. Communication both shapes and provides the means for meeting these interpersonal needs. This concent of communication can be explained by several axioms: 1) an individual cannot not communicate--verbal 
communication can be stopped but non-verbal communication is always present; 2) every communication has both content and relationship aspects; 3) a series of communications can be viewed as an ongoing, simultaneous process and an uninterrupted sequence; and 4) all communication relationships are either symetrical in which the communicators treat each other as equals, or complementary in which one partner is superior to the other. Within the context of the family these axioms point to communication as a powerful force in determining and meeting interpersonal needs. As Bach (9) states, a functional relationship depends on an ability to reveal uniqueness openly, an ability to understand differences which may arise from this uniqueness, and an ability to negotiate these differences in order to fit the persons involyed rather than to establish who is in control. Growth and development resulting in a sense of being lovable, significant, and autonomous are largely dependent on how messages are sent and received by the parent and child.

Sending messages in interpersonal communication has important functions for the individual. It lets others know what the individual has learned or what he thinks he has learned. It allows him to make his expectations for others known. How others appear to him and how he interprets what others do is made explicit. He can let others know what his intentions are. In essence, sending messages in interpersonal communication allows him to give meaning to his experience by sharing his reality with others and by checking out his perceptions with those of others. As Wenburg and Wilmot point out, "to each individual, perception is reality. No matter how distorted one's perception mav 
be to another person, it is accurate to the perceiver" (118, p. 119). If the individual is ever to correct the distortions in his perception and enlarge the area of shared meaning, he must be able to communicate functionaliy.

In functional communication, the individual can firmly state his message, clarify and qualify what he says, ask for feedback, and be receptive to feedback when he gets it (97). The "style" in which messages are sent can also contribute to the effectiveness of communication. Satir (98) describes a style of communicating known as "leveling" in which 1) the message is single and straight (verbal cues match non-verbal cues), 2) the message conveyed is the same as the person's inner state, and 3) the person's total self is involved in the message.

In contrast, dysfunctional communication is characterized in the following ways. The sender rarely checks out or specifies how he or others are using words. He uses pronouns vaguely and over-generalizes, such that meaning becomes cloudy and conversation is sidetracked. He sends incomplete messages or leaves out whole connections between messages. He may not even send a message at all but behave in relation to others as if he had. He leaves the receiver of the message groping and guessing as to his meanings. Misunderstandings occur easily and arriving at goals or outcomes is difficult. Many of these difficulties arise from the dysfunctional relationship within which the sender is operating. Rather than perceiving the other as a unique individual, he operates on false inages, false expectations, and numerous assumptions about how things "should be" and how things are "thought to be." 
Satir (98) has also proposed four styles of dysfunctional message sending. The "placater" sends messages in an ingratiating way, tries to please, apologizes profusely, and never disagrees. Rather than sending messages to convey information or feelings, the "placater" tries to elicit approval from others. The "blamer" sends fault-finding messages which place responsibility on others. He attempts to throw his weight around and elicit obedience from others. The "computer" can convey information in a correct and very reasonable way, and is "calm, c00l, and collected." His words, however, have no relationship to his feelings and he ignores the interpersonal context of communication. The fourth style is that of the "distractor." The "distractor" sends messages which lack focus and are unrelated to anything going on. His constant verbal and non-verbal motion prevent the occurrence of any kind of meaningfur and connected communication.

Another dysfunctional style of sending messages involves incongruency in which two or more messages sent via different levels seriously contradict each other. The occurrence of incongruent messages is common in parent-child interactions. Examples of this are the parent who says with a smile on his face, "I'm really angry at you, daughter, for staying out so late," the parent who says, while combing his child's hair, "You're getting to be so independent," or the parent who says "I love you," in a stern voice and with his arms crossed. The parent may be sending double level messages for reasons of which he may or may not be aware: 1) he has low self-esteem; 2) he is fearful about hurting the other's feelings; 3 ) he is worried about retaliation from the other; 4) he fears rupture of the relationship; 
5) he does not want to impose; or 6 ) he does not attach any significance to the interaction itself (98). Despite the parent's intent, these mixed messages are extremely frustrating and confusing to the child as she does not know which message to believe or what behavior to choose. The child may end up distrusting the parent and have doubts about the honesty or genuineness of the parent.

A final common form of dysfunctional message sending involves shifting the responsibility for the message from the sender to the receiver. This style of communication is typically characterized by numerous "you-messages" and very few "I-messages." Messages such as, "You stop that," "You shouldn't do that," and "You made me feel. . ." are often decoded by the child as an evaluation of herself and are a poor code for communicating what the parent is feeling or thinking. In contrast, "I-messages" are decoded by the child as a statement of fact about the parent. This shift in orientation from the child to the parent is illustrated in the following diagram (55, p. 117): 


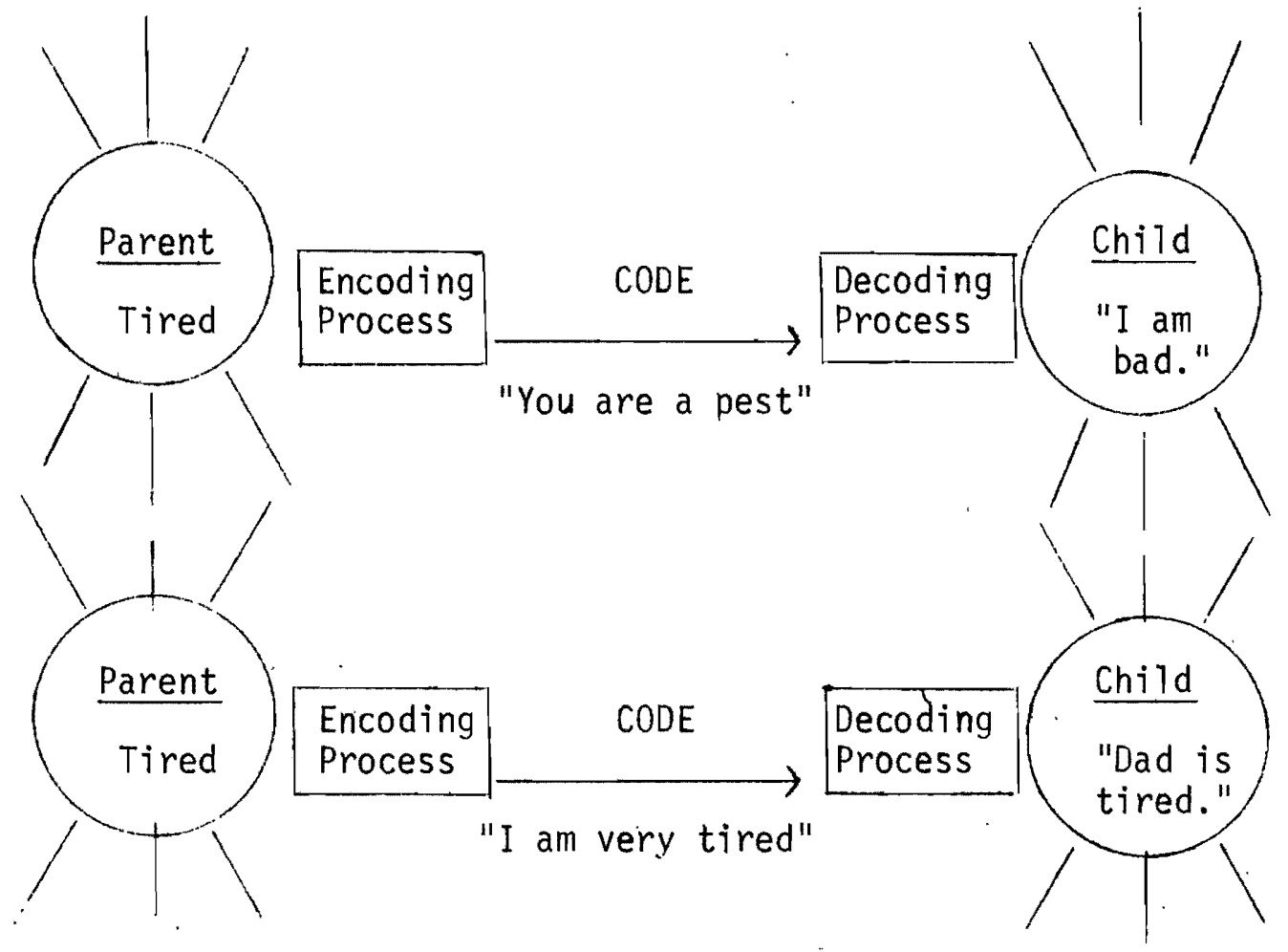

Figure 5. A replica of Gordon's "You" message-"I" message dichotomy.

When the parent uses "I" statements to send a message about himself the child is less threatened and given an opportunity to modify her behavior on her own. When a parent uses "You" statements the child feels blamed and that there is something bad about herself for just being the way she is.

Authentic communication depends not only on how messages are sent but also on how messages are received. The receiving aspect of communication has two major functions for the individual. Through receiving labels for objects and learning what can be expected from them, the individual learns to differentiate and relate the self to objects. Through receiving messages from and about people, the individual receives information about the nature of relationships. He learns expectations 
for socially approved ways to act, which behaviors please or displease others, why others respond as they do, their intentions toward him, how they report things about themselves, how he appears to others, and how others react to and evaluate him (97). This information about objects, people, and the nature of relationships is received in two basic ways-through observation of verbal and non-verbal behavior and through asking for verbal responses.

A person sending messages simultaneously communicates by his verbal meaning, tone of voice, facial expression, gestures, body posture, and movement. This communication occurs within a context involving a "when," "where," "with whom," "under what circumstances," and "with what expectations." The person receiving these messages must not only assess a11 these different, ways that the sender is sending messages but must also be aware of his own receiving or interpretation system. The receiver must decode the message at the denotative level (the literal content of the message) and at the metacommunicative level (97). The metaconmunicative level of the message provides comments on the literal content of the message as well as on the nature of the relationship between the persons involved. Metacommunication is a message about a message and may consist of the sender's attitude toward himself, or the sender's attitudes, feelings, or intentions toward the receiver.

In order to assess and decode the sender's message, the receiver must devote his whole attention to the sender and attempt to understand what it is the sender is feeling or what his message means or conveys. The receiver must be available for listening and keep an open frame of mind. Rather than assuming he understands the message, he puts his 
understanding of it into his own words and feeds it back to the sender for verification. He does not begin sending messages of his own until he feels that the sender's message has been understood. The effects of this kind of "active listening" are many. The most important is that the sender feels understood, which will promote trust and warmth in the relationship. Open receiving conveys that the other's ideas and feelings are worthwhile and worth considering and encourages him to share more. It facilitates problem-solving and fosters reciprocity: because the receiver is willing to listen to the sender's messages the sender will be more likely to listen to the receiver when he begins sending messages.

A breakdown in receiving can occur both at the level of assessment and at the level of decoding. Because of the large amount of incoming stimuli, the receiver may assess only part of the sender's message. For example, the receiver may ignore the body language of the sender. He may fail to take into account the social context in which the message is sent or may misinterpret it. The mother who responds to her son's "good-bye" at home with a kiss has failed to take into account the social context if she responds in a similar fashion in front of the football team.

A number of common errors are frequently made in decoding by the receiver. By beginning to decode too soon the receiver may jump to conclusions and interrupt the sender. If the message is one that the receiver does not want to hear, he may decode the message in such a way as to discount it or the sender. He may make little effort to understand what the sender means and rarely tests his understanding of the message. He may instead operate on assumptions. Responding to the sender's 
message in a dysfunctional way may make the sender feel judged or guilty, restrict expression of honest feelings, threaten the sender, foster feelings of unworthiness or low self-esteem, and block problem-solving or constructive change.

Individuals may also develop "habitual blind spots" or dysfunctional styles of receiving. Satir's four communicator patterns which have previously been discussed also have their counterparts in receiving. The "placater" is hypersensitive to approval and evaluates all messages on this basis. The "blamer" is always ready to become defensive and hears azz messages as an attack on himself. The "computer" blocks out incoming feelings and emotions and responds only to the denotative level of the message. The "distractor's" fear of focusing on anything too closely leads to responses which are never to the point or which ignore the sender's message entirely.

The styles of sending and receiving just discussed both originate within the family and have implications for family and individual functioning. Families develop rules or patterns (functional or dysfunctional) for communicating which tend to be relatively consistent and stable over time. If these patterns are functional, the family is better able to adapt or respond to crises or developmental pressures. If, on the other hand, these patterns are dysfunctional, the family's response will most likely be inappropriate and non-productive, and exacerbate the crisis. This is particularly evident in families with adolescents. Because both the adolescent and her parents are undergoing developmental changes and are in a state of vulnerability, the lack of effective communication skills can have far-reaching consequences--the 
lack of skills not only aggravates the situation, it also prevents them from resolving it. Unable to restore a sense of family equilibrium, family members experience a sense of isolation and upheaval.

These dynamics tend to occur around certain common issues in families with adolescents as presented by authors such as Andrews (9), Bienvenu (25), Bronfenbrennar (29), and Hill (62). The first of these issues involves relating to others. For each family member, family life is a process of fulfilling individual needs while at the same time accommodating to the needs of others. This process can break down if, instead of an "I count, You count" philosophy, one member must always have "his own way." If parents expect their adolescent children to respect others as well as themselves, the parent must set an example in actions as well as in words. The parents must comrriunicate that everyone's needs are important and make this a reality for the adolescent by conveying a recognition of the adolescent as a separate and unique individual and, at the same time, by being available for affiliative companionship. In families with dysfunctional styles of communicating, too often the idea that the adolescent is an "object" rather than a person and therefore does not "count" is conveyed. At one extreme, family members may feel that they have no real relationship with other family members. At the other extreme, family members may feel that others in the family grant them no privacy or time to themselyes. The family lacks a sense of itself as an integrated, interrelated, functioning unit.

A second common issue in families with adolescents involves the communication of support. Within the family, individuals have a need 
to feel appreciated and to have others recognize and comment on their gains and growth. The adolescent desires parental he1p in learning appropriate behavior, and parental respect for and encouragement of the adolescent's desire for individuality and independence. Parents can express their support by assuming the role of the "watchful bystander," and by taking an interest in and accepting the adolescent's activities and friends. By talking to the adolescent in a warm and affectionate way, the parent can convey acceptance and build un the adolescent in a positive manner. In contrast, parents who communicate dvsfunctionally may convey rejection. Nagging, scolding, ridiculing, constant complaining, making unfavorable comparisons to others, and intentionally making hurtful remarks are all examples of ways in which parents convey non-support. The adolescent may feel scapegoated, attacked, unappreciated, and "cut-down." Rather than feeling accepted by her parents, the adolescent may feel that they are attempting to "program her" or make her fit a preconceived model. Without support to create a cohesive bonding among family members, rejection or the fear of rejection promotes defensiveness and suspicion among family members.

Control is another issue which frequently causes difficulty in families with adolescents. Parents who communicate functionally will let their children know in words and in actions what is expected of them. Once expectations have been made explicit, each family member knows where she stands with the others and has a.shared understanding of the situation. On that basis, shared negotiation is possible: parents can decide on limits and policies with the adolescent and offer supervision and guidance in a way that is acceptable to and will be 
used by the adolescent. Adolescents need to know where their parents stand, and also need to know that that stand is not rigid and inflexible. Parents who are "wishy-washy," insecure in decision-making, and confused about firmness and discipline communieate unclear expectations to their children. They may over-react to rule violations (which were unclearly communicated to begin with) and punish severely, withdraw trust, or lose confidence in the adolescent. This may set up a self-defeating pattern: when parents treat an adolescent like a small child, the adolescent will tend to behave like a small child. Parents and adolescents may also find themselves locked in a struggle for control in which the following power tactics are employed: crying, temper tantrums, the "silent treatment,". developing physical symptoms, physical punishment, threats, or excuses. Families which communicate dysfunctionally around control issues may spend so much time battling that they lack time for anything else, and everyone ends up losing.

Family styles of communicating around the issues of relating to others, support, and control have a large impact on the family!s communication around problem-solving. If the family life style is generally healthy, family members can not only deal with life the way it is but can also take steps to make it better. Problems are seen realistically and are differentiated on the basis of those which are "givens" (beyond the control of family members) and must be accommodated or adapted to, and those which are amenable to change or resolution by family members. Parents with effective problem-solving skills help the adolescent to recognize what choices are possible and what consequences will result from each choice. Parents teach the adolescent to accept responsibility 
for her behavior by encouraging the adolescent to look ahead at the possible results of various actions and allowing the adolescent to live with the results of her choices. Parents also model problem-solving skills in the way they handle family conflicts. Rather than using the same rigid method in all conflicts, parents employ a variety of problemsolving skills as delineated by Andrews (9). In accommodation, the message is "this time we'll do it your way, next time my way." In compromise, each party "goes half-way" and a solution acceptable to all is reached. In mutual negotiation, a solution is reached in which all needs are met so that "everyone gets what she wants."

In families where dysfunctional communication prevails, the issue becomes not "how can we best solve this problem?" but "who is boss?" There is no recognition that parents as we 1.1 as adolescents can make concessions even when they would rather not. Members are not allowed to take responsibility for making their own choices or resolving conflicts. Family members are not only lacking in problem-solving skills which address mutual needs, they are also confused as to which problems are appropriately within the realm of family problem-solving. 'Parents may see problems where none exist--for example, the parent who becomes concerned over the amount of time her daughter spends in front of the mirror (something which is quite normal for an adolescent). Parents may also refuse to directly acknowledge problems and abdicate their responsibility--for example, the parent who ignores her daughter's developing sexuality and need for privacy and "invades" her daughter's bedroom without permission. Parents may carry this to an extreme and model very destructive methods of dealing with problems. Adolescent 
use of drugs and alcohol may be a reflection of parental use of drugs and alcohol to avoid problems. Parental desertion may set a precedent for adolescent runaway behavior when things get too "tough." Adolescent truancy and $i 11$ health may be a counterpart of job-absenteeism and a heavy use of sick-leave from work on the part of the parent. Failure to recognize and respond appropriately to problems and conflicts make it extremely difficult for this kind of family to function during crises.

Functional communication around the previously discussed issues of relating to others, support, control, and problem-solving depends primarily on the ability of family members to appropriately send and receive both information messages and feeling messages. Information messages are those which convey ideas, suggestions, or facts, and which rely on rationality, reasoning, and some reality-base. They are characterized as non-emotive and objective, and are generally either taskoriented or factual representations, with an external focus of attention. The following are examples of information messages: "I think it will rain tomorrow," "we should go to the beach today," "it's now $11: 30$," "let's fix lunch," etc. Feeling messages are those which convey subjective reactions to events or experiences. Usually accompanied by a somatic component (for examole, a reddening of the face, increased heart beat, tightening of muscles, etc.), feeling messages are characterized as emotive and expressive, and make a statement about an individual's internal state. Examples of feeling messages include these: "I feel angry when you are late for dinner," "I've had a hard day at work and I'm frustrated," "I love you," etc. 
Information messages and feeling messages are not mutually exclusive--each objective experience has a subjective counterpart. Since messages are always sent and received within the context of a relationship, it is often difficult to isolate statements of information from statements of feelings. Within the family, this is especially prevalent. Family members may confuse information messages and feeling messages, or they may rely exclusively on one or the other. This coupled with the previously discussed dysfunctional forms of sending and receiving such as over-generalization, vague use of pronouns, incomplete messages, double-level messages, misinterpretation of social context, disregard for body language, jumping to conclusions, failure to check for understanding, etc., can have a definite negative impact on the parent-child relationship and the adolescent's development. Dysfunctional forms of sending and receiving information and feelings not only create and maintain a distorted or inaccurate view of relationships, they also have important implications for the adolescent's sense of self-worth and autonomy. The way the adolescent perceives her parents communicating with her will in large part determine the adolescent's view as to where her parents fall on the relationship dimensions of love-hostility and control-autonomy. To illustrate this, common ways presented in the literature by such authors as Becker (15), Gordon (55), Hi11 (62), Jenkins (66), Mussen, Conger and Kagan (84), and Smith and Smith (1.07) that parents send and receive information and feelings both functionaliy and dysfunctionally will be categorized and their effects on the adolescent briefly discussed. 
1. Consistency between actions and words:

Consistency between actions and words means that the parent does what he says he is going to do. It does not mean that the parent is rigidly inflexible and ignores the inevitable change of perspective from day to day, from child to child, or from situation to situation. It means that information given can be seen as reliable. Parents who follow through on information conveyed create an atmosphere which is predictable and safe. They model a trust-worthy authority. Inconsistent parents, on the other hand, lack predictability, are poor models of authority, and create anxiety in their children and a need to test out each piece of information presented.

2. Use of information checks and explanations:

Information checks refer to the attempt to discover if the meaning intended by one individual is, in fact, the meaning understood by the other in the communication process. Rather than assuming that the message was clearly understood, feedback is asked for and received. Explanations are one means of clarifying communication and also provide a rationale for the information given. Explanations of parental rules of conduct and expectations for their children foster autonomy: specific reasons provide an adolescent with internal resources for evaluating her own behavior and for understanding her parents' view of her behavior. Parental authority which is based on a rationale available to and 
understood by their children promotes a positive identification with the parent and self-respect in the adolescent. However, if explanations are over-used and information checks rarely used, the adolescent may perceive the parent as not having confidence in the adolescent's judgment or ability to find her own solution. Rather than promoting autonomy and self-respect in the adolescent, constant explaining or advising promotes lack of self-respect, continuing dependence, and resentment.

3. Input into decision-making:

Input into decision-making refers to who in the family can contribute ideas or suggestions about decisions that must be made. At one extreme, parents may take total responsibility for making decisions involving the adolescent, and at the other extreme parents may take no responsibility. In neither of these situations does the adolescent have an opportunity to contribute input, and the adolescent may therefore see her parents as hostile and rejecting. On the other hand, parents who actively seek out and encourage input into decision-making from their adolescent children also give the message that the adolescent's ideas and suggestions are valued and that the adolescent is seen as an autonomous individual with a right to have some say in decisions affecting her. An additional benefit is that an adolescent is more motivated to carry out a decision in which she has participated than one which has been imposed 
upon her.

4. Use of threats:

Making threats is a method used by parents in an attempt to control an adolescent by telling her in a harsh or punitive way what consequences will occur if she does or does not do something. The use of threats implies a lack of parental respect for the adolescent and may evoke fear and submission or, more commonly, resentment and hostility. The adolescent may react defensively and take an even stronger stand in opposition to her parents, or may be tempted to push the parent into carrying out the threat. Adolescents do need information on the consequences of possible behaviors which will enable them to make decisions (rather than be controlled). If this information is conveyed in a non-judgmental, matter-of-fact way, adolescents will be less likely to perceive it as a threat and more likely to use it appropriately.

5. Use of verbal disruption:

Verbal disruption refers to a means by which one individual distorts or cuts off the flow of another's message. It includes jumping to conclusions and interrupting, which can occur either separately or concurrently. In jumping to conclusions, the receiver begins decoding the sender's message too soon and does not wait to hear all that the sender wishes to convey. This generally happens because of the receiver's preconceived ideas, biases, and/or 
assumptions. Rather than listening openly for the complete message and responding appropriately, the receiver responds according to her own agenda. In interrupting, the receiver begins verbally responding to the sender's message too soon and does not allow the sender to complete her message. In parent-adolescent interactions, verbal disruption or interference by parents may stem from a number of motives:

1) parental fears, anxieties, and feelings of insecurity; 2) parental desire for the adolescent to learn without making mistakes; 3 ) parental desire to impose parenta] concepts of right and wrong; 4) parental over-concern about what others will think of their children; and 5) parental desire to feel needed by their adolescents. The effects of verbal disruption, whether jumping to conclusions or interrupting has occurred, are the same. The adolescent may perceive the parent as interfering, intruding, moving in, or checking up. The parent's discounting and lack of respect for the adolescent's right of expression convey to the adolescent non-acceptance and a lack of trust.

6. Use of validation:

The use of validation in communication is one way in which individuals acknowledge or recognize others. It can be either positive or negative and contributes toward defining. the relationship between the communicators. When validation is used in a positive manner, each participant feels that her jdeas and her "self" are valued and seen as important by 
the other. Perhaps the highest level of validation which can occur is that of trust and its presence in a relationship. Between parent and adolescent, validation implies a permission for the adolescent to think and feel differently from parents and other adults. If an adolescent feels her parents respect her and see her as a worthwhile individual, she is more likely to be open to parental attempts to help her examine and clarify her beliefs and ideas. If, on the other hand, parents allow no variation in individual choice and convey to the adolescent that she is incapable of independent adult thinking and feeling, then she is likely to feel unloved, rejected, inferior, and resistive to what she views as parental unfairness. In sending "put-down" messages, parents impugn the adolescent's character, deprecate her as a person, undermine her self-esteem, underline her inadequacies, and cast a negative judgment on her person. To defend herself, the adolescent may resort to a blanket discounting of a11 parental communication and to counterattacks on the parent in an attempt to avoid their negative validation and protect her own self-image.

7. Use of preaching:

Preaching is used in an attempt to influence or control another by bringing to bear upon her the power of external authority, duty, or obligation. It general1y involves telling the other what she "should" or "ought" to do or have done, and is backed up with an endless supply of 
facts, counter-arguments, logic, and opinions. The use of preaching in the parent-adolescent relationship is based on the misconception that the best way to help the adolescent become something better in the future is to tell her what is not acceptable about her now. The effects of moralizing or exhorting on the adolescent are several: the adolescent may resist and defend her position even more strongly; she may feel that the parent does not trust her judgment; and/or she may view the parent as hostile, controlling, and narrowminded. In contrast, the absence of preaching enables the adolescent to present her "self" without fear of judgment, to draw her own conclusions without being forced into a position, and to move with confidence into self-initiated problem-solving.

\section{Expression of anger:}

Anger and its expression probably have the most potential for creating a breakdown in functional communication. Anger is almost invariably directed at another person and its appropriate expression is difficult. Individuals experiencing an intense anger need permission and time to ventilate their feelings and reduce or dissipate the level of activated energy. Once this has occurred; the individual can then constructively discuss the source of the anger and its implications for herself and her relationship with others. This, however, rarely occurs between parents and adolescents. Instead, anger tends to be managed in one of three common 
ways. The "silent treatment" involves a refusal to deal openiy and verbally with anger and may extend to a refusal to verbalize anything. It can be either a defensive maneuver or a power tactic, and its value lies in keeping the other person guessing. Parents using the "silent treatment" may generate frustration and uncertainty in their adolescent who feels she is being negated, denied importance, and placed in a position of powerlessness. "Retaliatory anger" occurs in response to the anger of another and is based on the idea that "the best defense is an offense." Rather than allowing the anger to be used in a constructive manner, its very presence is seen as a threat which must be defended against. Parents who engage in retaliatory anger convey to the adolescent that anger is not okay, that it is always destructive, and that it never solves anything. The adolescent may feel irresponsible, guilty, or ashamed at her expression of anger, or frustrated and even more angry at her parents' refusal to consider her feelings or demands. A third common manner of expressing anger is characterized as "gunny-sacking.". Rather than expressing and dealing with anger as it occurs, an individual stores her angry feelings until the build-up is such that the slightest provocation produces an intense explosion. The individual may also keep a mental tally sheet of angry feelings from the past which she introduces into present situations, thus confusing current issues and blowing them up out of 
proportion. When "gunny-sacking" occurs in families with adolescents, its effects are generally destructive. The adolescent experiences frustration in her attempt to deal with the present moment and the present feeling, and uncertainty in predicting what will make her parents angry. Her fear of touching off an explosion may lead to resentment, avoidance, or inhibition in her relationship with her parents.

9. Use of praise:

Praise here refers to recognizing or acknowledging positive qualities, aspects, or accomplishments of another. While the use of praise in the parent-adolescent relationship is generally beneficial due to its validating aspects, it can also have negative effects on the recipient. Praise may be seen by the adolescent as manipulative or a subtle means used by parents to influence her behavior. Praise that does not fit the adolescent's self-image may evoke hostility toward the parent and the parent's praise may be discounted or seen as hypocritical. Praise which draws unwanted attention to the adolescent, particularly in front of her friends, may cause her embarrassment or discomfort. Over-use of praise may lead to dependency in the adolescent or a feeling that she must always be perfect or right. DesDite the potential dangers of praise, its absence has definite negative consequences for the adolescent's self-image. A lack of recognition may lead the adolescent to feel worthless, 
non-productive, and alienated. If the lack of praise is coupled with constant criticism, the adolescent may feel that nothing she represents or does is acceptable and that she can never win the approval of her parents.

10. Expression of affect:

The expression of affect refers to a general ability to convey emotions both verbally and non-verbally. Because feelings along with information comprise the content of communication, affective expression is vitally important. Within the parent-adolescent relationship, freedom to openly convey affect contributes to honesty, trust, and sharing along varied dimensions. A lack of affective expression, on the other hand, cuts off or blocks out a major portion of communication. A parent who is unwilling to share feelings with an adolescent leaves the adolescent with no choice but to guess at the parent's internal state, the parent's subjective reactions to the outer world, and the parent's view of the relationship. The adolescent may perceive the parent as cold, controlling, withdrawn, uncaring, or robot-like. She may turn away in frustration and avoid all interactions with the parent or, at the other extreme, go to great lengths out of desperation to elicit some kind of affective reaction from her parent. These same consequences may also occur if a parent expresses affect incongruently--if the verbal message differs and/or contradicts the non-yerbal message. A double-level message 
confuses the adolescent: her uncertainty as to which affective message is genuine makes it difficult for her to know where her parent stands and what response she could appropriately make. She may begin doubting her own perceptions and experience a lack of trust in her own judgment.

11. Use of negation:

The use of negation here refers to messages which convey deprecation of an individual's worth and includes such things as name-calling, ridiculing, shaming, or ignoring. Negating messages deny that the other has anything of value to offer and that her needs, desires, etc., do not deserve consideration. Often used by parents in an attempt to influence or control the adolescent, negating messages generally have a disastrous effect on the adolescent's self-esteem and willingness to risk sharing herself. An adolescent who is continually ridiculed or shamed by her parent may feel unworthy, unloved, defensive, and/or hurt. She may retaliate in kind in an attempt to refute the negation or she may wholeheartedly accept the parent's view of her and become compliant and submissive in a futile attempt to win parental approval (even though she "knows" she can never deserve it). An adolescent whose expressions of self are ignored experiences a similar dilemma. Parents who refuse to acknowledge the adolescent's communication attempts convey that her messages are so inconsequential or meaningless that they are not even worth the effort of responding to. 
12. Use of empathy:

Empathy is that quality of an individual's communication that conveys to another that the 1 istener is feeling with the other, is putting herself in the shoes of the sender, and is living, for a moment, inside the sender. An important part of empathy is communicating to an individual that one perceives and feels her situation. In the parentadolescent relationship, a parent expresses empathy by actively demonstrating his acceptance and understanding of the adolescent so that the adolescent feels it. The parent may not like the adolescent's behavior, but he must be able to understand the way the adolescent feels: the parent may convey his dislike of or even forbid a behavior, but he must do so without demanding that the adolescent disown her honest reactions. This will allow the adolescent access to basic feelings of happiness, sadness, or anger and will encourage the adolescent to use these feelings in evaluating and testing out her experiences. Empathy becomes difficult for parents who may react to a feeling state of the adolescent as a personal affront and who then evaluate the adolescent's feelings as either good or bad. The adolescent may then come to distrust her inner self and be less confident and self-reliant. Intrusiveness, over-involvement, and judgments by the parent may result in the adolescent feeling misunderstood and unappreciated, while disinterest and under-involvement may lead to feelings of worthlessness 
and alienation. Parents effectively convey empathy when they are able to differentiate between when the adolescent is seeking an active listener, when the adolescent may want the privacy to live with her feelings, and when the adolescent is legitimately asking for information and guidance from her parents.

13. Use of guilt induction:

Guilt is the affect which accompanies an individual's judgment of herself as "bad." Gujlt induction is used by the parent to control the behavior of the child by the withholding of parental love, and is most frequently used in conflicts involving family values or "the way we are." These values then become the foci for judgments of loveworthiness by the parents. Whether anxiety over loss of love as a mechanism for the adolescent's adoption of family standards will be helpful rather than harmful depends on how this mechanism is employed by the parent. When disapproval and disappointment are confined to the adolescent's transgressions themselves rather than extended to the adolescent as a whole, and when disapproval is not extreme, harsh, or impulsive, socialization may be fostered. In families with adolescents, the areas which are most prone to the use of guilt induction by the parent are sexuality, parental illness, and socially appropriate behavior. Around these issues, guilt induction is a common strategy used by the parent to manipulate the adolescent in a 
dysfunctional manner to complete a task or act in a certain way. The parent may often rely on the threat of external factors with the message "you disgraced us" or "what will the neighbors think" in order to make the adolescent feel bad about what she has done and to keep her from thinking for herself. Parents are also able to exert control by emphasizing the sacrifices of the parent in order to provide for the whims of the adolescent. These power tactics are often accompanied by "solution messages" in which the parent then tells the adolescent what she must, shouzd, or ought to do, and this further undermines the adolescent's contribution to a mutual solution. If guiltinduction is used by the parent as "emotional blackmail" to control and dominate the adolescent, it may result in not only an overly anxious adolescent, but an adolescent whose development of autonomy, self-confidence, and self-. reliance is impaired.

The preceding categories of ways in which information and feelings can be sent and received and the effects different forms can have on the parent-adolescent relationship point to the importance of communication. The power of parental messages is reflected in Gordon's statement that "children often become what their parents tell them they are" (55, p.32). Adolescent perceptions of parental communication behaviors and the messages conveyed become the blueprint by which they organize both their internal and external realities. If perceived behaviors and messages 
are dysfunctional and negative, then the adolescent's view of herself and her ability to establish and maintain meaningful relationships with others will most likely be seriously undermined. 
Family Therapy

Family therapy is one way of intervening into troubled relationships between parents and adolescents. Its use is becoming more and more frequent, largely due to the changing nature of family therapy itself. In the last century, theraby with families has moved from a basically individual orientation to a specificallv family-centered orientation as indicated by Ackerman (1), Jackson (65), King (68), and Meissner (82). Early attempts at family therapy were influenced by psychoanalysis and psychiatry in which individuals and families were conceptualized in terms of intrapsychic and psychopathological points of view. The medical model approach dominated: the individual's "disease" was investigated, a diagnosis was made, and treatment focused on alleviating individual symptoms. The family was seen as the milieu from which the individual emerged with conflicts requiring individual resolution, and family therapy consisted of using the family to provide an opportunity for corrective intervention on behalf of one of $i$ ts members.

With the advent of greater theoretical sophistication and technical experience, emphasis in family therapy has shifted from the individual to the family as a whole. In an orientation that sees the family as an interactional or transactional system, psychopathology is redefined as a relationship problem and the family itself becomes the unit of diagnosis and treatment. The psychic functioning of an individual is viewed in the wider context of family role adaptations and the psychosocial organization of the family as a unit. Andrews offers 
an excellent description of this approach to the family:

The family is a social system with interdependent and interrelated forces of influence; each member of this svstem is mutually involved with each other member, and the systematic pattern of behavior that is the result of living together is due to the wholly interlocking nature of the human emotional relationships $(9$, p. 6$)$.

The family as a whole is thus seen as being greater than the sum of its "parts" or individual members in a psychodynamic sense.

Family therapy which utilizes a systems approach focuses on the interfaces and communication processes of the family system and its subsystems or individual family members according to Auerswald (12). This approach allows the use of a number of theoretical models dealing with interactional processes and information exchange and, at the same time, points to new technology for inducing change. By stressing the organization of events in time and tracing developmentally the individual's participation or isolation in relation to her family, theravists can determine more clearly where and what kind of assistance is necessary.

The systems approach to family therapy has important implications in the treatment of the acting-out adolescent. Friedman (49) points out that there is impressive evidence that delinquent adolescents fail to. respond to individual psychotherapy and other traditional forms of treatment. Treatment is more likely to be successful if parents are included in the treatment process and if a combination of psychological and environmental approaches is employed. Be11 (17) summarizes the importance of family therapy in the treatment of juvenile offenders as follows: 1) the family is the most important small group to which individuals belong; 2) the family may be and frequently is the primary source of 
the disorder leading to antisocial behavior; 3 ) since the family's influence will persist.into the future, family therapy has a certain preventative aspect; and 4) family therapy may increase the motivation and strengths available in the family for the redirection or control of the delinquent.

The discussion in a previous section of the interlocking maturational tasks of parents and adolescents also points to the need for family treatment. Conflict is essentially interpersonal and relational, and family treatment can offer the entire family certain benefits as presented by Scherz (103): 1) a direct channel for conflict-resolution is provided; 2) changes in role behavior and modes of communication are facilitated; 3) the problems of separateness and separation, sexual identity formation, educational and vocational achievement, and value orientation are addressed; 4) the symbolic death and reconstitution of the family can be worked through; and 5) opportunities for the release of affection and the development of new and more appropriate ways of expressing trust are available. In addition to these potential benefits, family therapy tends to generate enthusiasm for a number of other reasons. The idea of treating the entire family makes sense to those families longing for a closer family bond. Since whatever happens in family therapy is shared common knowledge, suspicion about treatment is reduced. And family therapists such as Satir (97) have reported a greater success in getting the father involved in treatment: fathers seem to be less reluctant to participate in family therapy than in individual therapy (where they are singled out as "having problems"). A number of therapists have spearheaded the movement to a 
family-centered orientation and the development of a rationale for using family therapy. Their differing approaches to the treatment of families are reflected in their proposed definitions for family therapy. Ackerman sees family therapy as ". . a systematic method of nsychotheraveutic intervention, designed to alleviate the multiple, interlocking emotional disorders of a family group" (2, p. 440). Bell offers the definition that "family group therapy is a social psychological treatment method to provide help so that the natural family group may solve its problems and continue to function more efficiently as a group" (18, p. 23). Satir defines family therapy in this way: ". . . if illness is seen to derive from inadequate methods of communication (by which we mean a11 interactional behavior), it follows that therapy will be seen as an attemnt to improve these methods.. . the emphasis will be on correcting discrepancies in communication and teaching ways to achieve more fitting outcomes" (97, p. 96). And finally, Zuk sees family therapy as ": . the technique that explores and attempts to shift the balance of pathogenic relating among family members so that new forms of relating become possible" (122, p. 377$)$. Despite differences in emphasis, these definitions all share the view that the major responsibility of family therapy is to enhance the family's sense of relatedness and concomitantly mobilize the family's natural self-healing functions.

The majority of family therapists also share a similar view of "symptoms." Symptoms presented by a family member are seen as the product of disruption in family interaction, and not as the product of intrapsychic conflicts. The manner in which the symptom, the person, and her family interlock is of primary concern. This kind of approach 
sheds a much different light on the concept of symptoms according to Auerswald (12): behavior that seems bizarre or pathological on the surface may instead be a healthy adaptation to circumstances which prevent a more socially acceptable or better differentiated means of need-meeting. As Framo states, "people present their difficulties in the only way they know how" and symptoms (or the expression of these difficulties) are "formed, selected, faked, exchanged, maintained, and reduced as a function of the relationship context in which they are naturally embedded" (46, p. 273).

An example of this process is provided in the work of Johnson and Szurek (49). They have developed the thesis, documented clinically from their work with parents and their adolescent children. with behavior problems, that the varents' unwitting sanction, indirect encouragement, or provocation is a major cause of and the specific stimulus for antisocial behavior. The child's delinquent behavior thus becomes an expression (or symptom) of a particular combination of family system dysfunctions or pathological family dynamics.

Zuk's description (123) of silencing strategies similarly reflects the idea that symptomology is rooted in the nature of family relationships. One or several family members use this strategy to either obtain compliance or conformity from another family member, or to use her as an object for the projection of their own feelings. Examples of silencing strategies include scapegoating, stereotyping, brainwashing, "changing the subject" (directed against an issue), and "the silent treatment". (directed against a person). Long-term use of these strategies may result in paranoid ideation, or delusional or hallucinatory 
symptoms which are expressed by an individual family member.

The individual family member expressing symptoms is commonly labeled the "identified patient" $(1,18,97,112)$. The family's desire for both change and stability places it in an ambiguous position which may create anxiety or emotional disturbance. In an attempt to resolve this, the family may take advantage of some individual family member's "oddities" and conclude that the family situation could be rectified if that individual would change. By labeling this person as "the problem," attention is diverted from the groun to her. Thus, the individual who first comes to the attention of outside forces or who is first referred for help is generally either the scapegoat for the pathology of the family or is a stand-in for a more critically disturbed famijy member.

Symptoms as expressed by the identified patient in the family can also be examined from a time perspective as Bell suggests (17). Conditions in the family may produce either short-term acute symptoms. or long-term chronicity. Acute crisis generally occurs when an individual is first exhibiting disturbing behavior, when her. symptoms suddenly "break out," or when her behavior has newly become a cause for family anxiety. The family is most probably facing an individual's demand for change in the family constellation which is communicated in such a manner and intensity as to effect disturbance in the group. Acute symptoms, such as runaway behavior, often occur in conjuction with developmental changes as the child matures. Chronicity, on the other hand, results from a non-resolution of acute symptoms. The symptom is incorporated into family patterns and perpetuated as a 
role which is habitual rather than communicative.

The process of effecting change in a disturbed or dysfunctional family system through the use of family therapy rests on a number of propositions $(17,18,65)$. Family rules are relationship agreements which operationally prescribe and 1 imit the individual.'s behaviors over a wide variety of both process areas (how communication will occur) and content areas (what will be communicated). These organize family interaction into a reasonably stable system. However, most family members potentially have available behavior patterns beyond those used in the family, and the family theranist, as an outside community figure, may be shown this behavior. Other family members must then respond to the new patterns revealed by revising their stereotypes and re-evaluating and responding differently to that individual family member. Having developed new modes of interaction which are supported by mutual commitment, the family consolidates these new patterns and equilibrium is once more restored. As Satir states, ". . . therapy is based on the premise that people can be taught to be congruent, to speak directly and clearly, and to communicate their feelings, thoughts, and desires accurately in order to be able to deal with what is" $(97$, p. 182).

Thus the primary goal of family therapy becomes that of changing family systems of interaction. By increasing the number of available communication patterns, developing a greater awareness of them, and promoting a more conscious choice of appropriate patterns, the means by which family interaction takes place are improved. By making family members conscious of roles in the family, an improved level of role complementarity is activated. In helping the family to achieve a 
clearer, more correct perception of family conflict, the family is also made aware of its essential unity and mutual interdependence--something which the runaway adolescent and her family may be sorely in need of. 


\section{Milieu Treatment}

An additional treatment modality that is being utilized for emotionally disturbed children and adolescents is the residential treatment center and the therapeutic milieu. Residential centers for children with emotional problems are a recent phenomenon. There appears to be no clear definition of what a residential treatment center is: in large part, residential treatment is characterized by a diversity of programs and services which have developed out of differences in history, population, purpose, and theoretical orientation. Some general characteristics of residential treatment centers have been enumerated by Adler (4): 1) structure or planned and controlled living; 2) authority, with opportunities for children to work out their feelings about it; 3 ) emphasis on health rather than pathology of the personality; 4) group living and individuation; 5) identification through opportunity for significant relationships; 6) child-staff interaction; 7) community--the sense of being an integral part of one; and 8) integration--the joint planning and evaluation of the child's treatment plan bv all staff.

Historically, residential treatment centers emanate from a wide variety of former institutions--orphanages, state institutions, correctional schools, reformatories, organizations that function as foster homes for dependent and neglected children, and special schools for emotionaliy or educationally retarded children. With the development of supportive services and income maintenance in recent years, the demand for long-term custodial care of children has diminished. The emphasis has shifted from care to treatment. 
The philosophical development of the therapeutic milieu as the treatment format of the residential treatment center is also a recent phenomenon. August Aichhorn is credited with first drawing attention to the use of the milieu as a therapeutic tool and with using the social structure of the institution as a part of the treatment strategy. Aichhorn developed his concepts from his work in a training school for delinquents during the 1920's in Austria and writes of his experiences in the book Wayward Youth (5).

The importance of the environment of the treatment center in supporting and nourishing the psychological development of the child has been the focus of the work of Bettelheim and Red]. Both Bettelheim and Redl emphasize the role of group living and the child-care worker from a psychological orientation $(23,91,92)$. In speaking of the milieu treatment of children, Redl has stressed the importance of dealing with the psychological problems of children as they arise, and in the situation in which they occur. The concept of the "life-space interview" was developed by Redl as appropriate for the therapeutic milieu and is described in the following way:

In contrast to interviewing in considerable detachment from the "here and now" of Johnny's life, like the psychoanalytic play therapy interview, the life-space interview is closely built around the child's direct life experience in connection with the issues that become the interview focus. Most of the time, it is held by a person who is perceived by the child as part of his "natural habitat or life space," with some pretty clear role and power in his daily living, as contrasted to the therapist to whom he is sent for "longrange treatment". (9., p. 6).

Bettelheim conceptualizes the therapeutic milieu in terms of "social solidarity," and his model of the milieu revolves around the importance of the role of the child-care worker in providing a consistent and "solid" 
environment for the emotionally disturbed child. Bettelheim points out that in the "typica]" psychiatric hospital, status is highest for those least involved with the patient; and, paradoxically, the child-care worker who has the most frequent and most direct contact with the child usually finds himself with the least status and the least authority to make decisions relating to his work and the child. Bettelheim has structured his therapeutic milieu on the belief, however, that the status of a worker is dependent on his involvement. with the patient and that decision-making depends not on rank, but on who has the greatest familiarity with or insights into the particular situation and the child. In his model, one worker is with the patient through all phases of the illness, and almost complete responsibility for task execution is in the hands of this worker.

Largely due to the influence of Redl, Bettelheim, child psychiatry, and child guidance, researchers as well as practitioners had been looking at milieu treatment from a psychological perspective. More recently, however, the problem of milieu has been approached from a sociological viewpoint $(6,34)$. These writers focus on the importance of the social systems which surround patient and staff in a treatment facility. An area of concern of Cumming and Cumming (34) is the social environment of the hospital and the issue of authority and control in a therapeutic milieu. They have discussed the problem of how the allocation of power and authority in the milieu can influence the process of ego restitution and growth in hospitalized psychiatric patients. They point out that there has been an increasing effort on the part of institutions to encourage staff members at all levels as well as 
patients to assume responsibility for making therapeutic decisions. These efforts have made the therapeutic milieu more of a reality in that the right to make decisions at the time and place most likely to lead to ego growth will also bring about an emphasis on free and open communication between staff members themselves and between staff members and patients.

These ideas have been further developed and incorporated into a therapeutic milieu program described by Richard Almond in the Healing Community (6) in which the emphasis is on trust, responsibility, and active involvement of al1 patients and staff members. The peer group in the milieu is seen by him as influential and crucial in bringing about a change in individual behavior, and the attempt is made to use the normative influence of the peer group for therapeutic purposes. In the hospital setting described by Almond, both patients (who in this case are adults) and staff feel responsible as members of the milieu "community" for the changing of behavior in others that does not conform with the community's expectation for "nonsick" behavior. This means that the staff and the healthier patients must approach newcomers who are exhibiting deviant behavior and convey to them their anticipation that the deviant behavior will change. Both staff and patients share a sense of responsibility for each other and for the intactness and functioning of the group as a whole in bringing about change.

The above-mentioned theories and conceptualizations of the milieu all indicate how powerful the milieu is as a therapeutic tool. They also demonstrate how individual personalities and the social system can be combined in a milieu to manage and change lives: While these theories 
and models have been developed in relation to a variety of settings and client groups, the emphasis has been on the interaction of the individual with the social environment and the manipulation of the environment to produce change. These studies have not indicated for whom residential and mitieu treatment is most appropriate. An additional question pertinent to this review is the adaptation of residential treatment to the needs of the adolescent.

Several studies $(3,13,54,56,73)$ have specifically dealt with the development of residential treatment facilities to meet the needs of adolescents and have discussed characteristics of adolescents which would indicate a need for residential placement. One orientation to the treatment of adolescents presented by Gralnick (56) is based on the premise that hospitalized adolescents suffer from disorders such as schizophrenia rather than "adolescent behavior problems" and that they exhibit symptoms similar to adults. Based upon this rationale, adolescents are then placed on adult wards, where they are mixed in regards to sex and age. They are treated like adults in an attempt to draw on the healthier aspect of their personality.

Adilman and Lewis $(3,73)$, however, discuss residential programs which treat adolescents with peers and which utilize the strong influence of peer relationships at this stage in the life of the adolescent. One such milieu program for adolescents has developed a means whereby those patients well into treatment serve as a positive peer group influence on those still in a resistance stage. This is called the "pro-treatment group process" and it is characterized by making the milieu group responsible for the behavior of each individual adolescent, and each 
adolescent responsible to the group for her behavior. Lewis, like other authors on the subject, also stresses the importance of utilizing staff who serve as models of identification for the adolescent in order to make such a treatment effort effective.

The cornerstone of the theories and programs mentioned above is the idea that it is the action of the adults and the adults' control of the environment of the child which can be coordinated in the milieu to improve children's lives. An additional premise is that if children are exposed to considerate and interested adults in their environment they will begin to reduce their hostile attitudes toward adults and society in general, and this will enable them to move on to more mature emotional development. Studies $(3,56,61)$ have indicated that children and adolescents placed in residential treatment appear to suffer from serious psychopathology and not merely from symptoms of crisis which are supposedly relievable by manipulation of external factors. The family situation is described (61) as one in which there is severe parent-child conflict, where the child's acting-out behavior mav express the parents' own unconscious rebel7jousness and may act as a source of gratification to the parent. Residential treatment is also indicated in certain situations where outpatient treatment is unsuccessful as long as the child remains with the parent and the parent is resistant to change in the child. It is felt that placement, in these cases, will introduce many positive forces to help counteract the negative effects of the family environment. An important aspect of the milieu environment then becomes the introduction and possibility of a positive relationship between the child and an adult which will reinforce the child's 
capacity for meeting the demands of living and for the capacity for self-control. Children who reach institutions have generally been exposed to negative role models who demonstrate to them self-defeating or unacceptable ways of behaving. A critical element in the milieu then becomes the exposure of the child to more positive adult models who will facilitate learning and growth in the child.

Trieschman, et al. (114) describe the child who is typically found in residential placement as a "relationship-resistant child" who cannot or will not allow the establishment of the "relationship" that is essential for therapeutic change. These children erect barriers to communication, are unresponsive to social reinforcers, and are rejecting of adult models. Thus, a primary aim of the adult worker is to break through these barriers by 1) increasing the child's communication with the adult; 2) increasing the child's responsiveness to social reinforcement provided by the adult; and 3) increasing the tendency of the child to model the behavior of the adult. Adults, as child-care workers, are able to facilitate this process with the child by decoding the "messages" of the child's behavior by understanding what these messages convey about the child's thoughts and feelings. In order for the adult to establish his value to the child as a social reinforcer. and a behavior mode], it is important to increase the interpersonal attraction between the adult and the child. This can be accomplished by "maximizing adult attractiveness" through gratification of needs and by "minimizing adult aversiveness". through the avoidance of power struggles.

There is some research $(22,88,89)$ that suggests that the more favorably the child regards the adult, the more receptive she will be 
to the adult's influence. In studying a group of institutionalized female adolescents, Bertcher (22) found that attitude change in the girls toward the staff was affected significantly by the amount of contact they had with the staff. It was further observed that the girls' attitudes toward staff became more positive when that staff was able to provide specific concrete help to the girls with issues that had a high degree of importance for them such as problems with parents or peers. The use of interpretation or confrontation was found to solidify resistance to attitude change rather than to enhance such change. This author felt that the use of authority, per se, did not lead to positive attitude change because of the girls' acute perception of inconsistency among individual staff members.

on the other hand, additional studies develop the thesis that the child-care worker becomes a positive influence on the child because of his power over the child's environment $(88,89)$. These studies develop a concept of modeling that states that the more power the model has over an individual, the more the individual will imitate the model's behavior. The assumption is then made and supported that because the child-care worker is in a position to give resources to the children and to take them away, he becomes the most powerful model in the child's environment and an extremely influential one.

A11 of these groups of studies, however, feel that one of the important ingredients of residential and milieu therapy is the warm, supportive, and, at the same time, limit-setting influence of childcare workers as parent sutistitutes. The daily interactions between the child and the adult are seen as an opportunitv for therapeutic "education" 
of the child and are an important process in any program of milieu therapy. 


\section{Chapter III}

METHODOLOGY

\section{Introduction}

Our methodology chapter will be divided into two parts. The first part will examine the development and organization of the measurement instrument. The second part will discuss the procedures used in administering the instrument.

Measurement Scale

Two instruments were used to collect data about adolescent girls involved in the program at The Bridge. The first instrument was a face sheet used to gather background information relating to the adolescent's age, family situation, education, runaway experiences, and program involvement. The format and categories of our face sheet were drawn from a similar but more extensive face sheet used by the agency. A copy of our face sheet is presented in Appendix A.

The second instrument used was a questionnaire designed to ascertain how adolescents perceive the communication behaviors of their parents and of other adults. Because the authors found few studies which specifically examined the area of parent-adolescent communication and no suitable measuring instruments, the decision was made to design a questionnaire which would address perceived communication behaviors. Our review of the literature revealed that basic dimensions of the parent-adolescent relationship include love-hostility and control- 
autonomy which are both reflected in and shaped by communication behaviors. These tend to fall into a number of common patterns as categorized in the previous chapter. In order to examine the expression of relationship dimensions more explicitly, the communication process was further broken down into severa' components dealing with sending and receiving information and feelings. Specifically, these components are as follows:

]. The adolescent's perception of how her parents send information messages to her;

2. The adolescent's perception of how her information messages are received by her parents;

3. The adolescent's perception of how her parents send feeling messages to her; and

4. The adolescent's perception of how her feeling messages are received by her parents.

A similar system was used in examining the adolescent's perceptions of communication behaviors by adults other than her parents. These are as follows:

1. The adolescent's perception of how adults (other than her parents) send information messages;

2. The adolescent's perception of how her information messages are received by adults (other than her parents);

3. The adolescent's perception of how adults (other than her parents) send feeling messages to her; and

4. The adolescent's perception of how her feeling messages are received by adults (other than her parents).

For a more detailed presentation of the category and purpose of each question in the instrument, see Appendix $B$.

The instrument designed was divided into two parts: the first section looked at adolescent perception of parental communication, and 
the second section looked at adolescent perception of communication of other aduzts. Each section was composed of twenty-six questions--six related to sending information, six related to receiving information, seven related to sending feelings, and seven related to receiving feelings. Each question was designed as a statement about communication behavior which was to be rated by the adolescent according to frequency of occurrence. Four responses were possible: "Always," "Often," "Seldom," and "Never." (The authors used a scale of four possible responses rather than five in order to prohibit noncommittal replies.) To avoid generalization, questions were phrased in both positive and negative terms, and were mixed to appear in random order on the questionnaire. "Approximately twenty: to thirty minutes were required by the adolescent to complete the questionnaire. Attached to the questionnaire was a cover sheet which explained the purpose of the questionnaire to the adolescent and informed them that their answers were confidential. A copy of the cover sheet and the questionnaire are included in Appendix C.

Administration of Questionnaire

The questionnaire was administered on an individuat basis to the adolescent when she initially became involved with The Bridge. The same questionnaire (with.a revised cover letter) was again administered to the adolescent if she officially completed the program after having been accepted. A total of twenty-eight questionnaires were completed by, girls involved in intake. Of these, eleven were completed by girls who had no further involvement in the program (due to an inappropriate 
referral or to lack of commitment), and four were completed by girls who were accepted into The Bridge but did not officially complete the program (due to runaway behavior or abrupt termination of program involvement). Eight questionnaires were obtained from girls who were accepted into and who officially completed the program. (Four girls in this category were not able to complete a final questionnaire due to circumstances surrounding their release.) This information is presented below in tabular form.

\section{TABLE III}

NUMBER AND PROGRAM INVOLVEMENT OF GIRLS COMPLETING QUESTIONNAIRES

\begin{tabular}{|c|c|}
\hline \multicolumn{1}{|c|}{ QUESTIONNAIRES COMPLETED } & Number \\
\hline \hline GIRLS INVOLVED IN PROGRAM INTAKE & 28 \\
\hline Girls with no further program involvement & 11 \\
\hline (Girls in crisis shelter care) & $(1)$ \\
\hline (Girls who refused to stay) & $(6)$ \\
\hline (Girls with parents who refused services) & $(3)$ \\
\hline (Girls not accepted due to drug use) & $(1)$ \\
\hline $\begin{array}{l}\text { Girls accepted into the program, } \\
\text { did not officially complete program }\end{array}$ & 4 \\
\hline $\begin{array}{l}\text { (Girls terminated due to drug use) } \\
\text { (Girls who ran away) }\end{array}$ & $(2)$ \\
\hline $\begin{array}{l}\text { Girls accepted into program, } \\
\text { officialiy completed program }\end{array}$ & 13 \\
\hline $\begin{array}{l}\text { (Girls who failed to complete questionnaire } \\
\text { upon release) }\end{array}$ & $(5)$ \\
\hline $\begin{array}{l}\text { (Girls who completed questionnaire upon } \\
\text { release) }\end{array}$ & $(8)$ \\
\hline TOTAL BEFORE PROGRAM INVOLVEMENT & 28 \\
\hline TOTAL AFTER PROGRAM INVOLVEMENT & 8 \\
\hline
\end{tabular}


Because The Bridge program is relatively small with only eight to ten girls in residence at any one time, the decision was made to gather information over a six-month period from June 15, 1976, to January 30, 1977.

The questionnaire was administered to the girls by Phyllis Koch, the full-time social worker at The Bridge. Because initial contact could occur at any time and intakes were not regularly scheduled, the authors decided that the social worker would be in the best position to administer the questionnaire due to her availability. While administering the questionnaire, she was instructed to define words (if asked) but not to define the meaning of the question for the adolescent. The social worker was also responsible for completing the face sheet on each girl based upon information she obtained at intake and through provision of services. The presentation of data collected will be in the following chapter. 


\section{Chapter IV}

PRESENTATION AND EVALUATION OF DATA

This chapter will be divided into three major sections. The first section will present in detail the method used in coding, tabulating, and scoring the data. The second section will examine population perceptions of the communication process in terms of the way in which parents and adults other than parents send and receive information and feelings. The third section will examine population perceptions of the communication content in terms of the thirteen categories presented in Chapter II, Review of the Literature, Communication, pages 56-68. Several statistical computations will be used in analyzing the data. For additional information, see Appendix D. 
SECTION I: CODING, TABULATION AND SCORING OF DATA

Our first step in preparing our data was to assign a number to each girl who participated in our study. These numbers ranged from 001 to 028: the numbers $001-008$ were assigned to those girls who completed both a before and after questionnaire, while the numbers 009-028 were assigned to those girls who only completed a before questionnaire. Within these groups a second criterion for number assignment was date of involvement with the program: dates were arranged chronologically and those girls with the earlier dates received the lower numbers.

Our next step was to code and tabulate the information contained on the face sheet for each girl. This included the following areas: contact and termination date, length of stay in weeks, age, most recent family setting, marital status of natural parents, last grade completed, current educational status, prior involvement with the law, place or person to which girl initially ran, days of current run, number of previous runs, and disposition. Originally we had planned to include the types of services provided by the Bridge (i.e. individual counseling, group therapy, and family meetings) and the number of contacts each girl experienced during her stay. However, this information was not ayailable to us in specific form, although each girl who completed the program did receive all three kinds of services.

After compiling the face sheet data, we next tabulated responses - from the questionnaire itself. This involyed transforming the raw 
responses into numerical scores on a scale from one to four. In order that responses would be equivalent and could be compared, we "translated" all questions into positive statements. The scale used in rating each response is presented in the following table.

TABLE IV

SCALE USTED IN RATING RESPONSES

\begin{tabular}{|l|c|c|}
\hline Question Response & $\begin{array}{c}\text { Number Assigned } \\
\text { Positive Question }\end{array}$ & $\begin{array}{c}\text { Number Assigned } \\
\text { Negative Question }\end{array}$ \\
\hline Always & 4 & 1 \\
Often & 3 & 2 \\
Seldom & 2 & 3 \\
Never & 1 & 4 \\
\hline
\end{tabular}

Thus, the higher the numerical value assigned to the response, the more positive the perceived communication behavior.

Some variation occurred in regard to the way questions were answered. If no response was made to the question, no numerical value was assigned. If two responses were checked which were not contiguous (i.e. "Always" and "Seldom," "Always" and "Never," or "Often" and "Never"), no numerical value was assigned. If two responses were checked which were contiguous (i.e. "Always" and "Often," "Often" and "Seldom," or "Seldom" and "Never"), the numerical yalue for the question was deriyed from an average of the assigned numerical yalue for each response:. For example, if both "Always" and "Often" were checked, the question received a score of $3.5\left(\frac{4+3}{2}=3.5\right)$. We were able to average 
the scores in this manner because we have continuous rather than discrete data.

These scaled responses were then organized according to the previously mentioned categories of Sending Information, Receiving Information, Sending Feelings and Receiving Feelings for parents and adults before and after program involyement. Questions within these categories as well as their positive or negative ratings are presented in the following tables.

TABLE V

QUESTIONS WITHIN THE. CATEGORY OF SENDING INFORMATION

\begin{tabular}{|c|c|c|c|}
\hline \multicolumn{2}{|c|}{$\begin{array}{c}\text { Questionna ire } \\
\text { Number }\end{array}$} & \multirow{2}{*}{$\begin{array}{c}\text { Positive } \\
\text { Negative } \\
\text { Rating }\end{array}$} & \multirow[b]{2}{*}{ Question } \\
\hline Parents & Adults & & \\
\hline 1 & 26 & + & $\begin{array}{l}\text { My parents (adults) do what they say } \\
\text { they are going to do. }\end{array}$ \\
\hline 9 & 6 & + & $\begin{array}{l}\text { My parents (adults) check to make sure } \\
\text { I understand what they tell me. }\end{array}$ \\
\hline $13^{\circ}$ & 23 & + & $\begin{array}{l}\text { When decisions are made concerning me, } \\
\text { my parents (adu ts) ask for my ideas. }\end{array}$ \\
\hline 5 & 3 & + & $\begin{array}{l}\text { My parents (adults) are willing to } \\
\text { explain rules. }\end{array}$ \\
\hline 17 & 12 & - & $\begin{array}{l}\text { My parents (adults) threaten or yell at } \\
\text { me when they want me to do something. }\end{array}$ \\
\hline 22 & 15 & - & $\begin{array}{l}\text { My parents (adults) talk to me as if I } \\
\text { were still a little girl. }\end{array}$ \\
\hline
\end{tabular}


TABLE VI

QUESTIONS WITHIN THE CATEGORY OF

RECEIVING INFORMATION

\begin{tabular}{|c|c|c|c|}
\hline \multicolumn{2}{|c|}{$\begin{array}{l}\text { Questionnaire } \\
\text { Number }\end{array}$} & \multirow{2}{*}{$\begin{array}{c}\text { Positive } \\
\text { Negative } \\
\text { Rating }\end{array}$} & \multirow[b]{2}{*}{ Question } \\
\hline Parents & Adults & & \\
\hline 15 & 8 & + & $\begin{array}{l}\text { When I talk to my parents (adults), they } \\
\text { listen calmly and without interruptions. }\end{array}$ \\
\hline 20 & 5 & + & $\begin{array}{l}\text { My parents (adults) respect my opinions } \\
\text { even if they don't agree with them. }\end{array}$ \\
\hline 3 & 16 & - & $\begin{array}{l}\text { My parents (adults) don't want to hear } \\
\text { what I have to say about decisions } \\
\text { affecting me. }\end{array}$ \\
\hline 7 & 1 & - & $\begin{array}{l}\text { My parents (adults) jump to conclusions } \\
\text { and don't let me finish what I want to say }\end{array}$ \\
\hline 25 & 20 & - & $\begin{array}{l}\text { My parents (adults) tel1 me my ideas are } \\
\text { dumb. }\end{array}$ \\
\hline 11 & 25 & - & $\begin{array}{l}\text { When I ask my parents (adults) a question, } \\
\text { they preach at me instead of answering my } \\
\text { question. }\end{array}$ \\
\hline
\end{tabular}


TABLE VII

QUESTIONS WITHIN THE CATEGORY OF

SENDING FEELINGS

\begin{tabular}{|c|c|c|c|}
\hline \multicolumn{2}{|c|}{$\begin{array}{c}\text { Questionnaire } \\
\text { Number }\end{array}$} & \multirow{2}{*}{$\begin{array}{c}\text { Positive } \\
\text { Negative } \\
\text { Rating }\end{array}$} & \multirow[b]{2}{*}{ Question } \\
\hline Parents & Adults & & \\
\hline 19 & 10 & + & $\begin{array}{l}\text { When my parents (adults) are angry at me, } \\
\text { they talk about it calmly with me. }\end{array}$ \\
\hline 26 & 24 & + & $\begin{array}{l}\text { My parents (adults) praise and encourage } \\
\text { me. }\end{array}$ \\
\hline 16 & 19 & + & $\begin{array}{l}\text { My parents (adults) give me messages that } \\
\text { they trust me. }\end{array}$ \\
\hline 8 & 2 & - & $\begin{array}{l}\text { It's hard for me to know what my parents } \\
\text { (adults) are feeling. }\end{array}$ \\
\hline 4 & 13 & - & $\begin{array}{l}\text { My parents (adults) give me the silent } \\
\text { treatment when they are angry at me. }\end{array}$ \\
\hline 23 & 14 & - & $\begin{array}{l}\text { When my parents (aduits) and I argue, they } \\
\text { bring up angry feelings related to other } \\
\text { things from the past. }\end{array}$ \\
\hline 12 & 22 & - & $\begin{array}{l}\text { My parents (adults) try to make me feel } \\
\text { guilty when I've done something they told } \\
\text { me not to do. }\end{array}$ \\
\hline
\end{tabular}


TABLE VIII

QUESTIONS WITHIN THE CATEGORY OF

RECEIVING FEELINGS

\begin{tabular}{|c|c|c|c|}
\hline $\begin{array}{c}\text { Questionnaire } \\
\text { Number }\end{array}$ & $\begin{array}{c}\text { Positive } \\
\text { Negative } \\
\text { Rating }\end{array}$ & \multicolumn{1}{c|}{ Question } \\
\hline 2 & 17 & + & $\begin{array}{l}\text { My parents (adults) try to understand how } \\
\text { I feel. }\end{array}$ \\
\hline 24 & 21 & + & $\begin{array}{l}\text { My parents (adults) listen when I tel1 } \\
\text { them about the things which have made me } \\
\text { happy. }\end{array}$ \\
\hline 21 & 4 & + & $\begin{array}{l}\text { My parents (adults) let me blow off steam } \\
\text { When I'm mad. }\end{array}$ \\
\hline 18 & 7 & - & $\begin{array}{l}\text { When I express my feelings, my parents } \\
\text { (adults) make fun of me. }\end{array}$ \\
\hline 14 & 9 & - & $\begin{array}{l}\text { My parents (adults) ignore me when I tel1 } \\
\text { them how I feel. }\end{array}$ \\
\hline 10 & 18 & - & $\begin{array}{l}\text { My parents (adults) tell me how I should } \\
\text { feel, instead of accepting the way I } \\
\text { realiy feel. }\end{array}$ \\
\hline $\begin{array}{l}\text { When I get angry at my parents (adults), } \\
\text { they then get angry at me. }\end{array}$ \\
\hline
\end{tabular}


Scored responses were tabulated according to category. Each girl was given a total score for each category based upon her responses within that category. If we were unable to assign a numerical value to questions within a category, a total score for that category was not given. Each question also received a total score based upon all responses given for that question.

Each girl also received a total score for her perception of parental communication and for her perception of adult communication behavior. This was done by adding together her total scores for each category. If a girl had not been given a total score for one of the four categories (due to incomplete responses within that category) her scores for the other three categories were averaged and the yalue obtained was used only in computing a total score for her perception of parental or adult communication behavior. This occurred in five cases for Parents, Before Program Involvement (005, 006, 015, 025, 028); in two cases for Adults, Before Program Involvement (017, 028); and once for Adults, After Program Involvement (008). If a girl had not been given a total score for two or more of the four categories (due to incomplete responses within that category); she was not given a total score for her perception of parental or adult communication behavior. This occurred in two cases for Parents, Before Program Involvement $(007,011)$; once for Adults, Before Program Involvement (007): and once for. Parents, After Program Involyement (005). This completed our coding, tabulating and scoring of the data obtained. 
SECTION II: POPULATION PERCEPTIONS OF THE COMMUNICATION PROCESS

This section will consist of four parts. The first part will examine population characteristics. Demographic information will be presented and relationships between this data and perception scores will be explored. The second part will present and describe the perception scores of the subjects before program involvement. The third part will present and describe the perception scores of the subjects after program involvement. The last part will compare perception scores before and after program involvement. The four parts are listed below:

1. Population characteristics.

2. Perception scores before program involyement.

3. Perception scores after program involvement.

4. Comparison of before and after perception scores.

\section{Population Characteristics}

Our first step was to determine whether there were any significant differences between the responses given by girls who completed both the before and after questionnaire (001-008) and girls who.completed only the before questionnaire (009-028). In order to test for significant differences, the Mann-Whitney U-Test was selected because we had ordinal data, small samples, and unequal numbers in each sample. Using the Mann-Whitney U-Test; comparisons were made between group 001-008 scores and group 009-028 scores for the following areas: 
1. Parents Sending Information;

2. Parents Receiving Information;

3. Parents Sending Feelings;

4. Parents Receiving Feelings;

5. Total Parents;

6. Adults Sending Information;

7. Adults Receiving Information;

8. Adults Sending Feelings;

9. Adults Receiving Feelings; and

10. Total Adults.

No significant differences were found in any of these areas which al lowed us to conclude that the two groups (001-008 and 009-028) came from the same population and can therefore be treated as one (001-028). We were then abje to determine median scores for the areas listed aboye which are presented in the following table. An examination of the table indicates a division of the population into three groups in order to make comparisons easier and for further statistical purposes. 
TABLE IX

MEDIAN SCORES BY CATEGORY AND POPULATION GROUP

\begin{tabular}{|l|l|l|l|}
\hline \multirow{2}{*}{ Category } & \multicolumn{3}{|c|}{ Population Group } \\
\cline { 2 - 5 } & $\begin{array}{c}001-008 \\
\text { Before }\end{array}$ & $\begin{array}{c}001-008 \\
\text { After }\end{array}$ & $\begin{array}{c}001-028 \\
\text { Before }\end{array}$ \\
\hline Parents: Sending Information & 15 & 18 & 14.75 \\
\hline Parents: Receiving Information & 16 & 18.83 & 14.50 \\
\hline Parents: Sending Feelings & 13.50 & 20 & 14.06 \\
\hline Parents: Receiving Feelings & 19.75 & 23 & 18 \\
\hline Total Parents Scores & 67.75 & 80 & 61 \\
\hline Adults: Sending Information & 18 & 18.67 & 16.75 \\
\hline Adults: Receiving Information & 17.75 & 18 & 16.30 \\
\hline Adults: Sending Feelings & 19.67 & 20.5 & 18.7 \\
\hline Adults: Receiving Feelings & 19 & 20.5 & 18.25 \\
\hline Total Adults Scores & 77 & 77.83 & 68.67 \\
\hline
\end{tabular}

To further describe the total population, we organized the demographic data obtained from the face sheets into tables. Each table examines a descriptive variable, and contains variable divisions, the number of girls in each division, and the percent of total in each division. (Percents may not total 100 due to errors in rounding.) These tables are presented below. Brief comments which note some interesting patterns will follow each table. 
TABLE $X$

LENGTH OF STAY IN TOTAL WEEKS

\begin{tabular}{|c|c|c|}
\hline No. of Weeks & No. of Girls & $\%$ Total \\
\hline $0-1.9$ & 11 & $39 \%$ \\
\hline $2-3.9$ & 5 & $18 \%$ \\
\hline $4-5.9$ & 2 & $7 \%$ \\
\hline $6-7.9$ & 2 & $7 \%$ \\
\hline $8-9.9$ & 5 & $18 \%$ \\
\hline $10-11.9$ & 2 & $7 \%$ \\
\hline $12-13.9$ & 1 & $4 \%$ \\
\hline
\end{tabular}

As presented in Table $X$, over half the girls (57\%) were involved with the program for less than four weeks.

TABLE XI

AGE OF GIRLS AT INTAKE

\begin{tabular}{|c|c|c|}
\hline Age & No. of Girls & $\%$ Total \\
\hline 12 & 2 & $7 \%$ \\
\hline 13 & 9 & $32 \%$ \\
\hline 14 & 6 & $21 \%$ \\
\hline 15 & 6 & $21 \%$ \\
\hline 16 & 5 & $18 \%$ \\
\hline
\end{tabular}


Excluding the two girls who were age twelve, there appears to be no real variation in the age of girls involved with the program according to Table $X I$.

TABLE XII

MARITAL STATUS OF NATURAL PARENTS

\begin{tabular}{|l|c|c|}
\hline Marital Status & No. of Girls & $\%$ Total \\
\hline Intact & 14 & $50 \%$ \\
\hline Separated & 1 & $4 \%$ \\
\hline Divorced & 12 & $43 \%$ \\
\hline Deceased & 1 & $4 \%$ \\
\hline
\end{tabular}

A finding that was of particular interest in Table XII was that half the girls (50\%) indicated that the marital status of their parents was intact. 
TABLE XIII

MOST RECENT FAMILY SETTING

\begin{tabular}{|l|c|c|}
\hline \multicolumn{1}{|c|}{ Setting } & No. of Girls & $\%$ Total \\
\hline Both Natura] Parents & 13 & $46 \%$ \\
\hline $\begin{array}{l}\text { Natural Mother and Step- } \\
\text { Father }\end{array}$ & 6 & $21 \%$ \\
\hline $\begin{array}{l}\text { Natura] Father and Step- } \\
\text { Mother }\end{array}$ & 1 & $4 \%$ \\
\hline Natura] Mother Only & 5 & $78 \%$ \\
\hline Grandparents & 1 & $4 \%$ \\
\hline Other* & 2 & $7 \%$ \\
\hline
\end{tabular}

*1 Adoptive Mother

1 Natural Mother and Boyfriend

In Table XIII, almost half the girls (46\%) Tisted both natural parents as their most recent family setting, while one-fourth (25\%) listed a family setting consisting of a natural parent and a stepparent. 
TABLE XIV

LENGTH OF TIME IN MOST RECENT, FAMILY SETTING

\begin{tabular}{|c|c|c|}
\hline No. of Years & No. of Girls & $\%$ Total \\
\hline $0-2.9$ & 5 & $18 \%$ \\
\hline $3-5.9$ & 2 & $7 \%$ \\
\hline $6-8.9$ & 1 & $4 \%$ \\
\hline $9-11.9$ & 2 & $7 \%$ \\
\hline Life & 16 & $57 \%$ \\
\hline Unknown & 2 & $7 \%$ \\
\hline
\end{tabular}

In conjunction with Table XIII, Table XIV illustrates that over half the girls (57\%) have spent all their lives in their most recent family setting.

TABLE XV

LAST GRADE COMPLETED

\begin{tabular}{|c|c|c|}
\hline Last Grade & No. of Girls & $\%$ Total \\
\hline 5 & 1 & $4 \%$ \\
\hline 6 & 1 & $4 \%$ \\
\hline 7 & 9 & $32 \%$ \\
\hline 8 & 7 & $25 \%$ \\
\hline 9 & 4 & $14 \%$ \\
\hline 10 & 5 & $18 \%$ \\
\hline 11 & 1 & $4 \%$ \\
\hline
\end{tabular}


Although Table XV presents a wide variation in last grade completed, Table XVI below indicates that a large majority of the girls (79\%) were currently in school prior to involvement with The Bridge.

TABLE XVI

CURRENT EDUCATIONAL STATUS PRIOR. TO BRIDGE

\begin{tabular}{|l|c|c|}
\hline \multicolumn{1}{|c|}{ Status } & No. of Girls & \% Total \\
\hline In School & 22 & $79 \%$ \\
\hline Dropped Out & 4 & $14 \%$ \\
\hline Other* & 2 & $7 \%$ \\
\hline
\end{tabular}

*1 Not allowed to attend school, custodian resides el sewhere. 1 About to be expelled.

TABLE XVII

PRIOR INVOLVEMENT WITH JUVENILE JUSTICE SYSTEM

\begin{tabular}{|c|c|c|}
\hline Invol vement & No. of Girls & $\%$ Total \\
\hline $\begin{array}{l}\text { Police Arrest - One Time } \\
\text { (Shoplifting) } \\
\text { (Prostitution) } \\
\text { (Status Offense) } \\
\text { (Unauthorized Use of } \\
\text { motor vehicle) }\end{array}$ & $\begin{array}{c}6 \\
(3) \\
(1) \\
(1) \\
(1)\end{array}$ & $21 \%$ \\
\hline None & 22 & $79 \%$ \\
\hline
\end{tabular}

Another finding that was of interest is contained in Table XVII which shows that less than one-fourth of the girls (21\%) had any prior involvement with the law. 
TABLE XVIII

PLACE TO WHICH GIRL INITIALLY RAN

\begin{tabular}{|l|c|c|}
\hline \multicolumn{1}{|c|}{ Place/Person } & No. of Girls & $\%$ Total \\
\hline Friend & 17 & $61 \%$ \\
\hline Street & 5 & $18 \%$ \\
\hline Court & 1 & $4 \%$ \\
\hline Other* & 2 & $7 \%$ \\
\hline $\begin{array}{l}\text { Removed from home by legal } \\
\text { agency }\end{array}$ & 3 & $11 \%$ \\
\hline
\end{tabular}

*1 threatened to run.

1 ran to her natural parents.

Table XVIII presents the finding that a girl's friends were involved with her in runaway episodes in well over half the cases (61\%).

TABLE XIX

NUMBER OF TIMES PREVIOUSLY RUN.

\begin{tabular}{|c|c|c|}
\hline No. of Times & No. of Girls & $\%$ Total \\
\hline 0 & 11 & $39 \%$ \\
\hline 1 & 7 & $25 \%$ \\
\hline 2 & 3 & $17 \%$ \\
\hline 3 & 3 & $11 \%$ \\
\hline 4 and over & 4 & $14 \%$ \\
\hline
\end{tabular}


It is interesting to note that although the program was designed to treat girls with a minimal number of runaway episodes, a smal1 percent of the population (14\%) did in fact have a large number of runs.

TABLE XX

DISPOSITION FROM BRIDGE

\begin{tabular}{|c|c|c|}
\hline \multicolumn{1}{|c|}{ Disposition } & No. of Girls & $\%$ Total \\
\hline $\begin{array}{c}\text { Return to Primary Family Home } \\
\text { (Girl Refused to Stay) } \\
\text { (Parents Refused Services) }\end{array}$ & $\begin{array}{c}14 \\
(5)\end{array}$ & $50 \%$ \\
\hline $\begin{array}{l}\text { Placed with Natural Father and } \\
\text { Step-Mother }\end{array}$ & 1 & $4 \%$ \\
\hline $\begin{array}{l}\text { Placed in Foster Homes } \\
\text { (Parents Refused Services) }\end{array}$ & 3 & $11 \%$ \\
\hline $\begin{array}{l}\text { Placed in Group Homes } \\
\text { (Parents Refused Services) }\end{array}$ & 2 & $7 \%$ \\
\hline $\begin{array}{l}\text { Placed in Shelter Care or Referred } \\
\text { Back to C.S.D. }\end{array}$ & 2 & $7 \%$ \\
\hline Ran from Program & 3 & $11 \%$ \\
\hline $\begin{array}{l}\text { Placed in Juvenile Institution } \\
\text { (Villa St. Rose) }\end{array}$ & 1 & $4 \%$ \\
\hline $\begin{array}{l}\text { Placed in Juvenile Detention After } \\
\text { Refusal to Stay }\end{array}$ & 2 & $7 \%$ \\
\hline
\end{tabular}

Our final demographic table indicates a wide variation in disposition of girls from the program and is essentially self-explanatory.

To determine whether any significant relationships existed between the descriptive demographic variables and the girls' perception scores, The Chi-Square Median Test was used. The following relationships were studied using Total Before Scores: 
1. The relationship of age to perception of parents;

2. The relationship of age to perception of adults;

3. The relationship of marital status of natural parents to perception of parents;

4. The relationship of most recent family setting to perception of parents;

5. The relationship of length of time in most recent family setting to perception of parents;

6. The relationship of current educational status to perception of parents;

7. The relationship of current educational status to perception of adults;

8. The relationship of prior involvement with the law to perception of parents;

9. The relationship of prior involvement with the law to perception of adults;

10. The relationship of the number of times previously run to perception of parents;

11. The relationship of consent to participate in program to perception of parents; and

12. The relationship of consent to participate in program to perception of adults.

None of these relationships were found to be significant at the .05 level, possibly due to our small sample size and the small number of girls in each variable division. This completed our study of population characteristics.

Perception Scores Before Program Involvement

The second part of Section II will examine more closely the perception scores for parents and for adults before program involvement using the population group of 001-028. Comparisons were made within 
the perception scores calculated for Parents to determine the following:

1. The difference between the way parents were perceived while sending information and while receiving information;

2. The difference between the way parents were perceived while sending feelings and while receiving feelings;

3. The difference between the way parents were perceived while sending information and while sending feelings; and

4. The difference between the way parents were perceived while receiving information and while receiving feelings.

Comparisons were made within the perception scores calculated for Adults to determine the following:

5. The difference between the way adults were perceived while sending information and while receiving information;

6. The difference between the way adults were perceived while sending feelings and while receiving feelings;

7. The difference between the way adults were perceived while sending information and while sending feelings; and

8. The difference between the way adults were perceived while receiving information and while receiving feelings.

Comparisons were also made between perception scores calculated for Parents and perception scores calculated for Aduzts to determine the following:

9. The difference between the way parents were perceived while sending information and the way adults were perceived while sending information;

10. The difference between the way parents were perceived while receiving information and the way adults were perceived while receiving information;

11. The difference between the way parents were perceived while sending feelings and the way adults were perceived while sending feelings;

12. The difference between the way parents were perceived while receiving feelings and the way adults were perceived while receiving feelings; and 
13. The difference between the total scores received by parents and the total scores received by adults.

In making these comparisons, the Mann-Whitney U-Test with a transformation of the $U$ value into a $z$ score was used. Values obtained were judged on the basis of levels of significance for one-tailed tests. Our results are presented below.

1. For the difference between the way parents were perceived while sending information and while receiving information $z$ calculated $(-.44)$ was greater than $z$ critical $(-1.645)$ at the .05 leve1. Therefore, there is no significant difference in the way parents send and receive information.

2. For the difference between the way parents were perceived while sending feelings and while receiving feelings, $z$ calculated $(-3.059)$ was less than $z$ critical $(-2.579)$ at the .005 level. Therefore, there is a difference in the way parents send and receive feelings; perception scores for receiving feelings are significantly higher than perception scores for sending feelings at the .005 level.

3. For the difference between the way parents were perceived while sending information and while sending feelings, $z$ calculated $(-.33)$ was greater than $z$ critical $(-1.645)$. at the .05 level. Therefore, there is no significant difference in the way parents send information and feelings.

4. For the difference between the way parents were perceived while receiving information and while receiving feelings, $z$ calculated $(-3.199)$ was less than $z$ critical $(-2.576)$ at the .005 level. Therefore, there is a difference in the way parents receive information and feelings; perception scores for receiving feelings are significantly higher than perception scores for receiving information at the .005 level.

5. For the difference between the way adults were perceived while sending information and while receiving information, $z$ calculated $(-.516)$ was greater than $z$ critical $(-1.645)$ at the .05 level. Therefore, there is no significant difference in the way adults send and receive information.

6. For the difference between the way adults were perceived while sending feelings and while receiving feelings, $z$ calculated $(-.810)$ was greater than $z$ critical $(-1.645)$ at the .05 level. Therefore, there is no significant difference in the way adults send and receive feelings. 
7. For the difference between the way adults were perceived while sending information and while sending feelings, $z$ calculated $(-1.254)$ was greater than $z$ critical $(-1.645)$ at the .05 level. Therefore, there is no significant difference in the way adults send information and feelings.

8. For the difference between the way adults were perceived while receiving information and while receiving feelings, $z$ calculated $(-2.553)$ was less than $z$ critical $(-2.326)$ at the .01 level. Therefore, there is a difference in the way adults receive information and feelings; perception scores for receiving feelings are significantly higher than perception scores for receiving information at the .01 level.

9. For the difference between the way parents were perceived while sending information and the way adults were perceived while sending information, $z$ calculated $(-1.831)$ was less than $z$ critical $(-1.645)$ at the .05 level. Therefore, there is a difference in the way parents and adults send information; adult perception scores for sending information are significantly higher than parent perception scores for sending information at the .05 level.

10. For the difference between the way parents were perceived while receiving information and the way adults were perceived while receiving information, $z$ calculated $(-2.185)$ was less than $z$ critical $(-1.960)$ at the .025 level. Therefore, there is a difference in the way parents and adults receive information; adult perception scores for receiving information are significantly higher than parent perception scores for receiving information at the .025 level.

11. For the difference between the way parents were perceived while sending feelings and the way adults were perceived while sending feelings, $z$ calculated $(-3.260)$ was less than $z$ critical $(-2.576)$ at the .005 level. Therefore, there is a difference in the way parents and adults send feelings; adult perception scores for sending feelings are significantily higher than parent perception scores for sending: feelings at the .005 level.

12. For the difference between the way parents were perceived while receiving feelings and the way adults were perceived while receiving feelings, $z$ calculated $(-.701)$ was greater than $z$ critical $(-1.645)$ at the .05 level. Therefore, there is no significant difference between the way parents and adults receive feelings.

13. For the difference between the total scores received by parents and the total scores received by adults, z calculated (-2.589) was less than $z$ critical $(-2.576)$ at the .005 level. Therefore, 
there is a difference in total scores for parents and adults; total perception scores for adults are significantly higher than total perception scores for parents at the .005 level.

The previous test results involving perception scores before program involvement are summarized in the table below. In this table, the following abbreviations are used (and will be used in other tables in this chapter):

$$
\begin{aligned}
& \text { SI = Sending Information } \\
& R I=\text { Receiving Information } \\
& S F=\text { Sending Feelings } \\
& \text { RF = Receiving Feelings }
\end{aligned}
$$


TABLE XXI

\begin{abstract}
SUMMARY OF TEST RESULTS FOR PERCEPTION SCORES
BEFORE PROGRAM INVOLVEMENT:

POPULATION GROUP 001-028
\end{abstract}

\begin{tabular}{|l|l|}
\hline \multicolumn{1}{|c|}{ COMPARISON } & \multicolumn{1}{|c|}{ RESULTS } \\
\hline \hline Parents SI to Parents RI & Not significant \\
\hline Parents SF to Parents RF & Significant, $\alpha=.005, \mathrm{RF}>\mathrm{SF}$ \\
\hline Parents SI to Parents SF & Not significant \\
\hline Parents RI to Parents RF & Significant, $\alpha=.005, \mathrm{RF}>\mathrm{RI}$ \\
\hline Adults SI to Adults RI & Not significant \\
\hline Adults SF to Adults RF & Not significant \\
\hline Adults SI to Adults SF & Not significant \\
\hline Adults RI to Adults RF & Significant, $\alpha=.01, \mathrm{RF}>\mathrm{RI}$ \\
\hline Parents SI to Adults SI & $\begin{array}{l}\text { Significant, } \alpha=.05, \\
\text { Adults }>\text { Parents }\end{array}$ \\
\hline Parents RI to Adults RI & $\begin{array}{l}\text { Significant, } \alpha=.025, \\
\text { Adults }>\text { Parents }\end{array}$ \\
\hline Parents SF to Adults SF & $\begin{array}{l}\text { Significant, } \alpha=.005, \\
\text { Adults }>\text { Parents }\end{array}$ \\
\hline Parents RF to Adults RF & Not significant \\
\hline $\begin{array}{l}\text { Total Parents to Total } \\
\text { Adults }\end{array}$ & $\begin{array}{l}\text { Significant, } \alpha=.005, \\
\text { Adults }>\text { Parents }\end{array}$ \\
\hline
\end{tabular}

In essence, the way parents and adults were perceived before program involvement while receiving feelings (as opposed to sending and receiving information and sending feelings) appears to be the area of greatest significance, particulariy for parents. Scores in this group were higher 
than those in any other group. A second major finding is that adults were perceived as using more positive communication behaviors than were parents in three out of four categories, and that total adult scores were more positive than total parent scores at a very high leve1 (.005) of significance.

Perception Scores After Program Involvement

The third part of Section II will examine more closely the perception scores for parents and for adults after program involvement using the population group of 001-008. Comparisons were made within the perception scores calculated for Parents to determine the following:

1. The difference between the way parents were perceived while sending information and while receiving information;

2. The difference between the way parents were perceived while sending feelings and while receiving feelings;

3. The difference between the way parents were perceived while sending information and while sending feelings; and

4. The difference between the way parents were perceived while receiving information and while receiving feelings.

Comparisons were made within the perception scores calculated for Aduzts to determine the following:

5. The difference between the way adults were perceived while sending information and while receiving information;

6. The difference between the way adults were perceived while sending feelings and while receiving feelings;

7. The difference between the way adults were perceived while sending information and while sending feelings; and

8. The difference between the way adults were perceived while receiving information and while receiving feelings.

Comparisons were also made between perception scores calculated for 
Parents and perception scores calculated for Adults to determine the following:

9. The difference between the way parents were perceived while sending information and the way adults were perceived while sending information.

10. The difference between the way parents were perceived while receiving information and the way adults were perceived while receiving information.

11. The difference between the way parents were perceived while sending feelings and the way adults were perceived while sending feelings.

12. The difference between the way parents were perceived while receiving feelings and the way adults were perceived while receiving feelings; and

13. The difference between the total scores received by parents and the total scores received by adults.

In making these comparisons, the Wilcoxen Matched-Pairs Signed-

Ranks Test was used when possible due to equal numbers within samples. When sample size fell below five, a Mann-Whitney U-Test was used.

Values obtained were judged on the basis of levels of significance for one-tailed tests. Our results are presented below.

1. For the difference between the way parents were perceived while sending information and while receiving information, the found $s$ (6.5) was greater than the critical value (2) at the .05 level. Therefore, there is no significant difference in the way parents send and receive information.

2. For the difference between the way parents were perceived while sending feelings and while receiving feelings, the found $s(4)$. was equal to the critical value (4) at the .05 level. Therefore, there is a difference in the way parents send and receive feelings; perception scores for receiving feelings are significantly higher than perception scores for sending feelings at the .05 level, with $p$ (probability) $=.0547$.

3. For the difference between the way parents were perceived while sending information and while sending feelinos, $U$ calculated (19.5) was greater than the theoretical U (11) at the .05 leve1. 
(We were unable to perform a Wilcoxen Test due to small sample size.) Therefore, there is no significant difference in the way parents send information and feelings.

4. For the difference between the way parents were perceived while receiving information and while receiving feelings, the found $s(0)$ was equal to the critical value $(0)$ at the .01 level. Therefore, there is a difference in the way parents receive information and feelings; perception scores for receiving feelings are significantly higher than perception scores for receiving information, with $p=.0078$.

5. For the difference between the way adults were perceived while sending information and while receiving information, the found $s$ (9.5) was greater than the critical value (2) at the .05 leve1. Therefore, there is no significant difference in the way adults send and receive information.

6. For the difference between the way adults were perceived while sending feelings and while receiving feelings, the found $s(5)$ was greater than the critical value (2) at the .05 level. Therefore, there is no significant difference in the way adults send and receive feelings.

7. For the difference between the way adults were perceived while sending information and while sending feelings, the found $s$ (3.5) was less than the critical value (4) at the .05 level. Therefore, there is a difference in the way adults send information and feelings; perception scores for sending feelings are significantly higher than perception scores for sending information at the .05 level, with $p=.0469$.

8. For the difference between the way adults were perceived while receiving information and while receiving feelings, the found $s$ (2) was equal to the critical value (2) at the .01 level. Therefore, there is a difference in the way adults receive information and feelings; perception scores for receiving feelings are significantly higher than perception scores for receiving information at the .01 leve1, with $p=.0117$.

9. For the difference between the way parents were perceived while sending information and the way adults were perceived while sending information, the found $s(3.5)$ was greater than the critical s (0) at the .05 level. Therefore, there is no significant difference in the way parents and aduits send information.

10. For the difference between the way parents were perceived while receiving information and the way adults were perceived while receiving information, the found $s(14.5)$ was greater than the critical value (5) at the .05 level. Therefore, there is no significant difference in the way parents and adults receive information. 
11. For the difference between the way parents were perceived while sending feelings and the way adults were perceived while sending feelings, the found $s(6.5)$ was greater than the critical value $(0)$ at the .05 level. Therefore, there is no significant difference in the way parents and adults send feelings.

12. For the difference between the way parents were perceived while receiving feelings and the way adults were perceived while receiving feelings, the found $s$ (8.5) was greater than the critical value (3) at the .05 level. Therefore, there is no significant difference in the way parents and adults receive feelings.

13. For the difference between the total scores received by parents and the total scores received by adults, the found $s(9.5)$ was greater than the critical value (3) at the .05 level. Therefore, there is no significant difference in total perception scores for parents and adults.

The previous test results involving perception scores after program involvement are summarized in the table below. 
TABLE XXII

SUMMARY OF TEST RESULTS FOR PERCEPTION SCORES

AFTER PROGRAM INVOLVEMENT:

POPULATION GROUP 001-008

\begin{tabular}{|l|l|}
\hline \multicolumn{1}{|c|}{ COMPARISON } & \multicolumn{1}{|c|}{ RESULTS } \\
\hline \hline Parents SI to Parents RI & Not significant \\
\hline Parents SF to Parents RF & Significant, $\alpha=.05$, RF $>$ SF \\
\hline Parents SI to Parents SF & Not significant \\
\hline Parents RI to Parents RF & Significant, $\alpha=.01$, RF $>$ RI \\
\hline Aduits SI to Adults RI & Not significant \\
\hline Aduits SF to Adults RF & Not significant \\
\hline Adults SI to Adults SF & Significant, $\alpha=.05$, SF $>$ SI \\
\hline Adults RI to Adults RF & Significant, $\alpha=.01$, RF $>$ RI \\
\hline Parents SI to Adults SI & Not significant \\
\hline Parents RI to Adults RI & Not significant \\
\hline Parents SF to AduTts SF & Not significant \\
\hline Parents RF to Adults RF & Not significant \\
\hline Total Parents to Total \\
Adults & Not significant. \\
\hline
\end{tabular}

In essence, perception of receiving feelings (as opposed to sending and receiving information and sending feelings) appears to be the area of greatest significance for parents. Scores in this group were higher than in any other parent group. In perception scores for adults, areas having to do with feelings were scored more positively than areas having to do with information. Sending feelings is perceived more positively 
than sending information, and receiving feelings is perceived more positively than receiving information.

A second major finding is that no differences were found after program involvement between the way in which parents were perceived and the way in which adults were perceived. This differed dramatically from the finding of the previous sub-section in which adult scores were much higher than parent scores.

It is important to note that although the size of the sample considered after program involvement equaled only eight, these eight are from the same population considered before program involvement. The perception scores of these eight after program involvement therefore reflect the probable perceptions of the larger group if they had been examined after program involvement. This factor enhances the reliability of the results of the statistical tests performed and just described.

\section{Comparison of Before and After Perception Scores}

The last part of Section II will examine more closely the difference in perception scores as a result of program involvement. Comparisons were made between the perception scores calculated for Parents to determine the following:

1. The difference between the way parents were perceived while sending information before program involvement and after program involvement;

2. The difference between the way parents were perceived while receiving information before program involvement and after program involvement;

3. The difference between the way parents were perceived while sending feelings before program involvement and after program involvement; 
4. The difference between the way parents were perceived while

- receiving feelings before program involvement and after program involvement;

5. The difference between the total scores received for parents before program involvement and after program involvement.

Comparisons were also made between the perception scores calculated for Aduzts to determine the following:

6. The difference between the way adults were perceived while sending information before program involvement and after program involvement;

7. The difference between the way adults were perceived while receiving infornation before program involvement and after program involvement;

8. The difference between the way adults were perceived while sending feelings before program involvement and after program involvement;

9. The difference between the way adults were perceived while receiving feelings before program involvement and after program involvement;

10. The difference between the total scores received for adults before program involvement and after program involvement.

In making these comparisons the Wilcoxen Matched-Pairs Signed-Ranks

Test was used when possible as it is. less dependent than the MannWhitney U-Test on independence of samples. However, when sample size fell below five, a Mann-Whitney U-Test was necessary. Values obtained were judged on the basis of levels of significance for one-tailed tests. Our results are presented below.

1. For the difference between the way parents were perceived while sending information before program involvement and after program involvement, the found $s$ (1) was greater than the critical value (0) at the .05 level. (However, the quasi-critical value equals 1 , with $p=.0625$.$) Therefore, there is no significant$ difference in the way parents send information before and after program .involvement. 
2. For the difference between the way parents were perceived while receiving information before program involvement and after program involvement, the found $s(0)$ was equal to the critical value (0) at the .025 level. Therefore, there is a difference in the way parents receive information before and after program involvement; perception scores for receiving information after program involvement are significant]y higher than perception scores for receiving information before program involvement at the .025 Tevel, with $p=.0156$.

3. For the difference between the way parents were perceived while sending feelings before program involvement and after program involvement, U calculated (5) was less than the theoretical $U(6)$ at the .025 level. (we were unable to perform a Wilcoxen Test due to small sample size.) Therefore, there is a difference in the way parents send feelings before and after program involvement; perception scores for sending feelings after program involvement are significantly higher than perception scores for sending feelings before program involvement at the .025 level.

4. For the difference between the way parents were perceived while receiving feelings before program involvement and after program involvement, the found $s \quad(2.5)$ was greater than the critical value $(0)$ at the .05 level. (However, the quasicritical value equals 1 , with $\mathrm{p}=.0625$.) Therefore, there is no significant difference in the way parents receive feelings before and after program involvement.

5. For the difference between the total scores received for parents before program involvement and after program involvement, the found $s$ (1) was less than the critical value (2) at the .05 leve1. Therefore, there is a difference in total parent scores before and after program involvement; perception scores for parents after program involvement are significantly higher than perception scores before program involvement at the .05 leve1, with $p=.0313$.

6. For the difference between the way adults were perceived while sending information before program involvement and after program involvement, the found $s$ (4) was greater than the critical value $(0)$ at the .05 level. Therefore, there is no significant difference in the way adults send information before. and after program involvement.

7. For the difference between the way adults were perceived while receiving information before program involvement and after program involvement, the found $s(3)$ was greater than the critical value $(0)$ at the .05 level. Therefore, there is no significant difference in the way adults receive information before and after program involvement. 
8. For the difference between the way adults were perceived while sending feelings before program involvement and after program involvement, the found $s(9)$ was greater than the critical value (2.) at the .05 leve1. Therefore, there is no significant difference in the way adults send feelings before and after program involvement.

9. For the difference between the way adults were perceived while receiving feelings before program involvement and after program involvement, the found $s(4.5)$ was greater than the critical value (2) at the .05 leve1. Therefore, there is no significant difference in the way adults receive feelings before and after program involvement.

10. For the difference between the total scores received for adults before program involvement and after program involvement, the found $s(7)$ was greater than the critical value (3) at the .05 leve1. Therefore, there is no significant difference in total adult scores before and after program involvement.

The previous test results. involving perception scores before and after program involvement are summarized in the table below. 
TABLE XXIII

SUMMARY OF TEST RESULTS FOR PERCEPTION SCORES

BEFORE AND AFTER PROGRAM INVOLVEMENT:

POPULATION GROUP 001-008

\begin{tabular}{|c|c|}
\hline COMPARISON & RESULTS \\
\hline 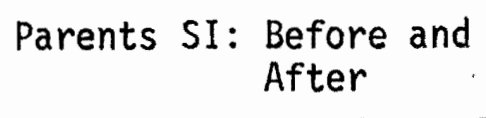 & $\begin{array}{l}\text { Not significant } \\
p=.0625\end{array}$ \\
\hline $\begin{array}{c}\text { Parents RI: Before and } \\
\text { After }\end{array}$ & $\begin{array}{l}\text { Significant, } \alpha=.025 \\
\mathrm{p}=.0156 \quad \text { After }>\text { Before }\end{array}$ \\
\hline 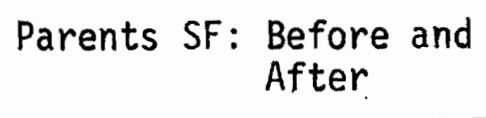 & $\begin{array}{l}\text { Significant, } \alpha=.025 \\
\text { After }>\text { Before }\end{array}$ \\
\hline $\begin{array}{c}\text { Parents RF: } \begin{array}{c}\text { Before and } \\
\text { After }\end{array}\end{array}$ & $\begin{array}{l}\text { Not significant } \\
p=.0625\end{array}$ \\
\hline $\begin{array}{l}\text { Parents Total: } \\
\text { Before and After }\end{array}$ & $\begin{array}{l}\text { Significant, } \alpha=.05 \\
\mathrm{p}=.0313 \text { After }>\text { Before }\end{array}$ \\
\hline $\begin{aligned} \text { Adults SI: } & \begin{array}{l}\text { Before and } \\
\text { After }\end{array}\end{aligned}$ & Not significant \\
\hline $\begin{array}{c}\text { Adults RI: } \begin{array}{l}\text { Before and } \\
\text { After }\end{array}\end{array}$ & Not significant \\
\hline $\begin{aligned} \text { Adults SF: } & \begin{array}{l}\text { Before and } \\
\text { After }\end{array}\end{aligned}$ & Not significant \\
\hline $\begin{array}{l}\text { Adults RF: } \begin{array}{l}\text { Before and } \\
\text { After }\end{array}\end{array}$ & Not significant \\
\hline $\begin{array}{l}\text { Adults Total: } \\
\text { Before and After }\end{array}$ & Not significant \\
\hline
\end{tabular}

In essence, program involvement appears to have had a significant impact on the perceived communication behaviors of parents, especially in the areas of recejving information and sending feelings. Program involvement does not appear to have had an impact on the perceived communication behaviors of adults. 


\section{SECTION III: POPULATION PERCEPTIONS OF COMMUNICATION CONTENT}

This section will consist of two parts. The first part will examine sending and receiving information and feelings from a content perspective. The second part will explore and describe more fully population perceptions of communication content using as a guide the thirteen basic content areas as categorized in Chapter II, Review of the Literature, Communication, pages 56-68.

\section{Process Areas from a Content Perspective}

In order to examine the process areas of sending and receiving information and feelings from a content perspective, the authors decided to determine which question(s) received the lowest score in each of these categories. It was felt that this would highlight the most problematical areas for adolescents in the communication process.

To determine the lowest score in each category, al1 questions were first transformed into positive statements with corresponding changes made in numerical scores. Scores were then converted to ratios in which the total score was divided by the highest possible score for the question. Thus, the closer the ratio to one, the more positive the perceived communication behavior. This procedure was necessary because of unequal responses to each question and unequal sizes in population groups. The use of ratios permits comparisons to be made between questions and between groups.

Examination of the ratios within each category yielded the lowest ratio. Where two ratios were equal or within .05 of each other, both 
127

questions were included for consideration. The questions which received the lowest ratio scores for the categories of Sending Information, Receiving Information, Sending Feelings, and Receiving Feelings for parents and adults before and after program involvement are presented in the following tables. The tables reflect the above-mentioned conversion of all questions into a positive form. The words typed in capitals are additions to the actual question as it appeared on the questionnaire. The words in parantheses are deletions from the actual question as it appeared on the questionnaire. 


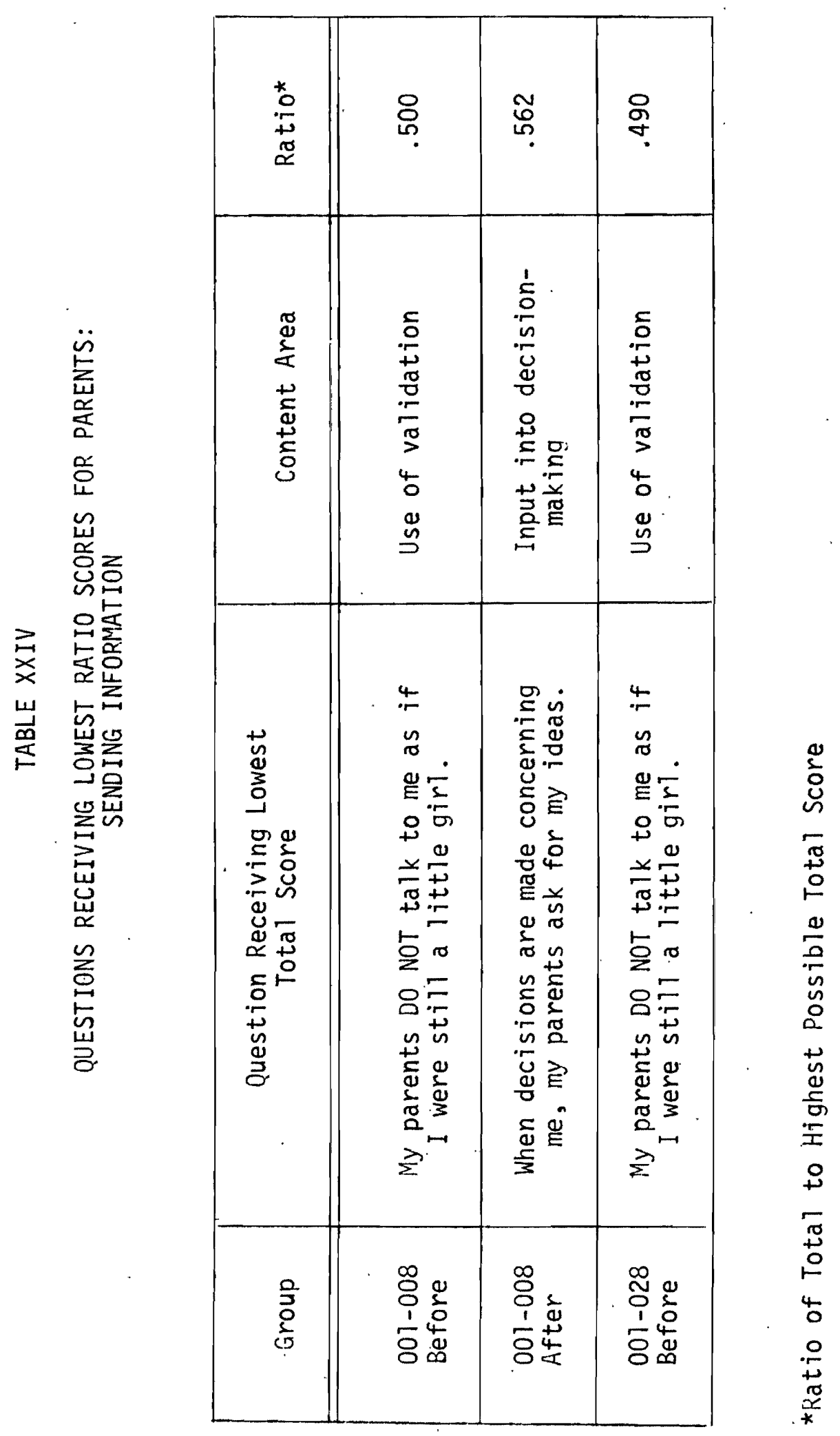




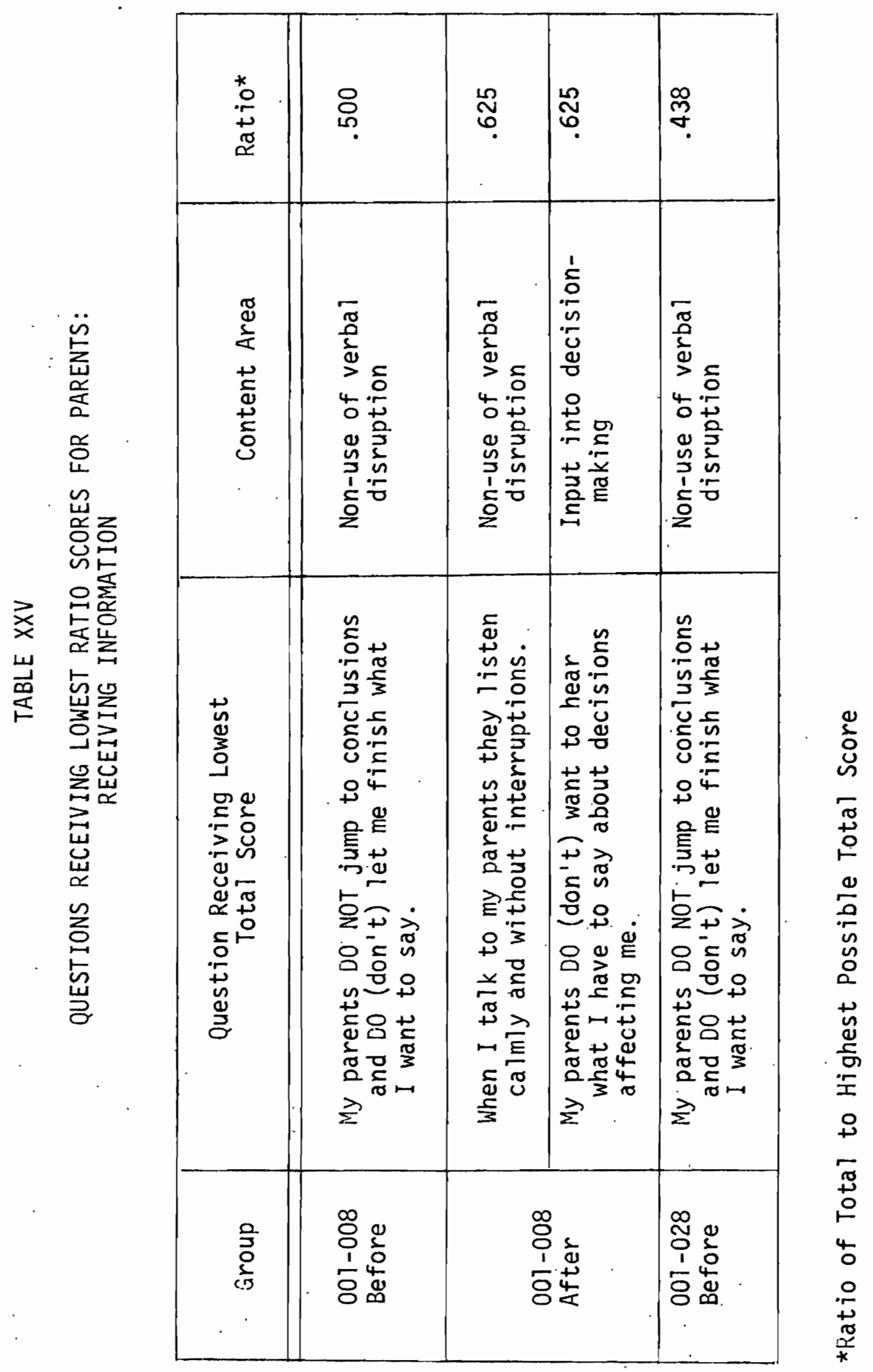




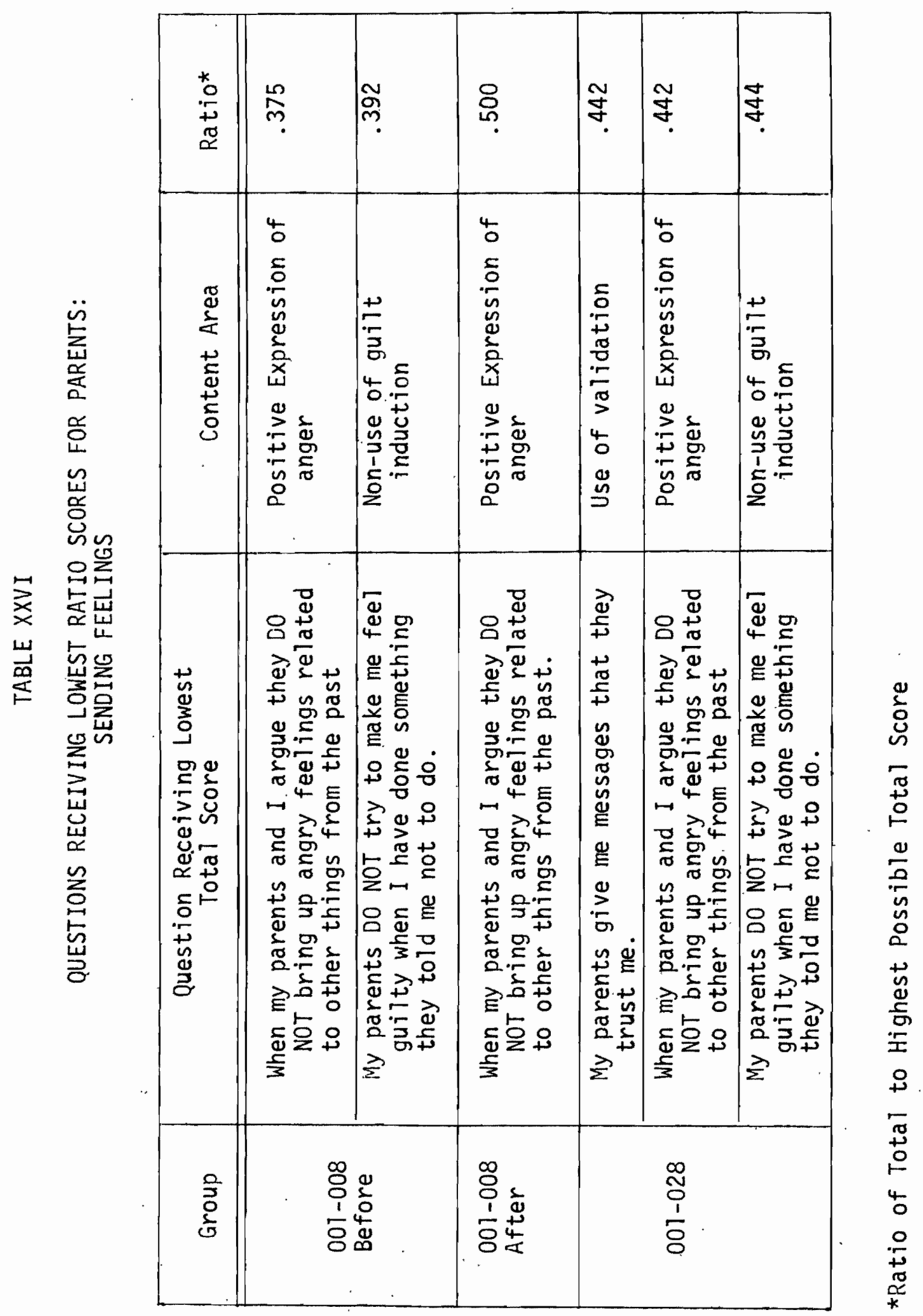




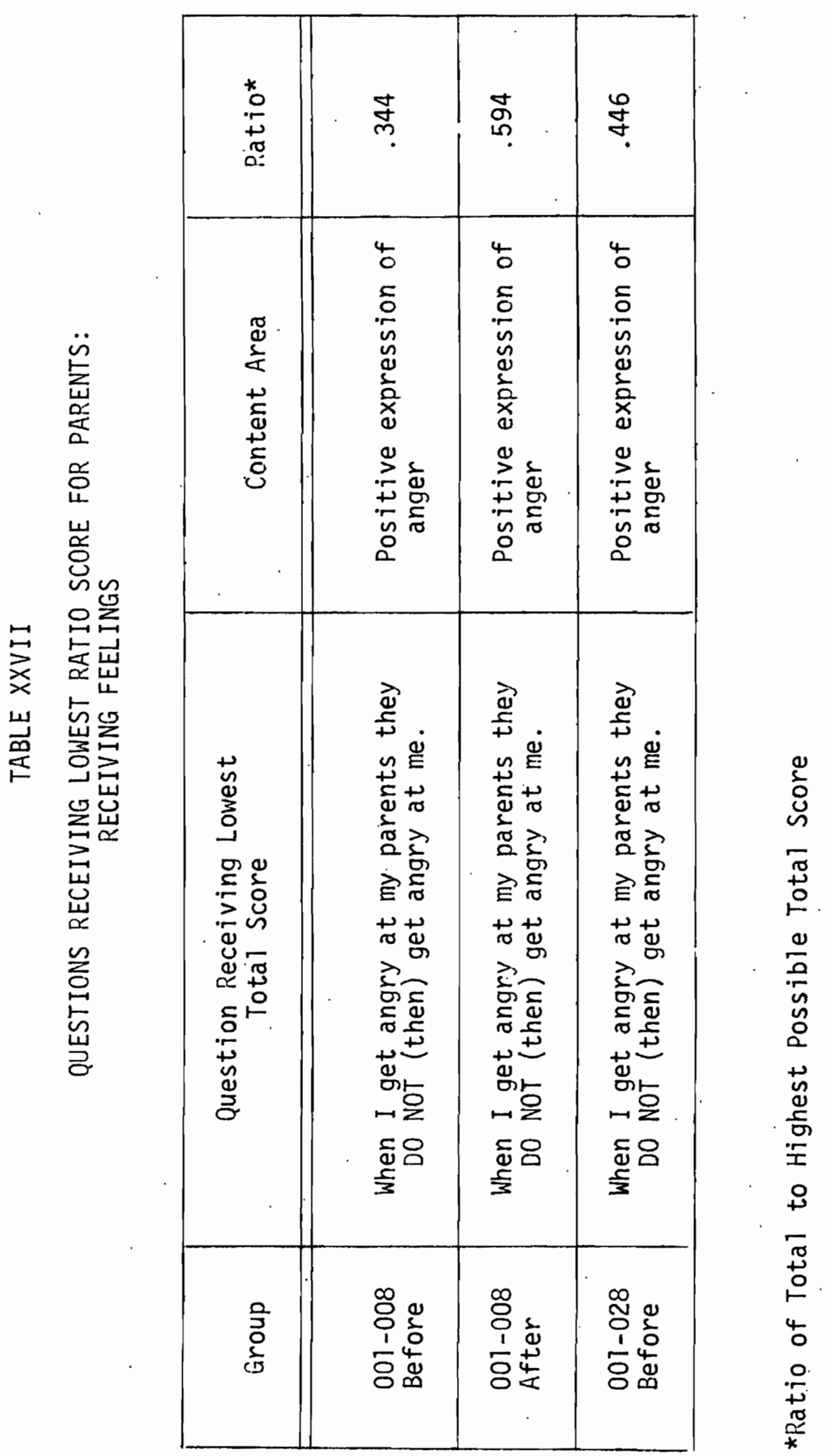




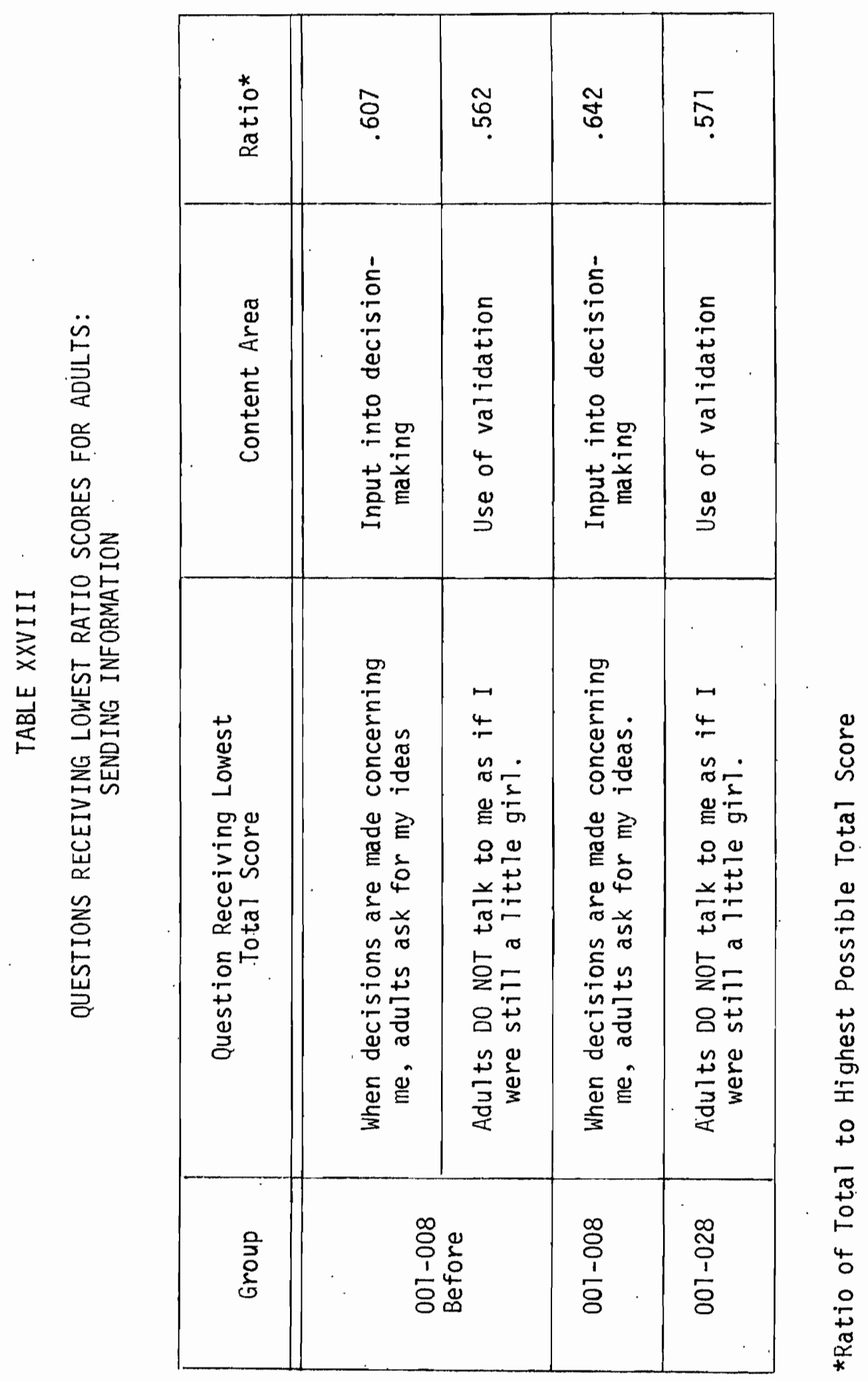




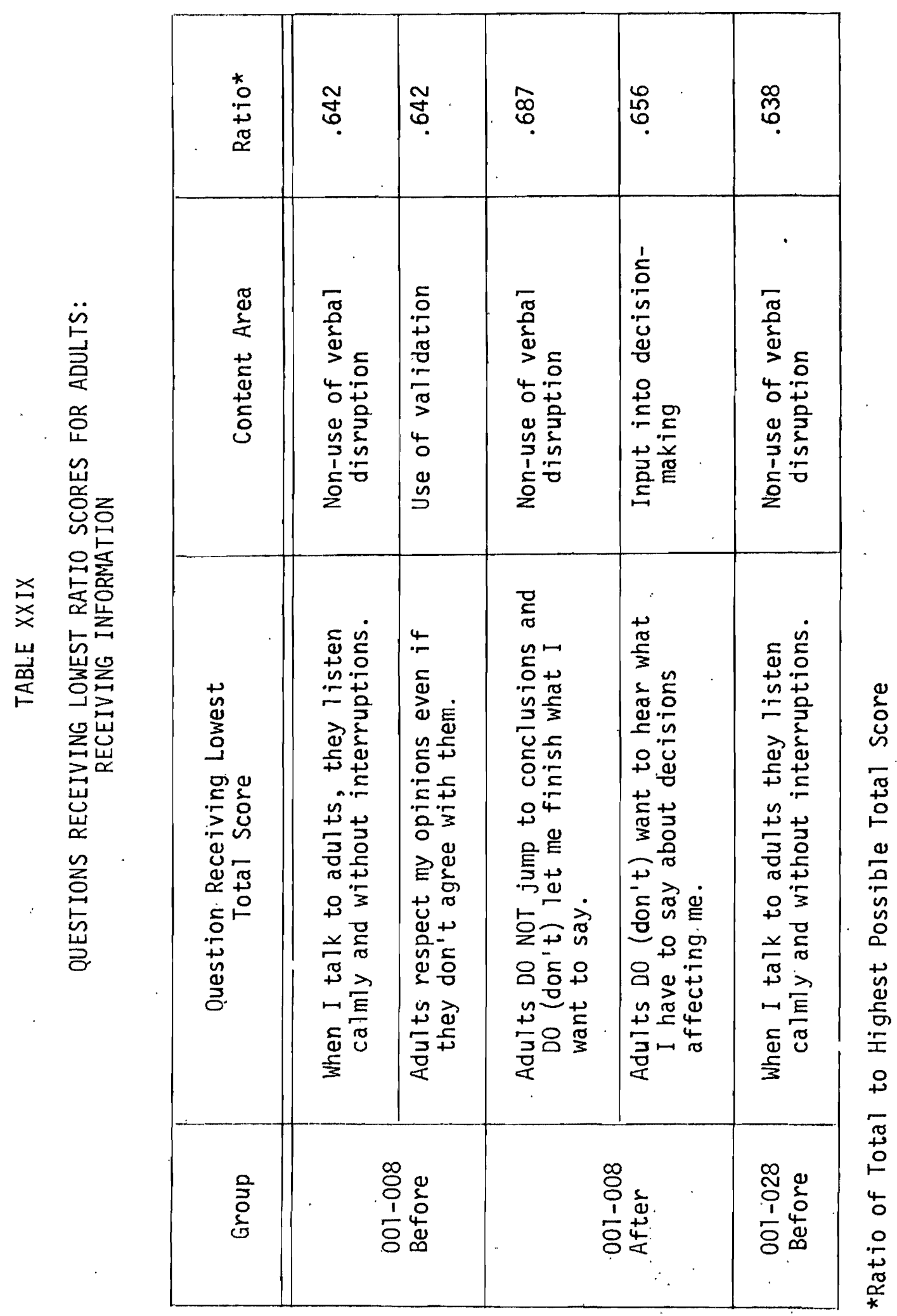




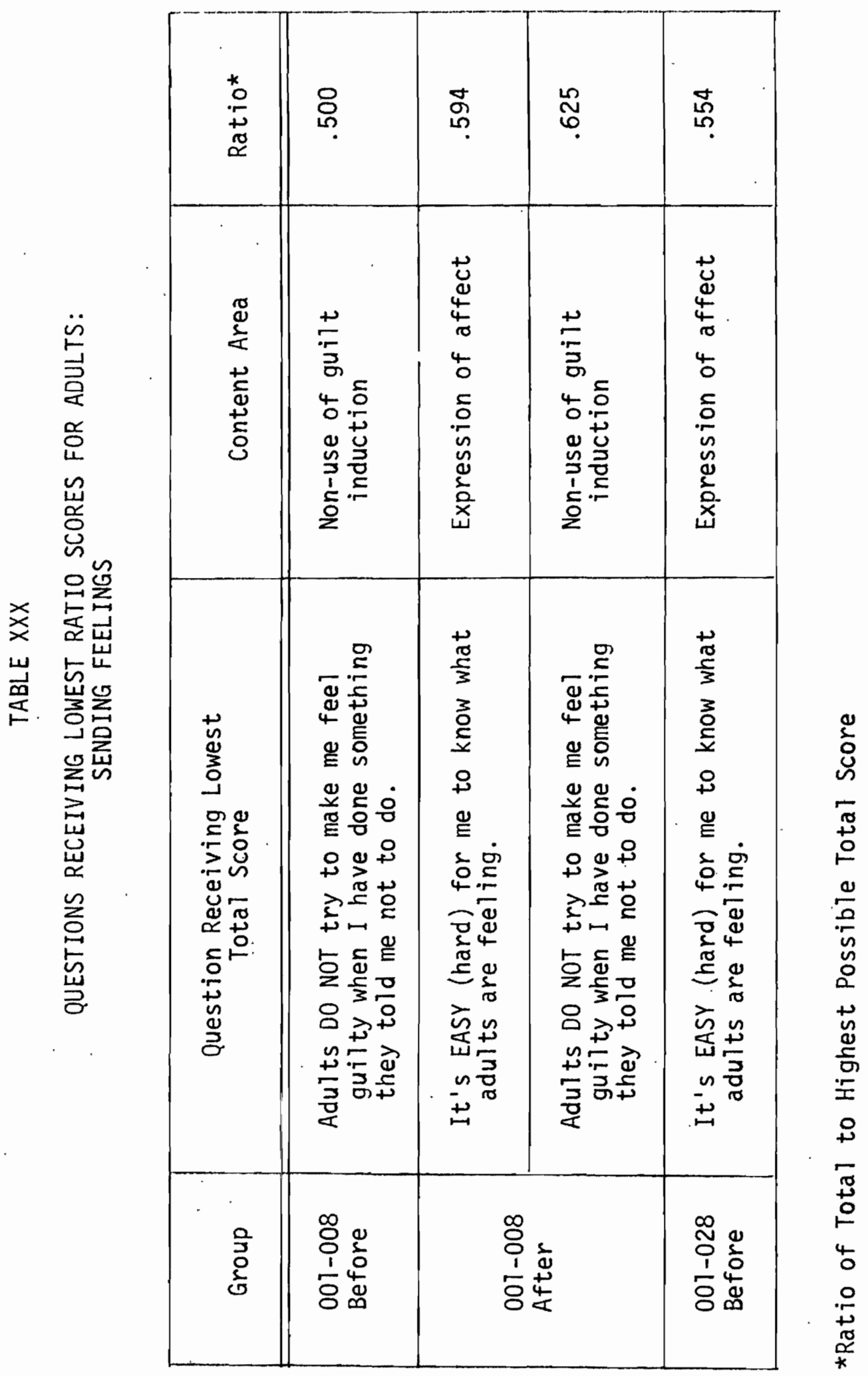




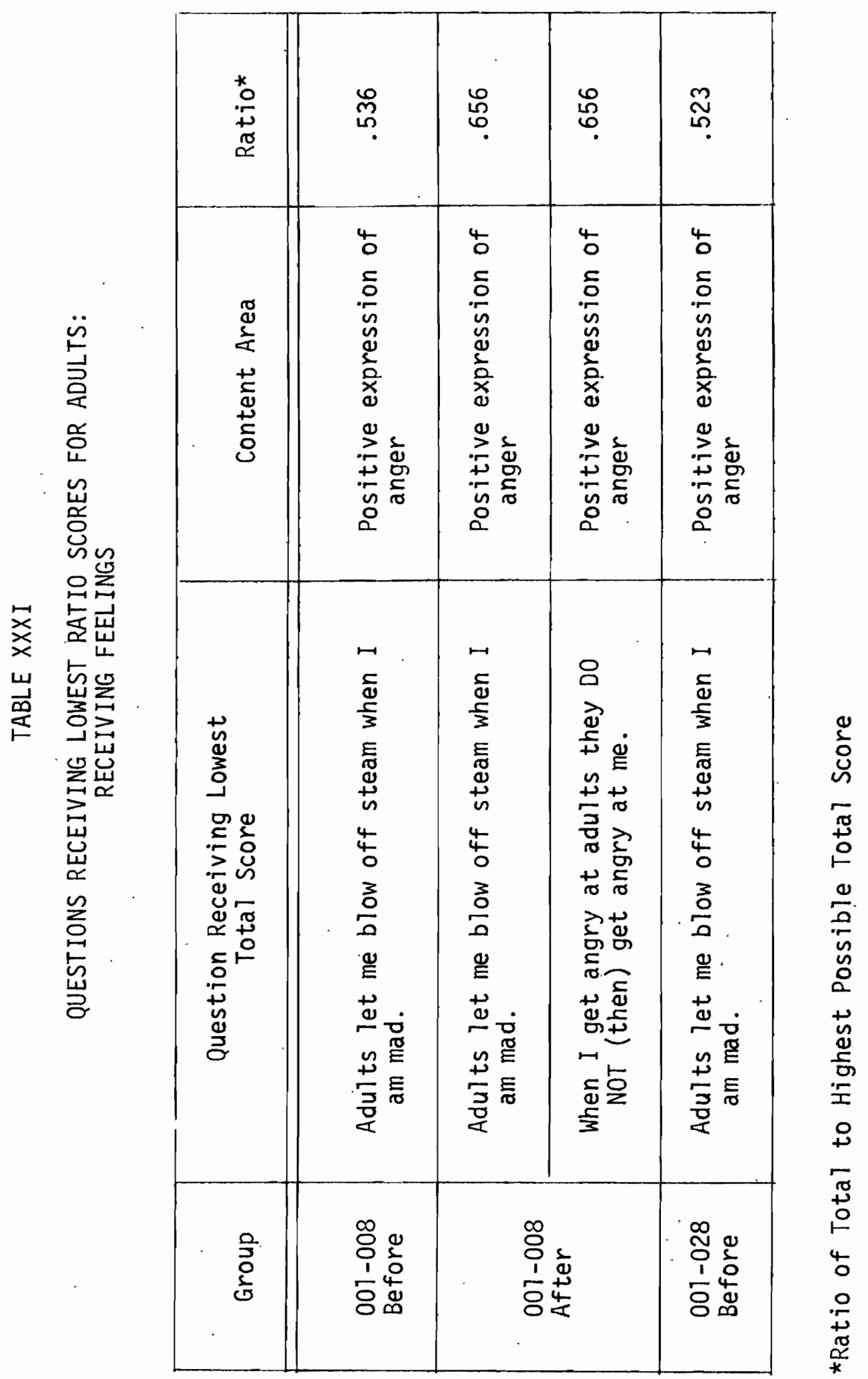


As Table XXIV indicates, for parents in the category of Sending Information, the question receiving the lowest ratio score before program involvement indicates problems in the kind of validation being used. After program involvement, however, the lowest ratio score indicates problems in the area of input into decision-making.

For parents in the category of Receiving Information (Table XXV), the question receiving the lowest ratio score before program involvement indicates problems with the use of verbal disruption. This area also received one of the lowest ratio scores after program involvement, although there was some improvement as reflected by a higher ratio after program involvement. In addition, problems were perceived in the area of input into decision-making after program involvement.

For parents in the category of Sending Feelings (Table XXVI), the question receiving the lowest ratio score before program involvement for population group 001-008 indicates problems in the use of guiltinduction and expression of anger. Similar problems are perceived by population group 001-028 before program involvement with an additional problem area of validation. Expression of anger again received the lowest score after program involvement al though there was some improvement as reflected by a higher ratio score after program involvement.

For parents in the category of Receiving Feelings (Table XXVII), the question receiving the lowest ratio score both before and after program involvement indicates problems with the expression of anger. However, there was some improvement as reflected by a higher ratio score after program involvement.

In examining the questions which received lowest ratio scores for 
a11 categories for parents, it is apparent that several areas are problematical in more than one category. The use of validation received the lowest ratio score in both Sending Information and Sending Feelings and occurred only as an issue (in terms of receiving the lowest ratio score) before program involvement. Input into decision-making received the lowest ratio score in both Sending Information and Receiving Information and occurred only as an issue (in terms of receiving the lowest ratio score) after program involvement. Both questions which reflect non-use of verbal disruption appeared in the lowest ratio scores for Receiving Information and were seen as issues (in terms of receiving the lowest ratio scores) before program involvement. Positive expression of anger received the lowest ratio scores in both Sending Feelings and Receiving Feelings (along with the non-use of guilt induction in the category of Sending Feelings). Anger was an issue (in terms of receiving the lowest ratio score) both before and after program involvement. As Table XXVIII indicates, for adults in the category of Sending Information, the questions receiving the lowest ratio scores before program involvement indicate problems in the areas of input into decision-making and the use of validation. Input into decision-making aga in received the lowest ratio score after program involvement al though there was a slight improvement as reflected by a higher ratio score after program involvement.

For Adults in the category of Receiving Information (Table XXIX), the questions receiving the lowest ratio scores before program involvement indicate problems in the areas of the use of validation and the non-use of verbal disruption. The non-use of verbal disruption again 
received one of the lowest ratio scores after program involvement al though slight improvement did occur as reflected by a higher ratio score after program involvement. The other question receiving the lowest ratio score after program involvement indicates problems in the area of input into decision-making.

For adults in the category of Sending Feelings (Table $X X X$ ), the questions receiving the lowest ratio scores both before and after program involvement indicate problems in the expression of affect and the use of guilt induction. However, there was some improvement in both areas as reflected by higher ratio scores after program involvement.

For adults in the category of Receiving Feelings (Table XXXI), the question receiving the lowest ratio score before and after program involvement indicates problems in the area of positive expression of anger. However, some improvement did occur as reflected by higher ratio scores after program involvement.

In examining the questions which received the lowest ratio scores for all categories for adults, it appears that certain areas tend to be problematical in only certain categories. The non-use of verbal disruption is an issue in Receiving Information both before and after program involvement. The non-use of guilt-induction and the expression of affect are issues in Sending Feelings both before and after program involvement. The positive expression of anger is an issue in Receiving Feelings both before and after program involvement. Input into decisionmaking is an issue in Sending Information both before and after program involvement. However, it is also an issue in Receiving. Information after program involvement. The use of validation is an issue in both 
Sending Information and Receiving Information but only before program involvement. A summary for both parents and adults of the questions receiving lowest ratio scores by content areas before and after program involvement is presented in the following table.

TABLE XXXII

QUESTIONS RECEIVING LOWEST RATIO SCORES BY CONTENT

AREA AND PROCESS AREA BEFORE AND AFTER

PROGRAM INVOLVEMENT

\begin{tabular}{|l|l|l|}
\hline $\begin{array}{c}\text { Content Area for Questions } \\
\text { Receiving Lowest Ratio } \\
\text { Scores }\end{array}$ & Parents & Adults \\
\hline Use of validation & $\begin{array}{l}\text { SI-Before } \\
\text { SF-Before }\end{array}$ & $\begin{array}{l}\text { SI-Before } \\
\text { RI-Before }\end{array}$ \\
\hline Input into decision-making & $\begin{array}{l}\text { SI-After } \\
\text { RI-After }\end{array}$ & $\begin{array}{l}\text { SI-Before } \\
\text { SI-After } \\
\text { RI-After }\end{array}$ \\
\hline Non-use of verbal disruption & RI-Before & $\begin{array}{l}\text { RI-Before } \\
\text { RI-After }\end{array}$ \\
\hline Positive expression of anger & SF-Before & $\begin{array}{l}\text { RF-Before } \\
\text { RF-After }\end{array}$ \\
& SF-After \\
RF-After & SF-Before & SF-Before \\
\hline Non-use of guilt induction & SF-After \\
\hline Expression of Affect & -- & $\begin{array}{l}\text { SF-Before } \\
\text { SF-After }\end{array}$ \\
\hline
\end{tabular}

Some interesting differences are noted in Table XXXII when parent ratio scores are compared with adult ratio scores. On the whole, adult ratio scores for questions receiving the lowest ratio scores tend to be higher than parent ratio scores in a 11 categories and population groups. 
There is also a difference when the patterns of problem-issues for parents and adults are compared. For parents, certain issues tended to occur as problems in related process areas. For example, use of validation was a problem in both Sending Information and Sending Feelings. For adults, on the other hand, a different issue tended to occur as a problem in each process area. For example, expression of affect was only a problem in Sending Feelings. For parents, areas that occurred as problems before program involvement did not occur as problems (in terms of receiving the lowest ratio score) after program involvement with the exception of positive expression of anger. (It received the lowest ratio scores both before and after program involvement.) In contrast, for adults, areas that occurred as problems before program. involvement also occurred as problems after program involvement in all cases but one. Use of validation was a problem in Sending Information and Receiving Information before program involvement but did not receive the lowest ratio scores after program involvement. With the exception of expression of affect (which was only a problem issue for adults), use of validation, input into decisionmaking, non-use of verbal disruption, positive expression of anger, and non-use of guilt-induction received the lowest ratio scores for both parents and adults. Use of validation occurred as an issue for both groups before program involvement. Input into decision-making occurred as an issue for both groups in Sending and Receiving Information after program involvement. (However, for adults, it was also an issue in Sending Information before program involyement.) Non-use of verbal disruption occurred as an issue for both groups in Receiving 
Information before program involvement. (However, for adults, it was also an issue in Receiving Information after program involvement.) Positive expression of anger occurred as an issue for both groups in Receiving Feelings both before and after program involvement. (In addition; it also occurred as an issue for parents in Sending Feelings before and after program involvement.) Non-use of guilt induction occurred as an issue for both groups in Sending Feelings before program involvement. (In addition, it also occurred as an issue for adults after program involvement.)

Basic Content Areas

This part of Section III will examine more fully the responses to the questionnaire in terms of content areas. Ratio scores will again be used. In order to arrive at a ratio score for each content area, the ratio scores for questions within the area were averaged. (For a detailed presentation of each question and its content category, see Appendix B.) Content area ratio scores were determined for parents and adults before and after program involvement and are presented in the following tables. 
TABLE XXXIII

RATIO SCORES FOR CONTENT AREAS: PARENTS

\begin{tabular}{|l|c|c|c|}
\hline \multicolumn{1}{|c|}{ Content Area } & $\begin{array}{c}\text { Ratio: } \\
001-008 \\
\text { Before }\end{array}$ & $\begin{array}{c}\text { Ratio: } \\
001-008 \\
\text { After }\end{array}$ & $\begin{array}{c}\text { Ratio: } \\
\text { 001-028 } \\
\text { Before }\end{array}$ \\
\hline $\begin{array}{l}\text { (1) Consistency Between Words and } \\
\text { Actions }\end{array}$ & .656 & .781 & .696 \\
\hline $\begin{array}{l}\text { (2) Use of Information Checks and } \\
\text { Explanations }\end{array}$ & .678 & .734 & .727 \\
\hline (3) Input into Decision-Making & .642 & .594 & .620 \\
\hline (4) Non-use of Threats & .571 & .786 & .574 \\
\hline (5) Non-use of Verbal Disruption & .550 & .695 & .468 \\
\hline (6) Use of Validation & .612 & .719 & .557 \\
\hline (7) Non-use of Preaching & .642 & .781 & .635 \\
\hline (8) Positive Expression of Anger & .544 & .658 & .534 \\
\hline (9) Use of Praise & .642 & .781 & .625 \\
\hline (10) Expression of Affect & .464 & .656 & .509 \\
\hline (11) Non-use of Negation & .783 & .812 & .743 \\
\hline (12) Use of Empathy & .716 & .828 & .704 \\
\hline (13) Non-use of Guilt-Induction & .483 & .672 & .527 \\
\hline
\end{tabular}


TABLE. XXXIV

RATIO SCORES FOR CONTENT AREAS: ADULTS

\begin{tabular}{|l|c|c|c|}
\hline \multicolumn{1}{|c|}{ Content Area } & $\begin{array}{c}\text { Ratio: } \\
\text { 001-008 } \\
\text { Before }\end{array}$ & $\begin{array}{c}\text { Ratio: } \\
\text { 001-008 } \\
\text { After }\end{array}$ & $\begin{array}{c}\text { Ratio: } \\
\text { 001-028 } \\
\text { Before }\end{array}$ \\
\hline $\begin{array}{l}\text { (1) Consistency Between Words and } \\
\text { Actions }\end{array}$ & .718 & .719 & .683 \\
\hline $\begin{array}{l}\text { (2) Use of Information Checks and } \\
\text { Explanations }\end{array}$ & .783 & .812 & .773 \\
\hline (3) Input into Decision-Making & .633 & .650 & .670 \\
\hline (4) Non-use of Threats & .781 & .812 & .737 \\
\hline (5) Non-use of Verbal Disruption & .666 & .734 & .650 \\
\hline (6) Use of Validation & .734 & .750 & .691 \\
\hline (7) Non-use of Preaching & .781 & .812 & .670 \\
\hline (8) Positive Expression of Anger & .671 & .725 & .641 \\
\hline (9) Use of Praise & .688 & .719 & .670 \\
\hline (10) Expression of Affect & .625 & .594 & .554 \\
\hline (11) Non-use of Negation & .750 & .766 & .738 \\
\hline (12) Use of Empathy & .700 & .797 & .709 \\
\hline (13) Non-use of Guilt-Induction & .550 & .672 & .598 \\
\hline
\end{tabular}


After determining content area ratio scores, comparisons were made to determine the following:

1. The difference between the way parents were perceived in terms of content areas and the way aduzts were perceived in terms of content areas before program involvement;

2. The difference between the way parents were perceived in terms of content areas and the way adults were perceived in terms of content areas after program involvement;

3. The difference between the way parents were perceived in terms of content areas before program involvement and the way parents were perceived in terms of content areas after program involvement;

4. The difference between the way aduzts were perceived in terms of content areas before program involvement and the way adults were perceived in terms of content areas after program involvement;

5. The difference between the way parents were perceived in terms of content areas before and after program involvement (improvement made) and the way aduzts were perceived in terms of content areas before and after program involvement (improvement made).

In making these comparisons, the Wilcoxen Matched-Pairs Signed-Ranks Test

was used. Values obtained were judged on the basis of levels of significance for one-tailed tests.

1. For the difference between the way parents were perceived and the way adults were perceived before program involvement, the found $s(6)$ was less than the critical value (9) at the .005 level. Therefore, there is a difference in the way parents and adults are perceived in terms of content areas; content ratio scores for adults are significantly higher than content ratio scores for parents before program involvement at the .005 lever, with $\mathrm{p}=.0040$.

2. For the difference between the way parents were perceived and the way adults were perceived after program involvement, the found $s$ (36) was greater than the critical value (17) at the .05 leve1. Therefore, there is no significant difference in the way parents and adults are perceived in terms of content areas after program involvement. 
3. For the difference between the way parents were perceived before program involvement and after program involvement, the found $s(2)$ was less than the critical value (9) at the .005 leve1. Therefore, there is a difference in the way parents are perceived in terms of content areas before and after program involvement; content ratio scores for parents after program involvement are significantly higher than content ratio scores for parents before program involyement at the .005 level, with $p=.0040$.

4. For the difference between the way adults were perceived before program involvement and after program involvement, the found $s$ (7.5) was less than the critical value (9) at the .005 level. Therefore, there is a difference in the way adults are perceived in terms of content areas before and after program involvement; content ratio scores for adults after program involvement are significantly higher than content ratio scores for adults before program involvement at the .005 level, with $p=.0040$.

5. For the difference between the way parents were perceived before and after program involvement (improvement made) and the way adults were perceived before and after program involvement (improvement made), an "improvement" score was found for each content area by subtracting the before content ratio score from the after content ratio score. These differences were then compared with each other, yielding a found $s$ of 5 . This value was less than the critical value (9) at the .005 level. Therefore, there is a difference in the amount of improvement made by parents and by adults; the amount of improvement made by parents is significantly. greater than the amount of improvement made by adults at the .005 level, with $p=.0040$.

All these test results are summarized in the table below. 
TABLE XXXV

SUMMARY OF TEST RESULTS FOR CONTENT

RATIO SCORES

\begin{tabular}{|l|c|}
\hline Comparison & Results \\
\hline Before: Parents and Adults & $\begin{array}{c}\text { Significant, } \alpha=.005 \\
p=.0040 \\
\text { Adults }>\text { Parents }\end{array}$ \\
\hline After: Parents and Adults & Not Significant \\
\hline Parents: Before and After & $\begin{array}{c}\text { Significant, } \alpha=.005 \\
p=.0040 \\
\text { After }>\text { Before }\end{array}$ \\
\hline Adults: Before and After & $\begin{array}{c}\text { Significant, } \alpha=.005 \\
p=.0040 \\
\text { After }>\text { Before }\end{array}$ \\
\hline Improvement made: Parents and \\
Adults & $\begin{array}{c}\text { Significant, } \alpha=.005 \\
p=.0040 \\
\text { Parents }>\text { Adults }\end{array}$ \\
\hline
\end{tabular}

The major finding which emerges from our examination of content ratio scores for parents and adults before and after program involvement is that while content ratio scores for parents and other adults both increased after program involvement, the increase in content ratio scores for parents was much greater than that for adults. Given this plus the finding that adult content ratio scores were significantly higher than parent content ratio scores before program involvement while after program involvement there was no significant difference between them, it would 
appear that statistically parents "caught up" with adults. After program involvement there is no statistical difference in the perceptions of parent and adult communication behaviors with regard to content areas. In addition to examining total content ratio scores by population group before and after program involvement, individual content areas will also be examined. The authors were particularly interested in the content area of anger and its expression. To examine this area, ratio scores were again used. There were five questions in the questionnaire which addressed the issue of anger. The question ratio was determined by dividing the actual question score by the highest possible question score. Thus, the closer the ratio to one, the more positive the perceived expression of anger. Question ratio scores were determined for parents and adults before and after program involvement. These are presented in the following table. The table reflects the previously described conversion of each question into a positive form. The words typed in capitals are additions to the actual question as it appeared on the questionnaire. The words in parantheses are deletions from the actual question as it appeared on the questionnaire. 


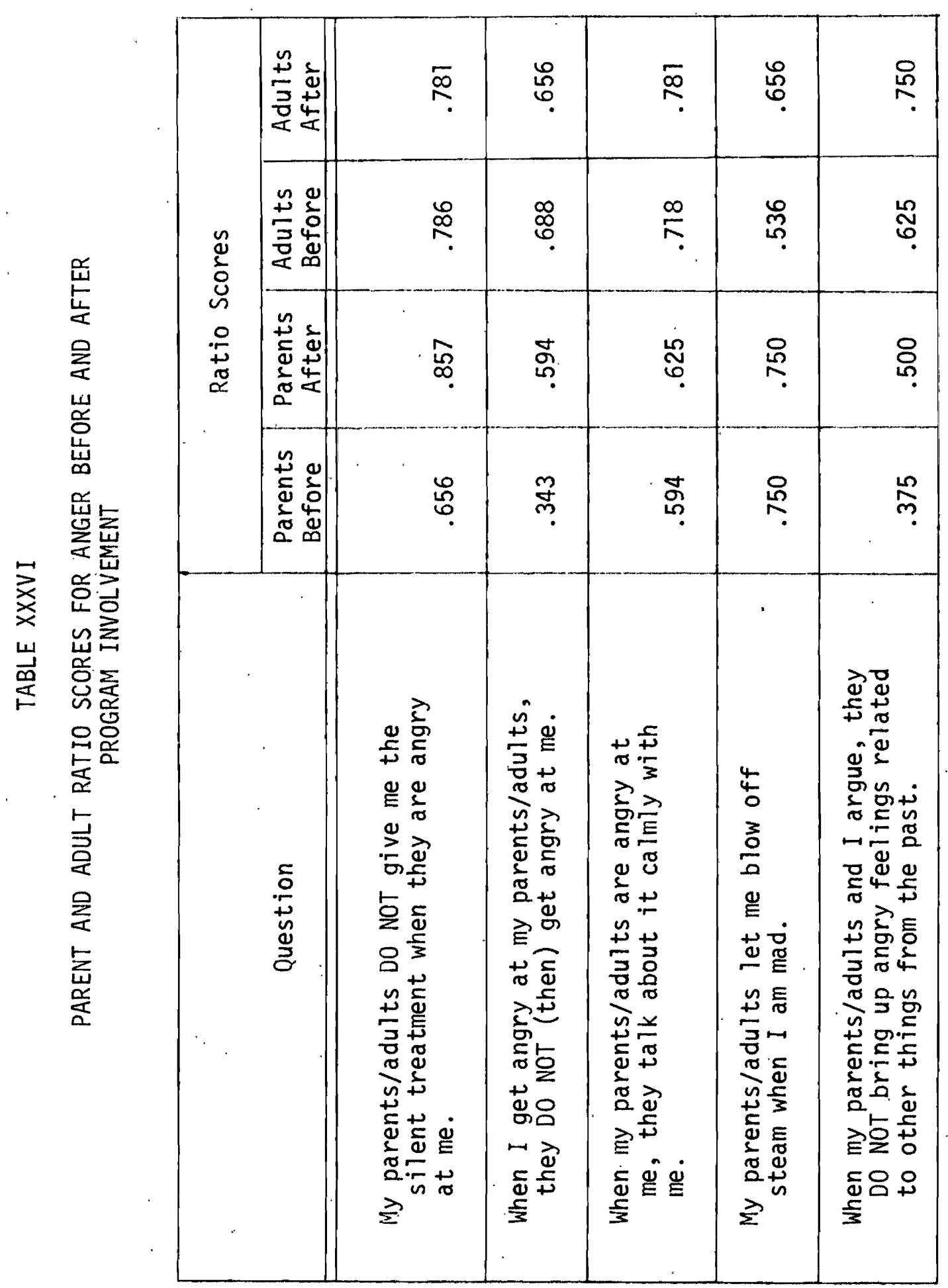


After calculating question ratio scores for expression of anger, comparisons were made to determine the following:

1. The difference in the way parents were perceived expressing anger and the way adults were perceived expressing anger before program involvement;

2. The difference in the way parents were perceived expressing anger and the way adults were perceived expressing anger after program involvement;

3. The difference between the way parents were perceived expressing anger before program involvement and the way parents were perceived expressing anger after program involvement: and

4. The difference in the way adults were perceived expressing anger before program involvement and the way adults were perceived expressing anger after program involvement.

In making these comparisons the Wilcoxen Matched-Pairs Signed-Ranks Test was used. Values obtained were judged on the basis of levels of significance for one-tailed tests. No significant differences at the .05 level were found. The authors feel that this is most likely due to the small number of questions (five) under consideration. Therefore, because of the 1 imited number of questions within each of the thirteen content categories, further attempts to determine statistical significance will be abandoned. Our examination will instead be descriptive and will focus on the way in which girls responded to questions within each category. This will be done by presenting the questions in each category for parents and adults and the percentage responses for the population before and after program involvement.

Expression of anger will again be examined using this procedure. Five questions in the questionnaire addressed the issue of anger. For question \#4, "My parents give me the 'silent treatment' when they are angry at me," $36 \%$ of the girls indicated "Always" or "Often" before 
program involvement. After program involvement only $14 \%$ responded with "Always" or "Often." For question \#10, "When I get angry at my parents they then get angry at me," $78 \%$ of the girls indicated "Always" or "Often" before program involvement. After program involvement $62 \%$ responded with "Always" or "Often." For question \#19, "When my parents are angry at me, they talk about it calmly with me," $68 \%$ of the girls indicated "Seldom" or "Never" before program involvement. After program involvement only $38 \%$ responded with "Seldom" or "Never." For question \#21, "My parents let be blow off steam when I am mad," $61 \%$ of the girls indicated "Seldom" or "Never". before program involvement. After program involvement only $28 \%$ responded with "Seldom" or "Never." And for question \#23, "When my parents and I argue, they bring up angry feelings related to other things from the past," $68 \%$ of the girls indicated "Always" or "Often" before program involvement. After program involvement, however, $75 \%$ of the girls responded with "Always" or "Often."

For question \#13, "Adults give me the 'silent treatment' when they are angry at me," $27 \%$ of the girls indicated "A7ways" or "Often" before program involvement. After program involvement $25 \%$ responded with "A7ways" or "0ften." For question \#18, "When I get angry at adults they then get angry at me," $39 \%$ of the girls indicated "Always" or "Often" before program involvement. After program involvement $38 \%$ responded with "Always" or "Often." For question \#10, "When adults are angry at me, they talk about it calmiy with me," $50 \%$ of the girls indicated "Seldom" or "Never" before program involvement. After program involvement only 10\% responded with "Seldom" or "Never." For question \#4, "Adults let me blow off steam when I am mad," $73 \%$ of the girls indicated 
"Seldom" or "Never" before program involvement. After program involvement only $38 \%$ responded with "Seldom" or "Never." And for question \#14, "When adults and I argue, they bring up angry feelings related to other things from the past," $27 \%$ of the girls indicated "Always" or "Often" before program involvement. After program involvement $25 \%$ responded with "Always" or "Often."

An examination of the parent percentage distribution indicates there was some improvement in perceived expression of anger after program involvement for four out of five questions. Question \#23 which dealt with parents who bring up past angry feelings when arguing was the only question in which responses indicating perception of negative communication behavior were greater after program involvement than before program involvement. The adult percentage distribution indicates that for all questions related to the expression of anger, improvement occurred (i.e., responses indicating perception of negative communication behavior were less after program involvement than before program involvement). However, in three out of five questions, improvement was only very slight. Before program involvement, a comparison of the parent percentage distribution and the adult percentage distribution indicates that adults were perceived as expressing anger more appropriately than were parents for four out of five questions. The only question in which parent communication behavior was perceived more positively than adult communication behavior dealt with permission to blow off steam when angry. In fact, the behavior focused on in this question was perceived the most negatively of all before program involvement for adults. For parents, the area perceived as most problematical before program involvement was 
retaliatory anger. After program involvement the question which dealt with parents who bring up past angry feelings when arguing was scored most negatively. Adults who refuse permission to blow off steam again was scored most negatively after program involvement along with the question related to retaliatory anger. Considered as a whole, a comparison of parent and adult questions focusing on the expression of anger after program involvement indicates that while adults were still perceived as expressing anger more appropriately, the perceived gap between adult communication behavior and parent communication behavior was not as great as before program involvement.

The issue of consistency between actions and words was addressed by one question in the questionnaire. For question \#1, "My parents do what they say they are going to do, "36\% of the girls indicated "Seldom" or "Never" before program involvement. After program involvement 25\% responded with "Seldom" or "Never." For question \#26, "Adults do what they say they are going to do," $37 \%$ of the girls indicated "Seldom" or "Never" before program involvement. After program involvement 25\% responded with "Seldom" or "Never."

An examination of the percentage distributions for consistency indicates that parents and adults were perceived almost identically both before and after program involvement (i.e., there was little difference between parent percentages before and adult percentages before, and little difference between parent percentages after and adult percentages after). Both groups were also seen as being more consistent after program involvement.

Two questions in the questionnaire addressed the issue of 
information checks and explanations. For question \#5, "My parents are willing to explain rules, "26\% of the girls indicated "Seldom" or "Never" before program involvement. After program involvement $25 \%$ responded with "Seldom" or "Never." And for question \#9, "My parents check to make sure I understand what they tell me," $45 \%$ of the girls indicated "Seldom" or "Never" before program involvement. After program involvement $25 \%$ responded with "Seldom" or "Never." For question \#3, "Adults are willing to explain rules," 18\% of the girls indicated "Seldom" or "Never". before program involvement. After program involvement $12 \%$ responded with "Seldom" or "Never." And for question \#6, "Adults check to make sure I understand what they tell me," 22\% of the girls indicated "Seldom" or "Never" before program involvement. After program invoivement $12 \%$ responded with "Seldom" or "Never."

An examination of the percentage distribution for use of information checks and explanations indicates there was some perceived improvement for both questions after program involvement for both parents and adults. Percentages were similar (although adults were perceived as being slightly more positive) and improvement was slight in all cases except for parental use of information checks. This area was perceived the most negatively of a 11 before program involvement and also showed the greatest improvement after program involvement.

Two questions in the questionnaire addressed the issue of input into decision-making. For question \#3, "My parents don't want to hear what I have to say about decisions affecting me," $44 \%$ of the girls indicated "Always" or "Often" before program involvement. After program involvement, however, $62 \%$ responded with "Always" or "Often." For 
question \#13, "When decisions are made concerning me, my parents ask for my ideas, " 59\% of the girls indicated "Seldom" or "Never" before program involvement. After program involvement $50 \%$ responded with "Seldom" or "Never." For question \#16, "Adults don't want to hear what I have to say about decisions affecting me," $39 \%$ of the girls indicated "Always" or "Often" before program involvement. After program involvement $38 \%$ responded with "Always" or "Often." For question \#23, "When decisions are made concerning me, adults ask for my ideas," $46 \%$ of the girls indicated "Seldom" or "Never" before program involvement. After program involvement $43 \%$ responded with "Seldom" or "Never."

An examination of the parent percentage distribution for input into decision-making indicates mixed results after program involvement. Although there was some perceived improvement in parent-initiated requests for input, there was a marked decrease in perceived willingness of parents to listen to adolescent input after program involvement. Adults, however, were perceived as using slightly more positive communication behavior after program involvement for both questions. They were also perceived as using more appropriate communication behavior in the area of input into decision-making both before and after program involvement than were parents.

The use of threats in communication was addressed by one question in the questionnaire. For question \#17, "My parents threaten or ye 17 at me when they want me to do something," $59 \%$ of the girls indicated "Always" or "Often" before program involvement. After program involvement only 14\% responded with "Aiways" or "Often." For question \#12, "Adults threaten or yell at me when they want me to do something," $18 \%$ 
of the girls indicated "A.1ways" or "Often" before program involvement. After program involvement $12 \%$ responded with "A7ways" or "Often." An examination of the percentage distribution for the question focusing on use of threats indicates that before program involvement, parents were perceived as using many more threats than adults. After program involvement, however, there was little difference between the way in which parents and adults were perceived, indicating a marked decrease in perceived parental use of threats. Adults were also perceived as using fewer threats after program involvement although improvement here was not as great.

Two questions in the questionnaire addressed the issue of verbal disruption. For question \#7, "My parents jump to conclusions and don't let me finish what I want to say," $78 \%$ of the girls indicated "Always" or "Often" before program involvement. After program involvement only $12 \%$ responded with "Always" or "Often." For question \#15, "When I talk to my parents, they listen calmly and without interruption, " $74 \%$ of the girls indicated "Seldom" or "Never" before program involvement. After program involvement only $38 \%$ responded with "Seldom" or "Never." For question \#1, "Adults jump to conclusions and don't let me finish what I want to say," $38 \%$ of the girls indicated "Always" or "Often" before program involvement. After program involvement 38\% again responded with "Always" or "Often." For question \#8, "When I talk to adults, they listen calmly and without interruptions," $48 \%$ of the girls indicated "Seldom". or "Never" before program involvement. After program involvement only $12 \%$ responded with "Seldom" or "Never."

The parent percentage distribution before program involvement 
indicates that parents were perceived as engaging in very high levels of verbal disruption. These levels decreased markedly after program involvement, especially for perceived verbal disruption by means of jumping to conclusions. Parental use of verbal disruption was also perceived to be much higher than adult use before program involvement. After program involvement, however, perceived parental use of jumping to conclusions was less than perceived adult use, possibly because no change occurred in adult percentages for this question. Perceived adult use of interruptions was less after program involvement than before program involvement and was also less than perceived parental use of interruptions after program involvement.

Four questions in the questionnaire addressed the issue of validation. For question \#16, "My parents give me messages that they trust me, " $85 \%$ indicated "Seldom" or "Never" before program involvement. After program involvement only 50\% responded with "Seldom" or "Never." For question \#20, "My parents respect my opinions even if they don't agree with them," $62 \%$ of the girls indicated "Seldom" or "Never" before program involvement. After program involvement only $12 \%$ responded with "Seldom" or "Never." For question \#22, "My parents talk to me as if I were still a little girl," $69 \%$ of the girls indicated "Always" or "Often" before program involvement. After program involvement only $25 \%$ responded with "Always" or "Often." And for question \#25, "My parents tell me my ideas are dumb," $41 \%$ of the girls indicated "Always" or "Often" before program involvement. After program involvement only $25 \%$ responded with "Always" or "Often."

For question \#19, "Adults give me messages that they trust me," 
$48 \%$ of the girls indicated "Seldom" or "Never", before program involvement. After program involvement only $12 \%$ responded with "Seldom" or "Never." For question \#5, "Adults respect my opinions even if they don't agree with them," $44 \%$ of the girls indicated "Seldom" or "Never" before program involvement. After program involvement only $12 \%$ responded with "Seldom" or "Never." For question \#15, "Adults talk to me as if I were still a little girl." $50 \%$ of the girls indicated "Always" or "Often" before program involvement. After program involvement only $25 \%$ responded with "Always" or "Often." And for question \#20, "Adults tell me my ideas are dumb," $14 \%$ of the girls indicated "Always" or "Often" before program involvement. After program involvement $12 \%$ responded with "Always" or "Often."

An examination of the parent percentage distribution indicates there was a definite improvement in perceived use of validation after program involvement for all four questions which focused on this issue. The adult percentage distribution reflects a similar pattern, although perceived improvement was not as dramatic as that for parents. A comparison of the parent percentage distribution and the adult percentage distribution before program involvement indicates that adult use of validation was perceived at a more positive level than parental use of validation. After program involvement, however, perceived parental use of validation and perceived adult use of validation are much closer (indicating that parents "caught up to" adults) except for the issue of conveyed trust. Conveying trust was perceived the most negatively before program involvement for parents. After program involvement, despite some perceived improvement, half the girls still felt that their parents rarely 
gave them messages that they were trusted.

The issue of preaching was addressed by one question in the questionnaire. For question \#11, "When I ask my parents a question, they preach at me instead of answering my question," $47 \%$ of the girls indicated "Always" or "Often" before program involvement. After program involvement only $12 \%$ responded with "Always" or "Often." For question \#25, "When I ask adults a question, they preach at me instead of answering my question," $43 \%$ of the girls indicated "Always" or "Often" before program involvement. After program involvement only $12 \%$ responded with "A7ways" or "Often."

An examination of the percentage distributions for the use of preaching indicates that parents and adults were perceived almost identically both before and after program involvement (i.e., there was little difference between parent percentages before and adult percentages before, and little difference between parent percentages after and adult percentages after). Both groups were also seen as using less preaching after program involvement.

The expression of affect was addressed by one question in the questionnaire. For question \#8, "It's hard for me to know what my parents are feeling," $81 \%$ of the girls indicated "Always" or "Often" before program involvement. After program involvement only $25 \%$ responded with "Always" or "Often." For question \#2, "It's hard for me to know what adults are feeling," $68 \%$ of the girls indicated "Always" or "Often" before program involvement. After program involvement $50 \%$ responded with "Always" or "Often."

An examination of the percentage distribution indicates that 
while both parents and adults were perceived as expressing more affect after program involvement than before program involvement, perceived improvement for parents was much greater. Although the perceived expression of affect by parents before program involvement was much less than that of adults, the perceived expression of affect by parents after program involvement was greater than that of adults. Parents "improved" and "surpassed" aduits after program involvement.

The use of praise was addressed by one question in the questionnaire. For question \#26, "My parents praise and encourage me," $62 \%$ of the girls indicated "Seldom" or "Never" before program involvement. After program involvement only $12 \%$ responded with "Seldom" or "Never." For question \#24, "Adults praise and encourage me," $43 \%$ of the girls indicated "Seldom" or "Never" before program involvement. After program involvement on $1 y 25 \%$ responded with "Seldom" or "Never."

An examination of the percentage distribution indicates that both parents and adults were perceived as using more praise and encouragement after program involvement than before program involvement. Although the perceived use of praise by parents before program involvement was much less than that of adults, after program involvement the perceived use of praise by parents was greater than that of adults. Parents again "improved" to the point of "surpassing" adults.

Two questions in the questionnaire addressed the use of negation. For question \#6, "My parents ignore me when I tell them how I feel," $41 \%$ of the girls indicated "Always" or "Often" before program involvement. After program involvement only $25 \%$ responded with "Always" or "0ften." For question \#18, "When I express my feelings, my parents make 
fun of me," $18 \%$ of the girls indicated "Always" or "Often". before program involvement. After program involvement only $12 \%$ responded with "Always" or "Often." For question \#11, "Adults ignore me when I tell them how I fee1," $28 \%$ of the girls indicated "Always" or "Often" before program involvement. After program involvement $12 \%$ responded with "Always" or "Often." For question \#7, "When I express my feelings, adults make fun of me, "7\% of the girls indicated "Always" or "Often" befare program involvement. After program involvement, however, 12\% responded with "ATways" or "Often."

An examination of the parent percentage distribution for use of negation indicates that parents were perceived as using less negation after program involvement than before program involvement. The adult percentage distribution, however, indicates mixed results after program involvement. Although adults were seen as engaging in less ignoring after program involvement, they were seen as using slightly more ridicule after program involvement. In comparing percentage distributions for parents and adults, parents were perceived as using more negation than adults before program involvement and about the same amount as adults after program involvement.

Two questions in the questionnaire addressed the use of empathy. For question \#2, "My parents try to understand how I feel," $61 \%$ of the girls indicated "Seldom" or "Never" before program involvement. After program involvement only $12 \%$ responded with "Seldom" or "Never." For question \#24, "My parents listen when I tell them about the things which have made me happy," $26 \%$ of the girls indicated "Seldom" or "Never" before program involvement. After program involvement none of the girls 
responded with "Se1dom" or "Never." For question \#17, "Adu1ts try to understand how I feel," $50 \%$ of the girls indicated "Se1dom" or "Never" before program involvement. After program involvement only $12 \%$ responded with "Se1dom" or "Never." For question \#21, "Adults Iisten when I te11 them about the things which have made me happy," $26 \%$ of the girls indicated "Seldom" or "Nevęr" before program involvement. After program involvement on 1 y $12 \%$ responded with "Seldom" or "Never."

An examination of the percentage distributions for use of empathy indicates that parents and adults were perceived quite similarly before program involvement, where the problematical issue centered around attempts to understand. Percentage scores here were much more negative for both parents and adults than they were for the question dealing with listening to things which made girls happy. After program involvement, perceived improvements were made in both these areas, resulting in almost identical percentages for both parents and adults.

Two questions in the questionnaire addressed the final issue of guilt induction. For question \#12, "My parents try to make me feel guilty when I have done something they told me not to do," $78 \%$ of the girls indicated "Always" or "Often" before program involyement. After program involvement only $38 \%$ responded with "Always" or "Often." For question \#14, "My parents tell me how I should feel, instead of accepting the way. I really feel," $60 \%$ of the girls indicated "Always" or "Often before program involvement. After program involvement only $38 \%$ responded with "Always" or "Often." For question \#22, "Adults try to make me feel guilty when I have done something they told me not to do, "61\% of the girls indicated "Always" or "Often" before program involvement. After 
program involvement 50\% responded with "Always" or "Often." For question \#9, "Adults te11 me how I should feel instead of accepting the way I really feel," $44 \%$ of the girls indicated "Always" or "Often" before program involvement. After program involvement only $12 \%$ responded with "Always" of "Often."

An examination of the percentage distributions for the issue of guilt-induction indicates that both parents and adults were perceived as using high levels of guilt-induction before program involvement, and that both groups were perceived as using less guilt-induction after program involvement. Parents were also perceived as using more guilt-induction than adults before program involvement for both questions. This pattern remained the same after program involvement for the question focusing on the use of "shoulds." However, for the question concerned with direct attempts at creating guilt feelings, adults were perceived more negatively than parents after program involvement.

To briefly summarize the results of examining content area perceptions by percentage distributions, responses indicating perception of negative communication behaviors by parents were less after program involvement than before program involvement in all content areas but two. Gains were made in four out of five questions dealing with expression of anger. For the area of input into decision-making, perceived parental communication behavior was scored more positively in one case and more negatively in the other after program involvement. Responses indicating perception of negative communication behaviors by adults were also less after program involvement in a11 content areas but two. One questionresponse pattern remained the same and one improved for the area of verbal 
disruption. And for the issue of negation, perceived adult communication behavior was scored more positively in one case and slightiy more negatively in the other after program involvement. On the whole, parents tended to make greater perceived gains within content areas than did adults.

In comparing perceived communication behaviors by content areas for parents and for adults before program involvement, adults were scored more positively in all areas except expression of anger and use of negation. Adults were scored more positively than parents for four out of five questions dealing with anger. In the area of negation, adults were scored more positively than parents on one question and the same as parents on the other. A much greater variation existed after program involvement. Adults were scored more positively than parents in the areas of information checks and explanations, input into decision-making, use of threats, and use of negation, while parents were scored more positively than adults for the areas of use of praise, expression of affect, and guilt-induction. Parents and adults were scored equally in the areas of consistency and preaching. Results were mixed in the areas of expression of anger, verbal disruption, validation, and empathy after program involvement.

To further summarize perceived communication behavior for parents and adults before and after program involvement, content areas will be ranked so that they may be seen in relation to one another. Content ratio scores will again be used (rather than percentages) to facilitate comparisons. The closer the ratio to one, the more positive the perceived communication behavior within the content area. Similarly, the higher the 
rank for the content area, the more positive the perception of the content area communication behavior. Content area ranks for parents and for adults are presented in the following tables.

TABLE XXXVII

RANK OF CONTENT AREAS FOR PARENTS BEFORE PROGRAM

INVOLVEMENT: HIGHEST TO LOWEST

\begin{tabular}{|c|l|c|}
\hline Rank & \multicolumn{1}{|c|}{ Content Area } & Ratio \\
\hline \hline 13 & Non-use of negation & .743 \\
\hline 12 & Use of information checks and explanations & .727 \\
\hline 11 & Use of empathy & .704 \\
\hline 10 & Consistency between actions and words & .696 \\
\hline 9 & Non-use of preaching & .635 \\
\hline 8 & Use of praise & .625 \\
\hline 7 & Input into decision-making & .620 \\
\hline 6 & Non-use of threats & .574 \\
\hline 5 & Use of validation & .557 \\
\hline 4 & Positive expression of anger & .534 \\
\hline 3 & Non-use of guilt-induction & .527 \\
\hline 2 & Expression of affect & .509 \\
\hline 1 & Non-use of verbal disruption & .468 \\
\hline
\end{tabular}


TABLE XXXVIII

RANK OF CONTENT AREAS FOR PARENTS AFTER PROGRAM

INVOLVEMENT: HIGHEST TO LOWEST

\begin{tabular}{|c|l|c|}
\hline Rank & \multicolumn{1}{|c|}{ Content Area } & Ratio \\
\hline 13 & Use of empathy & .828 \\
\hline 12 & Non-use of negation & .812 \\
\hline 11 & Non-use of threats & .786 \\
\hline 9 & Use of praise & .781 \\
\hline 9 & Non-use of preaching & .781 \\
\hline 9 & Consistency between words and actions & .781 \\
\hline 7 & Use of information checks and explanations & .734 \\
\hline 6 & Use of validation & .719 \\
\hline 5 & Non-use of verbal disruption & .695 \\
\hline 4 & Non-use of guilt-induction & .672 \\
\hline 3 & Positive expression of anger & .658 \\
\hline 2 & Expression of affect & .656 \\
\hline 1 & Input into decision-making & .594 \\
\hline & & \\
\hline
\end{tabular}


TABLE XXX.IX

RANK OF CONTENT AREAS FOR ADULTS BEFORE PROGRAM

INVOLVEMENT: HIGHEST TO LOWEST

\begin{tabular}{|c|l|c|}
\hline Rank & \multicolumn{1}{|c|}{ Content Area } & Ratio \\
\hline 13 & Use of information checks and explanations & .773 \\
\hline 12 & Non-use of negation & .738 \\
\hline 11 & Non-use of threats & .737 \\
\hline 10 & Use of empathy & .709 \\
\hline 9 & Use of validation & .691 \\
\hline 8 & Consistency between words and actions & .683 \\
\hline 6 & Non-use of preaching & .670 \\
\hline 6 & Use of praise & .670 \\
\hline 6 & Input into decision-making & .670 \\
\hline 4 & Non-use of verbal disruption & .650 \\
\hline 3 & Positive expression of anger & .641 \\
\hline 2 & Non-use of guilt-induction & .598 \\
\hline 1 & Expression of affect & .554 \\
\hline
\end{tabular}


TABLE XL

RANK OF CONTENT AREAS FOR ADULTS AFTER PROGRAM

INVOLVEMENT: HIGHEST TO LOWEST

\begin{tabular}{|c|l|c|}
\hline Rank & \multicolumn{1}{|c|}{ Content Area } & Ratio \\
\hline 12 & Non-use of preaching & .872 \\
\hline 12 & Non-use of threats & .812 \\
\hline 12 & Use of information checks and explanations & .872 \\
\hline 10 & Use of empathy & .797 \\
\hline 9 & Non-use of negation & .766 \\
\hline 8 & Use of validation & .750 \\
\hline 7 & Non-use of verbal disruption & .734 \\
\hline 6 & Positive expression of anger & .725 \\
\hline 4.5 & Consistency between actions and words & .719 \\
\hline 4.5 & Use of praise & .719 \\
\hline 3 & Non-use of guilt-induction & .672 \\
\hline 2 & Input into decision-making & .650 \\
\hline 1 & Expression of affect & .594 \\
\hline & & \\
\hline
\end{tabular}


In examining these rank orderings, the areas in which both parents and adults were perceived most negatively before program involvement were use of verbal disruption, expression of affect, use of guiltinduction, and expression of anger. For parents after program involvement, the issue of input into decision-making replaced that of verbal disruption, while the other three areas just mentioned remained in their low positions. The areas in which adults were perceived the most negatively after program involvement include expression of affect, input into decision-making, and use of guilt-induction.

This concludes our examination of content area perceptions as well as our chapter on the presentation and evaluation of data. The next chapter will present our conclusions and recommendations. 
Chapter V

CONCLUSIONS AND RECOMMENDATIONS

Before presenting our conclusions and recommendations, the following limitations must be considered.

\section{Limitations}

First, the scope of this study encompasses a population group drawn from only one program. The researchers were primarily interested in determining the manner in which adolescents perceived parents and adults other than parents, and in the impact of The Bridge upon these perceptions. There were no comparisons made between girls in other programs or settings.

Secondly, a control group composed of girls drawn from the "normal" adolescent population (i.e., the non-runaway, non-delinquent population) was not examined in this study. Therefore, the researchers have no way of determining similarities and differences between the perceptions of the study group and the normal population, and no way of knowing whether or not perception changes would have occurred independently of program involvement.

Thirdly, because the researchers were unable to obtain specific information pertaining to therapeutic interventions in the family, we were not able to assess their impact. We cannot state with certainty that perception changes were due to program involvement: they could 
also be attributed to the girls' absence from the home.

Fourthly, the researchers had neither the time nor the inclination to perform a follow-up study. Therefore, we do not know if perception changes were maintained over time.

Fifthly, a weakness exists in the measurement instrument in terms of content areas. In some cases, only one question was used to elicit data for a particular content area, thus weakening the results of our comparisons and the validity of our generalizations.

Last7y, the researchers' biases are apparent in the questions included in the measurement instrument and their positive or negative ratings. The questions used came out of the experience of the researchers as child-care workers and reflect our concerns about communication and its impact on the adolescent.

Given these limitations, we will now present the conclusions from our study.

Conclusions.

Before discussing our conclusions in detail, a brief statement will be made concerning each of the major assumptions as presented in Chapter I.

Assumption 1. Symptoms expressed by a family member may signify or represent a dysfunctional family system--one that is not meeting the needs of family members and promoting growth.

This assumption was strongly supported in the literature. Although our study did not specifically address this assumption, some inferences can be drawn which support our first assumption. Symptoms expressed (runaway behavior leading to program involvement) plus the presence of 
dysfunctional communication suggests that the family system is not meeting the needs of family members and promoting growth.

Assumption 2. The adolescent's perception of the behavior of others is more important in determining her adjustment than is the actual behavior of others.

This assumption is also supported by the 1iterature. It was beyond the scope of this study, however, to compare the actual behavior of others with the perceived behavior of others.

Assumption 3. The adolescent's perception of parent-adolescent communication is a contributing factor in her decision to run away.

Evidence was found to support this in the literature. Again, we did not directly address this issue. However, if dysfunctional communication is perceived as occurring and is not meeting the adolescent's needs and promoting growth, then her perception of parent-adolescent communication would seem to be a contributing factor in her decision to run away.

Assumption 4. The adolescent engages in perception generalization in that she assumes that other aduits will relate to her in the same manner that her parents relate to her.

Although there was some support in the literature for this assumption, our results indicate that perception generalization from parents to adults does not occur. A possible explanation for this discrepancy involves the degree of pathology and the age of the children considered. Studies in the literature examined young children with serious emotional disturbances while our study focused on adolescents with no history of serious pathology.

Assumption 5. Therapeutic intervention into the family system has an impact on the adolescent's perception of parental communication behaviors. 
Both the literature and our findings strongly support this assumption. Adolescents perceived their parents as communicating more positively after program involvement than before program involvement. However, we cannot conclusively state that the change in perception was a direct result of therapeutic intervention; the girl's absence from the home and the pressures there may have had an impact on her perception of her parents.

Assumption 6. Therapeutic exposure to adult role models who communicate functionally enables the adolescent to perceive adults other than parents in a more positive light.

Our final assumption received strong support in the literature. Our findings also support this assumption; adolescents perceived other adults as communicating more positively after program involvement than before program involvement. The authors feel that this change can be more directly attributed to program involvement than was the case for the change which occurred in perceived parental communication.

Our findings and conclusions will now be discussed in more detail. Some of these findings relate directly to the major assumptions just presented, while others emerged out of the way in which we chose to study adolescent perceptions of the communication process (sending and receiving information and feelings) and communication content (implicit messages conveyed).

One of the most unexpected results in our study was the finding that feelings were perceived more positively than information for both sending and receiving. Expression of feelings is popularly seen as an area of difficulty often leading to conflicts--particularly in families with adolescents. The researchers expected to find that information 
would be perceived more positively than feelings. The results of our study, however, indicate that this is not the case. In fact, before program involvement, the way in which parents received feelings was perceived the most positively of the four process areas examined for parents. For adults before program involvement, receiving feelings was perceived more positively than receiving information. After program involvement the same pattern existed for parents, while for adults both sending and receiving feelings were perceived more positively than sending and receiving information. Thus, there was no change in the relative positions of communication of feelings and communication of information. Perception of feelings was more positive than perception of information before program involvement and remained so after program involvement.

Another finding that was most unexpected was that adults were perceived much more positively than parents before program involvement and that there was no significant difference between the perception of parents and adults after program involvement. We had expected that the perception of adults would be very similar to the perception of parents before program involvement due to perception generalization. We had also expected that after program involvement, perception of adults would be more positive than perception of parents due to exposure of the girls to positive role models. This, however, was not the case. At the time of program entry adolescents were able to discriminate between the communication behaviors of parents and adults other than parents and saw adults in a more positive light. At the end of program involvement, parent communication behavior had apparently improved in such a way 
that adolescents perceived parents and adults as communicating similarly.

This conclusion is supported by our findings that parents made significant "gains" in perceived communication behavior. Table XXIII illustrates that the total parent scores for process areas were higher after program involvement than before program involvement. Table XXXV illustrates that the total parent scores for content areas were higher after program involvement than before program involvement and that "improvement made" by parents was much greater than "improvement made" for adults.

Another area the researchers wished to explore was that of the most problenatical issues for adolescents in the communication process. Problematical issues were identified through the questions receiving the lowest ratio scores in each process area before and after program involyement as categorized according to content area (Table XXXII). These questions all fell within six content areas: use of validation, input into decision-making, non-use of verbal disruption, positive expression of anger, non-use of guilt-induction, and expression of affect. The "content lows". for process areas were similar for both parents and adults. This implies that despite adolescent discrimination between the communication behavior of parents and of adults other than parents, certain issues override this discrimination and are perceived as problematical regardless of who the adolescent is communicating with. When these problematical issues were examined before and after program involvement, some interesting differences emerged for parents and adults. Parents appear to have more generalized communication problems as reflected in the occurrence of a content issue as a problem 
in related process areas (Table XXXII). If a content issue was a problem in information, it was generally a problem in both sending and receiving information. However, content issues within process areas tended to be a problem for parents before program involvement only or after program involvement only.

Adults appear to have more discrete communication problems as reflected in the occurrence of a content issue as a problem in only one process area. For example, positive expression of anger was only a problem for adults in receiving feelings. And if a content issue was a problem within a process area before program involvement, it was also a problem in that process area after program involvement.

This implies that problems in parent-adolescent communication are more pervasive and occur more often. Problems in adult-adolescent communication, on the other hand, occur less often and are not as extensive. Because the problematical issues for parents were readily apparent and an area of program emphasis, the problematical issues were specifically dealt with. The apparent lack of improvement in problematical issues for adults can most likely be accounted for by the fact that these issues were not specifically perceived as problems and addressed as such.

Our examination of content areas (independent of process areas) supports the hypothesis presented in the literature that the theoretical dimension of control-autonomy creates more difficulty than the dimension of love-hostility. Content areas related to love-hostility tended to be ranked more positively than content areas related to control-autonomy. The content areas for parents and for adults that were ranked the lowest were non-use of verbal disruption, expression of affect, non-use of 
guilt induction, positive expression of anger, and input into decisionmaking. All of these are ways of attempting to control the adolescent and undermine her sense of autonomy.

An examination of the individual content area ratios lends support to this general trend even though alz content areas were rated more positively after program involvement than before program involvement. However, the researchers were surprised at the way in which certain content areas were scored and at how they were perceived in relation to the others. Therefore, each content area will be briefly commented upon.

The non-use of negation yielded perhaps the most unexpected results of any category. It received one of the two highest ranks for parents and was also ranked very high for adults. The percentage distribution indicates that parents were perceived as using some ignoring but very little overt ridicule, and that adults were perceived as using very little of either. We had expected to find a greater perceived use of negation.

The high ranking of the use of empathy was also unexpected, given the common complaint of adolescents that parents and adults "don't care." However, when the individual questions in this area were examined independently of one another, the findings revealed that empathy was perceived when expressed feelings were positive. Adolescents did not perceive parents or adults as attempting to understand their feelings in general before program involvement. Program involvement apparently had an impact, however, for perceptions were much more positive after program involvement for this question. 
The researchers expected the use of information checks and explanations to be ranked and rated lower before program involvement than it actually was. The researchers also expected it to be ranked and rated higher after program involvement than it actually was. This indicates that the clarifying of communication and the provision of rationale--both necessary for promoting autonomy--emerged as issues upon leaving the program.

The perceived use of consistency by parents was also unexpected to the researchers. We had expected that the girls would perceive their parents as lacking predictability and as not following through. Instead, most of the girls felt that their parents did what they said they were going to do. Because this finding strongly contradicts our experience in working with parents and adolescents, we doubt the validity of the question used to measure consistency and feel this area needs more exploration.

Perceived "improvements" made in the use of praise over the course of program involvement conformed to our expectations. We thought that parents and adults would be perceived as using little praise upon program entrance and more praise by the end of the program. However, we did not expect the position of praise relative to other content areas for adults to fall in the rank ordering of all content areas.

Parents and adults were perceived similarly in their use of preaching before program involvement and both were perceived to have made "improvements" after program involvement. However, this area was ranked the most positively for adults after program involvement while for parents its rank position stayed constant. This indicates that 
parents still continued to use preaching as a way of influencing or controlling.

Parental use of threats before program involvement was a definite issue for adolescents and appeared to be one of the overt control tactics used by parents. It was not an issue for adults, probably due to the girls not having been involved in many situations in which adults would use threats (i.e., most of the girls were still in school and had not had much involvement with the juvenile justice system). After program involvement, the use of threats was not seen as an issue by the girls for either parents or adults and was ranked among the three most positive content areas.

The researchers expected that the use of validation would be ranked low relative to other content areas for parents. We did not expect, however, that this content area would contain the question which received the most negative response of any question on the measuring instrument. Responses to the question, "My parents give me messages that they trust me," indicate that the girls do not feel valued by their parents and do not feel that their parents see them as being capable of independent mature thinking and feeling.

The finding that the non-use of verbal disruption was ranked the most negatively of all content areas examined for parents before program involvement was unexpected, but makes sense in light of the trust issue. Verbal disruption is perceived as intrusion, interference and controlling on the part of the parent, and also conveys lack of trust and respect for the adolescent. In terms of the rank ordering, adults were seen as using less verbal disruption than parents both before and after program involve- 
ment although verbal disruption was a definite issue for adults also.

Expression of affect received one of the two lowest ranks for both parents and adults both before and after program involvement. The researchers expected this finding before program involvement but did not expect this same pattern after program involvement. This indicates that girls continued to have difficulty with knowing what their parents and other adults were feeling and were forced to guess. Thus, a major portion of communication was apparently blocked out.

A number of results were unexpected for the content area of non-use of guilt-induction. The researchers expected its use to be fairly common as a control tactic, but not to be as pervasive as it in fact was. We also expected that parents would be perceived as using more guilt-induction than adults. This was true before program involvement. However, after program involvement adults were seen as making more attempts than parents to create guilty feelings.

The content area of positive expression of anger yielded some interesting results. The "silent treatment" as a.means of dealing with anger occurred infrequently. The researchers consider this to be a "positive" finding since the refusal to deal openty and verbally with angry feelings can have devastating effects upon the adolescent. Retaliatory anger and bringing up angry feelings from the past were perceived to be the most common methods used by parents in expressing anger. Retaliatory anger conveys the message that "being angry is not okay" while bringing up past anger confuses present issues. Adults were also perceived as engaging in retaliatory anger and, in addition, were seen as refusing permission for the adolescent to ventilate her angry 
feelings. Adults apparently rely on their status as authority figures when faced with anger, while parents tend to engage in defensive maneuvers.

The last content area to be considered is input into decisionmaking. A comparison of the rank orderings for content areas before and after program involvement $i 11$ ustrates a dramatic change in position for input into decision-making. After program involvement, this area received one of the two lowest ranks for both parents and adults. An examination of the question responses within this area indicates that although parents were perceived as being more willing to ask for the adolescent's suggestions, they were perceived as being much less willing to listen to her input. This implies that adolescents felt they were having little impact upon decisions being made concerning them at the end of program involvement when the major issue was their disposition from The Bridge.

When these individual content areas are considered in combination, a definite pattern emerges which points to control-autonomy as a major issue. This is particularly evident for the adolescents in our study upon program termination. Content ratio scores indicate that adolescents perceived both parents and adults as allowing them litt]e input into decision-making. Neither group was perceived as being willing to listen to what the adolescent had to say about decisions affecting her. At the same time, the girls felt that it was very difficult for them to know what their parents and other adults were feeling. The girls were receiving few cues and/or mixed messages which placed them in a position of not knowing how their parents or other adults felt about 
important decisions affecting the girls. Thus, the girls had to guess at what responses were appropriate. The lack of clear explanations and rationales also contributed to the uncertainty. This ambiguity left them more vulnerable to the use of guilt-induction, retaliatory anger, and "gunny-sacking" (bringing up angry feelings related to other things from the past).

These findings paint a picture of the termination process as undermining the adolescent's sense of autonomy. The girls were apparently trying to exercise their autonomy by attempting to have some input as to their future upon leaving the program. Instead of fostering the girls' efforts to take charge of themselves, parents and adults were perceived as lacking trust in the girls and as attempting to sabotage their efforts. Parents and adults continued to be seen as judgmental and moralistic in their use of guilt-induction, Present issues were confused with past issues; during arguments, angry feelings about past events were used as defensive weapons to discount change in the girls. This made it more difficult to resolve present conflicts. The use of retaliatory anger and verbal disruption contributed to the spiral effect, making calm discussion about the future a rarity. The use of these control mechanisms conveyed the message to the girl that she was not capable of being responsible for herself or of making responsible decisions.

Considering these findings in conjunction with the finding that information was perceived more negatively than feelings lends additional support to our conclusion that the control-autonomy dimension creates more difficulty than the dimension of love-hostility during adolescence. Information provides a base for decision-making and problem-solving, and 
is necessary for a rational consideration of choices, options, and consequences. Sending and receiving information allows instrumental needs to be met and enhances the feeling that the self is responsible and successfully coming to grips with the environment.

It appears that parents and adults in general do have more difficulty in adjusting to the adolescent's need for autonomy as was suggested in the literature review. The adolescent's need for love is relatively stable over time and is more easily addressed by parents and adults as reflected in our findings. The changing need for autonomy as the child moves from infancy to adolescence, however, presents a dilemma for parents and adults, and becomes a source of conflict in their relationships with adolescents. Torn between allowing the adolescent to take responsibility for herself and establish an identity separate from them and between their continuing desire to provide control and guidance to the adolescent, parents and adults appear to vacillate in their struggle to find a balance between two extremes. When faced with an issue such as termination from program involvement, this struggle readily surfaces and almost assumes the qualities of a crisis.

\section{Implications for Program Develoument}

The conclusions presented in the preceding section strongly indicate a need for greater program intervention into the area of control-autonomy. Although this occurred as a definite issue upon program termination, the researchers feel that this area should be addressed throughout program involvement. Parents and adolescents need education on the process of decision-making and on problem-solving and conflict-resolution. 
Recognition and resolution of relationship problems will be more effective and more acceptable to those involved if parents and adolescents have at their command a variety of problem-solving skills such as accommodation (where the message is "this time we'11 do it your way, next time my way"), compromise (where each party "goes half-way" and a solution acceptable to a11 is reached), and mutual negotiation (where a solution is reached in which a 11 needs are met so that "everyone gets what she wants").

In conjunction, parents and adolescents also need more education on the expression of anger. Certain misconceptions need to be corrected. Because anger occurs when needs are not met and it is impossible to meet a1] needs at a11 times, anger will inevitably occur. Anger is not necessarily "bad"; it can be viewed as a healthy sign of dissatisfaction and its appropriate expression seen as "okay." Appropriate expression of anger means that anger is sent openly and verbally (rather than through silence) and at the time it occurs (rather than "gunny-sacked" until later). It also means that anger is received in a non-defensive way (rather than as something which calls for a "return attack") and with tolerance (rather than with attempted repression).

Therapeutic programs can provide this information to parents and adolescents, and program staff can act as role models for both the appropriate expression of anger and the process of decision-making. Our findings indicate that these would be areas for improvement among The Bridge staff; our experience indicates that many programs need improvement in these areas.

Our findings also indicate that the use of guilt-induction is an area that needs to be more specifically recognized and addressed as a 
problem for both parents and adults. Both groups need to be more conscious of the amount of guilt-induction being used and of its impact on the adolescent. If they are to limit their use of guilt-induction, they must be able to discriminate between guilt which is reality-based and between manipulative guilt-induction. Reality-based guilt is a feeling which arises in the child and occurs as a natural part of internalizing expectations and values. Violation of these standards have consequences which are rooted in a rational cause-and-effect relationship. In contrast, manipulative guilt-induction is an attempt to impose feelings on the child as a way of controlling her. Whether or not the child experiences the natural consequences of her behavior as punishing, her parents (or other adults) attempt to make her feel guilty over the hurt or disappointment or anger she has "caused" in them. Use of guiltinduction distorts the issues involved in decision-making, conflictresolution, and expression of anger, and undermines the adolescent's sense of autonomy and her fee]ings of being trustworthy. Program efforts should be directed toward encouraging parents and adults to examine their expectations for behavior and their criteria for granting trust, and to openly specify and discuss these with adolescents.

This openness would give adolescents a better understanding of what their parents and adults are feeling--an issue that our findings indicated was a definite problem. Not only did the girls express a need for more cues from their parents and other adults, they al so expressed a reciprocal need to have their ideas and feelings receive more consideration. Skills need to be developed which would promote "active listening" rather than. "reactive listening." Conveying empathy and/or understanding facilitates 
identification of the issues involved in control-autonomy and creates an atmosphere in which resolution is possible.

Throughout our discussion of areas for further program development, the idea that program staff as well as parents need to re-examine their communication has been implicit. Too often program efforts are directed only toward modifying the parent's style of communicating and the girl's style of communicating, and not toward modifying the communication behavior engaged in by adults in the adolescent's environment.

This is illustrated in our findings pertaining to the pattern of changes which occurred as a result of program involvement for parents and adults. Although problems in parent-adolescent communication were found to be more extensive and more frequent than problems in adultadolescent communication before program involvement, more improvement had occurred at the end of program involvement for parents than for adults. The authors attribute this finding to the program focus on parent-child interaction as the area requiring intervention. While this is necessary and valid, the authors feel that more attention should have been given to the area of adult-adolescent interaction.

This is confirmed when the findings which relate to the "content lows" in process areas for parents and adults before and after program involvement (Table XXXII) are examined. Because the problematical issues for parents were different after program involvement than before program involvement, it would appear that these issues were readily identified and seen as requiring intervention. However, because the same problematical issues for adults occurred both before and after program involvement, it would appear that few intervention efforts were made. It would 
seem that because problems in adult-adolescent communication are less entrenched, therapeutic intervention would be easier. However, this requires that these problem areas are in fact addressed.

In concluding our presentation of implications for program development, the authors wish to again emphasize the importance of adult communication behavior in the therapeutic process. If program staff are to be effective agents of change and appropriate role models for both adolescents and parents, they first need to be aware of their own communication behavior and its impact, and then act upon that awareness. Information and adequate training around the communication process should be made available to program staff: not only will parents and adolescents benefit, but program staff will find their ability to deal with the control-autonomy issue enhanced and their professional functioning made easier.

\section{Implications for Future Studies}

A number of recommendations can be made for future studies. The need for a control group is evident, and should consist of a large number of subjects drawn from the "normal" population. Both males and females should be included, as well as different age groups. Attention should also be given to socio-economic status as a possible influence on communication behavior. This kind of study would allow comparisons to be made between adolescents involved in programs/institutions and adolescents still in the home, which would enable the effects of program involvement to be more precisely determined. With the baseline provided by a control group, programs could also be more reliably compared to each other to 
determine relative effectiveness.

Additional areas for further exploration also exist. A comparison of the "perceived improvement" in parental communication behavior with the number and kind of therapeutic contacts (e.g., family meetings) could determine if any correlation exists between the two. This would be a method of evaluating therapeutic effectiveness. Another way of evaluating therapeutic effectiveness would be to conduct a follow-up study in order to examine the permanence of perception changes which had occurred. This would also give some indication as to whether a program designed as short-term can have a lasting significant impact on parent-adolescent interaction.

The researchers would be very interested in a study which would further explore the relationship between perceived communication behavior and feelings of autonomy. This could be done by presenting the adolescent with two sets of questionnaires: one measuring her perception of the communication behaviors of parents and adults, and the other measuring her feelings of being love-worthy, esteem-worthy, significant, responsible, and autonomous. This would help determine if the relationship between perceived communication behavior and the issue of controlautonomy is as strong as our results imply. It would also shed light on the relationship between the perceived behaviors of others and the way in which the self is perceived.

Another area in which additional information is required involves the importance of perceptions vs. "reality" in determining behavior. A comparison of the adolescent's perception of a situation to the objective reality of that situation would ascertain similarities and differences 
between the two and would point to areas of distortion needing intervention. A comparison of the adolescent's perceptions to those of her parents and adults other than her parents would similarly point to areas of distortion and areas where meaning is not shared.

Finally, an in-depth exploration of content areas would yield much valuable information. Each content area presented in our study could be expanded into an independent study and examined in much more detail. This would compensate for any biases influencing our results and would serve as an added check upon the validity of the questions used to measure content area perceptions. It would also allow the dynamics involved in the content area under study to be understood more precisely: 


\section{Chapter VI}

\section{EPILOGUE}

Throughout this study, the researchers have been primarily motivated by the desire to explore the gaps and problems in communication which keep parents and adults and adolescents alienated and dissatisfied with each other. We strongly feel that communication which allows uniqueness to be revealed openly and which promotes an understanding and negotiation of the differences which may arise from this uniqueness is the key to enhancing the adolescent's relationships with others. It is hoped that this study will contribute to the knowledge necessary to make the "I count, You count" philosophy a reality for adolescents. 
LIST OF WORKS CONSULTED 


\section{LIST OF WORKS CONSULTED}

1. Ackerman, Nathan. "Family Psychotherapy and Psychoanalysis: The Implications of Difference." In Famizy Process, pp. 5-18. Edited by Nathan W. Ackerman. New York: Basic Books, 1970:

2. Group and Family Therapy, pp. 440-456. Edited by Clifford $J$. Sager and Helen Singer Kaplan. New York: Brunner/Maze1, 1972.

3. Adilman, Philip H. "Some Concepts of Adolescent Residential Treatment." Adolescence 8 (Winter 1973): 547-568.

4. Adler, Jack. "General Concepts in Residential Treatment of Disturbed Children." Child Welfare 47 (November 1968): 519-523.

5. Aichhorn, August. Wayward Youth. New York: The Viking Press, 1951.

6. Almond, Richard. The Healing Community: Dynamics of the Therapeutic Milieu. New York: Jason Aronson, 1974.

7. Ambrosino, Lillian. Runaways. Boston: Beacon Press, 1971.

8. American Association for Children's Residential Centers, comp. From Chaos to Order: A Collective View of the Residential Treatment of Children. New York: Child Welfare League of America, 1972.

9. Andrews, Ernest E. The Emotionally Disturbed Family and Some Gratifying Alternatives. New York: Jason Aronson, 1974.

10. Anthony, James. "The Reactions of Adults to Adolescents and Their Behavior." In Adolescence: Psychosocial Perspectives, pp. 54-78. Edited by Gerald Caplan and Serge Lebovici. New York: Basic Books, 1969.

11. Aubrey, Roger F. Experimenting with Living: Pros and Cons. Columbus, Ohio: Charles E. Merri11, 1973.

12. Auerswald, Edgar. "Interdisciplinary vs. Ecological Approach." In Family Process, pp. 235-248. Edited by Nathan W. A.ckerman. New York: Basic Books, 1970.

13. Barish, Julian. "The Adolescent Within an Adolescent Treatment Program." In Mental Health Services for Adolescents, pp. 131-142. Edited by Sol Nichtern. New York: Frederick A. Praeger, 1968. 
14. Baumrind, Diana. "Authoritarian vs. Authoritative Parental Control." Adolescence 3 (Fal1 1968): 255-272.

15. Becker, Wesley C. "Consequences of Different Kinds of Parenta1 Discipline." In Review of Child Development Research. Vo1. 1, pp. 169-208. Edited by Martin L. Hoffman and Lois W. Hoffman. New York: Russe11-Sage Foundation, 1964.

16. Beker, Jerome. Critical Incidents in Child Care: A Case Book for Child Care Workers. New York: Behavioral Publications, 1972.

17. Be11, John Elderkin. Family Therapy. New York: Jason Aronson, 1975.

18. "A Theoretical Position for Family Group Therapy." Family Process 2 (March 1963): 1-14.

19. Be11, Richard Q. "Retrospective Attitude Studies of Parent-Child Relations." Child Development 29 (September 1958): 323-337.

20. Berkowitz, Irving $H$. and Sugar, Max. "Indications and Contraindications for Adolescent Group Psychotherapy." In The Adolescent in Group and Family Therapy, pp. 3-26. Edited by Max Sugar. New York: Brunner/Maze], 1975.

21. Bertcher, Harvey J. "The Child Care Worker as Role Model." Chizd Care Quarterly 2, no. 3 (1973): 178-191.

22. "Factors that Affect the Attitudes of Girls Toward Staff in a Correctional Institution." D.S.W. dissertation, University of Southern California, 1966.

23. Bettelheim, Bruno. A Home for the Heart. New York: Alfred A. Knopf, 1974.

24. Bienvenu, Millard J., Sr. "Measurement of Parent-Adolescent Communication." The Family Coordinator (Apri1 1969): 117-121.

25. - Parent-Teenager Communication: Bridging the Generation Gap. Public Affairs Pamphlet No. 438, Public Affairs Committee, 1969.

26. Brood, Linda, and D'Ange10, Rocco. "A Progress Research Report on Value Issues in Conflict Between Runaways and Their Parents." Journal of Marriage and the Family (August 1974): 486-491.

27. Blos, Peter. On Adolescence: A Psychoanalytical Interpretation. New York: The Free Press, 1962.

28. "Three Typical Constellations in Female Delinquency.". In Family Dynamics and Female Sexual Delinquency, pp. 99-110. Edited by Otto Pollak and Alfred S. Friedman. Palo Alto, California: Science and Behavior Books, 1969. 
29. Bronfenbrennar, Urie. "Toward a Theoretical Model for the Analys is of Parent-Child Relationships in a Social Context." In Parental Attitudes and Child Behavior, pp. 90-109. Edited by John C. Glidewe11. Springfield, Illinois: Charles C. Thomas, 1961.

30. Chorost, S. B. "Parental Child Rearing Attitudes and the Correlates in Adolescent Hostility." Genetic Psychology Monographs 66 (1962): 49-90.

31. Cleghorn, John M. and Levin, Sol. "Training Family Therapists by Setting Learning Objectives." American Journal of Orthopsychiatry 43 (Apri1 1973): 439-446.

32. Committee on the Family Group for the Advancement of Psychiatry. Treatment of Families in Conflict: The Clinical Study of Family Process. New York: Science House, 1970.

33. Conrad, Gertrude. "The Runaway Adolescent Girl." In Selected Current Essays on Runaway Youth, pp. 19-40. Edited by Rocco D'Ange10. Ohio State University: School of Social Work, 1975.

34. Cumming, John and Cumming, Elaine. Ego and Milieu: Theory and Practice of Environmental Therapy. New York: Atherton Press, 1963.

35. D'Amato, Gabriel. Residential Treatment for Child Mental Health: Towards Ego-Social Development and a Comminity-Child Model. Springfield, Illinois: Charles C. Thomas, 1969.

36. D'Ange10, Rocco, ed. Dialogues on Key Issues Relevant to Runaway Youth Programs and Policies. Ohio State University: School of Social Work, 1974.

37. D'Ange10, Rocco, et a1. Families of Sand: A Report Concerning the Flight of Adolescents from Their Families. Ohio State University: School of Social Work, 1974.

38. Duncan, Pam. "Parental Attitudes and Interactions in Delinquency." Child Development 42, no. 6 (1971): 1750-1765.

39. Dyer, Wayne W. Your Erroneous Zones. New York: Funk \& Wagna11s, 1976.

40. Elder, Glen H., Jr. "Parental Power Legitimation and Its Effect on the Adolescent." Sociometry 26 (1963): 50-65.

41. . "Structural Variations in the Child Rearing Relationship." Sociometry 25 (1962): 241-262.

42. Erikson, Erik. Chizdhood and Society. New York: W. W. Norton and Company, 1950. 
43. - Identity, Youth and Crisis. New York: W. W. Norton and Company, 1968.

44. Fischer, Joel. Analyzing Research: A Guide for Social Workers. Research Monograph. University of Hawaii: School of Social Work, 1975.

45. Foster, Randa11 M. "Intrapsychic and Environmental Factors in Running Away from Home." American Journal of Orthopsychiatry 32 (1962): 486-49].

46. Framo, James L. "Symptoms from a Family Transactiona] View-Point." In Progress in Group and Family Therapy, pp. 271-308. Edited by Clifford J. Sager and Helen Singer Kapian. New York: Brunner/Maze1, 1972.

47. Freeman, Ellen W. "Youth Flight and Family Authority." In Selected Current Essays on Runcway Youth, pp. 41-53. Edited by Rocco D'Angelo. Ohio State University: School of Social Work, 1975.

48. Freud, Anna. "Adolescence as a Developmental Disturbance." In Adolescence: Psychosocial Perspectives, pp. 5-10. Edited by Gerald Caplan and Serge Lebovici. New York: Basic Books, 1969.

49. Friedman, Alfred, ed. Therapy with Families of Sexually Acting-Out Girls. New York: Springer Publishing, 1971.

50. Gerson, David. Patterns of Social Functioning in Families with Marital and Parent-Child Problems. Toronto, Canada: University of Toronto Press, 1967.

51. Gi]dea, Margaret C. -L.; Glidewe11, John C.; and Kantor, Mildred B. "Maternal Attitudes and General Adjustment in School Children." In Parental Attitudes and Child Behavior, pp. 42-89. Edited by John C. Glidewell. Springfield, Illinios: Charles C. Thomas, 1961.

52. Glasser, Paul H. "Changes. in Family Equilibrium During Psychotherapy." In Families in Crisis, pp. 302-319. Edited by Paul H. Glasser and Lois N. Glasser. New York: Harper \& Row, 1970.

53. Glasser, Paul and Glasser, Lois. "Adequate Family Functioning." In Families in Crisis, pp. 290-301. Edited by Paul H. Glasser and Lois N. Glasser. New York: Harper \& Row, 1970.

54. Glasser, William. Reality Therapy: A New Approach to Psychiatry. New York: Harper \& Row, 1975. 
55. Gordon, Thomas. P.E.T. - Parent Effectiveness Training: The Tested New Way to Raise Responsible Children. New York: Plume Books, 1975.

56. Gralnick, Alexander. "The Adolescent Within an Adult Treatment Program." In Mental Health Services for Adolescents, pp. 117131. Edited by Sol Nichtern. New York: Frederick A. Praeger, 1968.

57. Grant, Quentin Rae and Kantor, Mildred B. "Some Limitations of the Effects of Maternal Attitudes on Child Behavior." In Parental Attitudes and Child Behavior, pp. 183-187. Edited by John C. Glidewe11. Springfield, I1linois: Charles C. Thomas, 1961.

58. Haley, Jay. "Family Therapy." In Progress in Group and Family Therapy, pp. 261-270. Edited by Clifford J. Sager and Helen Singer Kaplan. New York: Brunner/Maze1, 1972.

59. Hamblin, Robert and Vanderplas, James $M$. "Some Notes on the Strategy of Research." In Parental Attitudes and Child Behavior, pp. 188-206. Edited by John C. Glidewel1. Springfield, I1linois: Charles C. Thomas, 1961:

60. Hammer, Signe. Daughters and Mothers: Mothers and Daughters. New York: The New York Times Book Company, 1975.

61. Hersche1, A1t. Residential Treatment for the Disturbed Child: Basic Principles in Planning and Design of Programs and Facilities. New York: International Universities Press, 1960.

62. Hi11, Margaret. Parents and Teenagers. Public Affairs Pamphlet No. 490, Public Affairs Committee, 1973.

63. Hoffman, Martin L. "Power Assertion by the Parent and Its Impact on the Child." Chizd Development 31 (1960): 129-143.

64. Howe11, M. C.; Emmons, E. B.; and Franks, D.'A.' "Reminiscences of Runaway Adolescents." American Journal. of Orthopsychiatry 43 (October 1973): 840-853.

65. Jackson, Don D. "The Study of the Family." In Family Process, pp. 111-130. Edited by Nathan W. Ackerman. New York: Basic. Books, 1970.

66. Jenkins, Richard L. "The Runaway Reaction." American Journal of Psychiatry 128 (1971): 168-173.

67. Jourard, Sidney M. and Remy, Richard. "Perceived Parental Attitudes, the Self, and Security." Journal of Consulting Psychology 19 (1955): $364-366$. 
68. King, Charles H. "Family Therapy with the Deprived Family." Social Casework 48 (Apri1 1967): 203-208.

69. Konopka, Gisela. The Adolescent Girl in Conflict. Englewood Cliffs, New Jersey: Prentice-Ha11, 1966.

70. Young Girls: A Portrait of Adolescence. Englewood Cliffs, New Jersey: Prentice-Ha11, 1967.

71. Kovar, Lillian Cohen. Faces of the Adolescent Girl. Englewood C1iffs, New Jersey: Prentice-Ha11, 1968.

72. Lerner, Richard M. and Knapp, John R. "Actual and Perceived Intrafamilial Attitudes of Late Adolescents and Their Parents." Journal of Youth and Adolescence 4 (1975): 17-36.

73. Lewis, J. M. "The Development of an Inpatient Adolescent Service." Adolescence 5 (1970): 303-311.

74. Lidz, Theodore.: "The Adolescent and His Family." In Adolescence: Psychosocial Perspectives. Edited by Gerald Caplan and Serge Lebovici. New York: Basic Books, 1969.

75. Lin, Nan. The Study of Human Communication. Indianapolis: The Bobbs-Merri11 Company, 1973.

76. Loevinger, Jane and Sweet, Blanche. "Construction of a Test of Mothers' Attitudes." In Parental Attitudes and Child Behavior, pp. 110-123. Edited by John C. Glidewe11. Springfield, I1linois: Charles C. Thomas, 1961.

77. Maier, Henry W. Three Theories of Child Development: The Contributions of Erik H. Erikson, Jean Piaget, and Robert R. Sears, and Their Applications. New York: Harper \& Row, 1965.

78. Maluccio, Anthony N. and Marlow, Wilma 0. "Residential Treatment of Emotiona17y Disturbed Children: A Review of the Literature." Social Service Review 46 (1972): 230-250.

79. Matek, Ord. "Adolescent Flight: Three Basic Variations of Acting Out." In Selected Current Essays on Runaway Youth, pp. 7-18. Edited by Rocco D'Angelo. Ohio State University: School of Social Work, 1975.

80. Mayer, Morris Fritz. "The Parental Figures in Residential Treatment." Social Service Review 34 (1960): 273-285.

81. Mays, John Barron. "The Adolescent as a Social Being." In Modern Perspectives in Adolescent Psychiatry, pp. 126-151. Edited by John G. Howe11s. New York: Brunner/Maze1, 1971. 
82. Meissner, W. W. "Thinking About the Family-Psychiatric Aspects." In Family Process, pp. 131-170. Edited by Nathan W. Ackerman. New York: Basic Books, 1970.

83. Munns, Meredith. "Is There Really a Generation Gap?" Adolescence 6 (Summer 1971): 197-206.

84. Mussen, Paul Henry; Conger, John Janeway; and Kagan, Jerome. Child Development and Personality. New York: Harper \& Row, 1956.

85. Muus, Rolf E. Theories of Adolescence. New York: Random House, 1964.

86. Offer, Daniel and Offer, Judith. "Four Issues in the Developmental Psychology of Adolescents." In Modern Perspectives in Adolescent Psychiatry, pp. 117-129. Edited by John G. Howel1s. New York: Brunner/Maze1, 1971.

87. Offer, Daniel and VanderStoep, Evert. "Indications and Contraindications for Family Therapy." In The Adolescent in Group and Family Therapy, pp. 145-160. Edited by Max Sugar. New York: Brunner/Maze1, 1975.

88. Portnoy, Sanford M. "Power of Child Care Worker and Therapist Figures and Their Effectiveness as Models for Emotionally Disturbed Children in Residential Treatment." Journal of Consulting and Clinical Psychology 40 (1973): 15-19.

89. Portnoy, Sanford M.; Biller, Henry B.; and Davids, Anthony. "The Influence of the Childcare Worker in Residential Treatment." American Journal of Orthopsychiatry 42 (Ju7y 1972): 719-722.

90. Poteet, Lou. "Manifesto on Youth Liberation:" In Selected Current Essays on Runaway Youth, pp. 55-63. Edited by Rocco D'Angelo. Ohio State University: School of Social Work, 1975 .

91. Red1, Fritz. "Strategies and Techniques of the Life Space Interview." American Journal of Orthopsychiatry 29 (1959): 1-19.

92. When We Deal with Children. New York: The Free Press, 1966 .

93. Riemer, Morris D. "Runaway Children." American Journal of Orthopsychiatry 10 (1940): 522-526.

94. Robey, Ames. "The Runaway Gir1." In Family Dynamics and Female Sexual Delinquency, pp. 127-137. Edited by Otto Pollak and Alfred S. Friedman. Palo Alto, California: Science and Behavior Books, 1969. 
95. Robey, Ames, et a1. "The Runaway Girl: A Reaction to Family Stress." American Journal of Orthopsychiatry 34 (1964): $762-767$.

96. Rode, Alex. "Perceptions of Parental Behavior Among Alienated Adolescents." Adolescence 6 (Spring 1971): 19-38.

97. Satir, Virginia. Conjoint Family Therapy: A Guide to Theory and Technique. Palo Alto, California: Science and Behavior Books, 1967.

98. - Peoplemaking. Palo Alto, California: Science and Behavior Books, 1972.

99. "You as a Change Agent." In Helping Families to Change, pp. 37-62. Edited by Virginia Satir, James Stachowiak, and Harvey A. Tachsman. New York: Jason Aronson, 1975.

100. Schaefer, Ear] S. "Chi]dren's Reports of Parental Behavior: An Inventory." Child Development 36 (1965a): 413-424.

101.

"Converging Conceptual Mode1s for Maternal Behavior and for Child Behavior." In Parental Attitudes and Child Behavior, pp. 124-146. Edited by John C. Glidewe11. Springfield, I1linois: Charles C. Thomas, 1961.

102. Schaefer, Earl S. and Be11, Richard Q. "Development of a Parental Attitude Research Instrument." Child Development 29 (September 1958): 339-361.

103. Scherz, Frances H. "The Crisis of Adolescence in Family Life." Social Casework 48 (Apri1 1967): 209-215.

104. Shapiro, Roger L. "Adolescent Ego Autonomv and the Family." In Adolescence: Psychosocial Perspectives, pp. 113-121. Edited by Gerald Caplan and Serge Lebovicj. New York: Basic Books, 1969.

105. Sheehy, Gai1. Passages: Predictable Crises of Adult Life. New York: E. P. Dutton \& Company, 1974.

106. Shellow, Robert; Schamp, Juliana R.; Liebow, Elliot; and Unger, Elizabeth. Suburban Runaways of the 1960's. Monographs of the Society for Research in Child Development, 32, no. 3. Chicago: The University of Chicago Press, 1967.

107. Smith, Judith and Smith, Donald. Child Management: A Program for Parents and Teachers. The University of Michigan: Ann Arbor Publishing, 1964. 
108. Stachowiak, James. "Functional and Dysfunctional Families." In Helping Families to Change, pp. 65-77. Edited by Virginia Satir, James Stachowiak, and Harvey A. Tachsman. New York: Jason Aronson, 1975.

109. Stierlin, Helm. Separating Parents and Adolescents: A Perspective on Running Away, Schizophrenia and Waywardness. New York: The New York Times Book Company, 1974.

110. Stinnett, Nick; Farris, Jo Ann; and Walters, James. "Parent-Child Relationships of Male and Female High School Students." Journal of Genetic Psychology 125 (1974): 99-106.

111. Sutherland, Rosemary Brown. "Residential Treatment of Emotional1y Disturbed Adolescents." M.S.W. Practicum, Portland State University, 1976.

112. Tachsman, Harvey. "Developments and Innovations in Family Therapy in a Changing Society." In Helping Families to Change, pp. 17-35. Edited by Virginia Satir, James Stachowiak, and Harvey A. Tachsman. New York: Jason Aronson, 1975.

113. Thomas, Darwin L.; Gecas, Vicktor; Weigart, Andrew; and Rooney, Elizabeth. Family Socialization and the Adolescent: Determinants of Self-Concept, Conformity, Religiosity, and Counterculture Values. Lexington, Massachusetts: D. C. Heath and Company, 1974.

114. Trieschman, Albert E.; Whittaker, James K.; and Brendtro, Larry. The Other 23 Hours: Childcare Work with Emotionally Disturbed Children in a Therapeutic Milieu. Chicago: Aldine Publishing, 1969.

115. Vedder, Clyde and Sommerville, Dora B. The Delinquent Girl. Springfield, Illinois: Charles C. Thomas, 1970.

116. Wattenberg, William. The Adolescent Years. 2nd ed. New York: Harcourt Brace Jovanovick, 1973.

117. Weinar, Irving B. "The Generation Gap--Fact and Fancy." AdoZescence 6 (Summer 1971): 155-166.

118. Wenberg, John and Wilmot, William. The Personal Communication Process. New York: John Wiley \& Sons, 1973.

119. Wilmot, William. Dyadic Comminication: A Transactional Perspective. Reading, Massachusetts: Addison-Wesley Publishing, 1975.

120. Wineman, David. "The Life-Space Interview.". Social Work 4 (January 1959): 3-17. 
121. Wynne, Lyman. "Communication Disorders and the Quest for Relatedness in Families of Schizophrenics." In progress in Group and f'amily Therapy, pp. 595-615. Edited by Clifford J. Sager and Helen Singer Kaplan. New York: Brunner/Maze1, 1972.

122. Zuk, Gerald H. "The Side-Taking Function." In Progress in Group and Family Therapy, pp. 376-384. Edited by Clifford J. Sager and Helen Singer Kaplan. New York: Brunner/Mazel, 1972.

123. "The Victim and His Silencers: Some Pathogenic Strategies Against Being Silenced." In Family Therapy and Disturbed Families, pp. 106-117. Edited by Gerald H. Zuk and Ivan Boszormenyi-Nagy. Palo A7to, California: Science and Behavior Books, 1967. 
APPENDIX A

DEMOGRAPHIC FACE SHEET 
APPENDIX A

DEMOGRAPHIC FACE SHEET

Date of entrance

Date of release

1. Client ID Number

2. Age

3. Client's most recent family setting:

Both natural parents

Natural mother and stepfather

Natural father and stepmother

Natural mother only

Natural father only

Foster parents

Relatives. Specify

other. Specify

4. Length of time client has lived in most recent family setting

5. Marital status of client's natural parents:

Intact

Separated

Divorced

Deceased

Never married

6. Last grade completed: $\begin{array}{llllllllllll}1 & 2 & 3 & 4 & 5 & 6 & 7 & 8 & 9 & 10 & 11 & 12\end{array}$

7. Client's current educational status prior to Bridge:

In school

Dropped out. Length of time.

Suspended or expelled. Length of time

other. Specify

8. Client's prior involvement with the juvenile justice system (status or delinquent):

None

Police arrest. No. of times

Institutionalized

Reason(s)

Placed on probation 
Client ID Number.

$-2-$

9. Place to which client initially ran:

Other than runaway or pushout

Friend

Relative

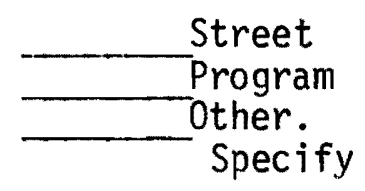

10. Duration of $\mathrm{client's} \mathrm{current} \mathrm{run} \mathrm{at} \mathrm{intake} \mathrm{(days)}$

11. Number of times client has previously run

12. Services provided to the client on an ongoing basis (total number upon release).

Individua 1
Family
Peer

13. Disposition of client's case:

Returned to primary family home

Placed with relatives. Specify

Placed with friends. Specify

Placed in foster home

Placed in group home

placed in other alternative living arrangement. Specify. Independent living

Went to street

Removed by police, court or legal system.

other. Specify. 
APPENDIX B

QUESTION CONTENT AND PROCESS CATEGORIES 


\section{APPENDIX B \\ QUESTION CONTENT AND PROCESS CATEGORIES}

The following statements were used in the measuring instrument to determine adolescent perceptions of communication behavior. The statement (with its corresponding questionnaire number) related to parent communication behavior appears first and is followed by the statement (with its corresponding questionnaire number) related to adult conmunication behavior. These statements are classified according to process and content category. For more information on process categories, see Chapter II, pages 42-54. For more information on content categories, see Chapter II, pages 56-68.

01) My parents do what they say they are going to do.

26) Adults do what they say they are going to do.

Process Category: Sending Information.

Content Category: Consistency between actions and words.

02) Wy parents try to understand how I fee].

17) Adults try to understand how I feel.

Process Category: Receiving Feelings.

Content Category: Use of empathy.

03) My parents don't want to hear what I have to say about decisions affecting me.

16) Adults don't want to hear what I have to say about decisions affecting me.

Process Category: Receiving Information.

Content Category: Input into decision-making. 
04) My parents give me the "silent treatment" when they are angry at me. 13) Adults give me the "silent treatment" when they are angry at me.

Process Category: Sending Feelings.

Content Category: Expression of anger.

05) My parents are willing to explain rules.

03). Adults are willing to explain rules.

Process Category: Sending Information

Content Category: Use of information-checks and explanations.

06) My parents ignore me when I tell them how I feel.

11) Adults ignore me when I tell them how I feel.

Process Category: Receiving Feelings.

Content Category: Use of negation.

07) My parents jump to conclusions and don't let me finish what I want to say.

01) Adults jump to conclusions and don't let me finish what I want to say.

Process Category: Receiving Information.

Content Category: Use of verbal disruption.

08) It's hard for me to know what my parents are feeling.

02) It's hard for me to know what adults are feeling.

Process Category: Sending Feelings.

Content Category: Expression of affect.

09) My parents check to make sure I understand what they tell me.

06) Adults check to make sure I understand what they tell me.

Process Category: Sending Information.

Content Category: Use of information-checks and explanations. 
10). When I get angry at my parents, they then get angry at me.

18) When I get angry at adults, they then get angry at me.

Process Category: Receiving Feelings.

Content Category: Expression of anger.

11) When I ask my parents a question, they preach at me instead of answering my question.

25) When I ask adults a question, they preach at me instead of answering my question.

Process Category: Receiving Information

Content Category: Use of preaching.

12) My parents try to make me feel guilty when I have done something they told me not to do.

22) Adults try to make me feel guilty when I have done something they told me not to do.

Process Category: Sending Feelings.

Content Category: Use of guilt-induction.

13) When decisions are made concerning me, my parents ask for my ideas.

23) When decisions are made concerning me, adults ask for my ideas.

Process Category: Sending Information.

Content Category: Input into decision-making.

14) My parents tell me how I should feel, instead of accepting the way I really feel.

09) Adults tell me how I should feel, instead of accepting the way I really feel.

Process Category: Receiving Feelings.

Content Category: Use of guilt-induction. 
15) When I talk to my parents, they 1 isten calmly and without interruptions.

08) When I talk to adults, they jisten calmly and without interruptions.

Process Category: Receiving Information

Content Category: Use of verbal disruption.

16) My parents give me messages that they trust me.

19) Adults give me messages that they trust me.

Process Category: Sending Feelings.

Content Category: Use of validation.

17) My parents threaten or yell at me when they want me to do something.

12) Adults threaten or yell at me when they want me to do something.

Process Category: Sending Information.

Content Category: Use of threats.

18) When I express my feelings, my parents make fun of me.

07) When I express my feelings, adults make fun of me.

Process Category: Receiving Feelings.

Content Category: Use of negation.

19) When my parents are angry at me, they talk about it calmly with me.

10) When adults are angry at me, they talk about it calmly with me.

Process Category: Sending Feelings.

Content Category: Expression of anger.

20) My parents respect my opinions even if they don't agree with them.

05) Adults respect my opinions even if they don't agree with them.

Process Category: Receiving Information.

Content Category: Use of validation. 
21) My parents let me blow off steam when I am mad.

04) Adults let me blow off steam when I am mad.

Process Category: Receiving Feelings.

Content Category: Expression of anger.

22) Mly parents talk to me as if I were still a little girl.

15) Adults talk to me as if I were still a little girl.

Process Category: Sending Information.

Content Category: Use of validation.

23) When my parents and I argue, they bring up angry feelings related to other things from the past.

14) When adults and I argue, they bring up angry feelings related to other things from the past.

Process Category: Sending Feelings.

Content Category: Expression of anger.

24.) My parents listen when I tel] them about the things which have made me happy.

21) Adults listen when I tell them about the things which have made me happy.

Process Category: Receiving Feelings.

Content Category: Use of empathy.

25) My parents tell me my ideas are dumb.

20) Adults tell me my ideas are dumb.

Process Category: Receiving Information.

Content Category: Use of validation.

26). My parents praise and encourage me.

24) Adults praise and encourage me.

Process Category: Sending Feelings.

Content Category: Use of praise. 
APPENDIX C

COVER SHEETS AND QUESTIONNAIRE 


\section{APPENDIX C}

\section{COVER SHEETS AND QUESTIONNAIRE}

This cover letter was attached to the questionnaire which the girls filled out before program involvement.

The Bridge is a new program to help you and your family work out hassles and get along better. In order for us to understand these hassles and to help us improve the program, it is important for us to know how you see your parents and how you see other adults. We would like you to fill out the questions on the following pages. Your answers will help us to make the program better for you.

Your answers will be confidential. Neither your parents nor staff members of the Bridge will see your individual answers. At the end of the study, everybody's answers will be added up by the research team and these anonymous results will be available to the Bridge.

We hope that you will answer each question frankly and truthfully. If you have any questions, ask the person who is giving the questionnaire.

Thank you for your cooperation.

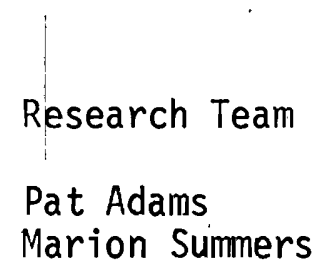


This cover letter was attached to the questionnaire which the girls filled out after program involvement.

When you first came to the Bridge, you were asked to fill out a questionnaire to let us know how you saw your parents and other adults. Now that you are leaving the Bridge, we would like to have you fill out a similar questionnaire. We would like to know how you see your parents and how you see other adults right now. Your answers will help us to improve the program at the Bridge.

Your answers will be confidential. Neither your parents nor staff members of the Bridge will see your individual answers. At the end of the study, everybody's answers will be added up by the research team and these anonymous results will be available to the Bridge.

We hope that you will answer each question frankly and truthfully. If you have any questions, ask the person who is giving the questionnaire. Thank you for your cooperation.

Research Team

Pat Adams

Marion Summers 
The girls were given this questionnaire before and after program involvement with the appropriate cover letter attached.

Please answer all the following questions. Place an $X$ next to the answer that best describes how you see your parents.

1) My parents do what they say they are going to do.

2) My parents try to understand how I feel

3) My parents don't want to hear what I have to say about decisions affecting me.

4) My parents give me the "silent treatment" when they are angry at me.

5) My parents are willing to explain rules

6) My parents ignore me when I tel1 them how I feel.

7) My parents jump to conclusions and don't let me finish what I want to say.

8) It's hard for me to know what my parents are feeling.
A Tways

Often

Seldom

Never

Always

often

Seldom

Never

Always

Often

Seldom

Never

Always

Often

Seldom

Never

Always

often

Seldom

Never

Always

Often

Seldom

Never

Always

Often

Seldom

Never

Always

Often

Seldom

Never
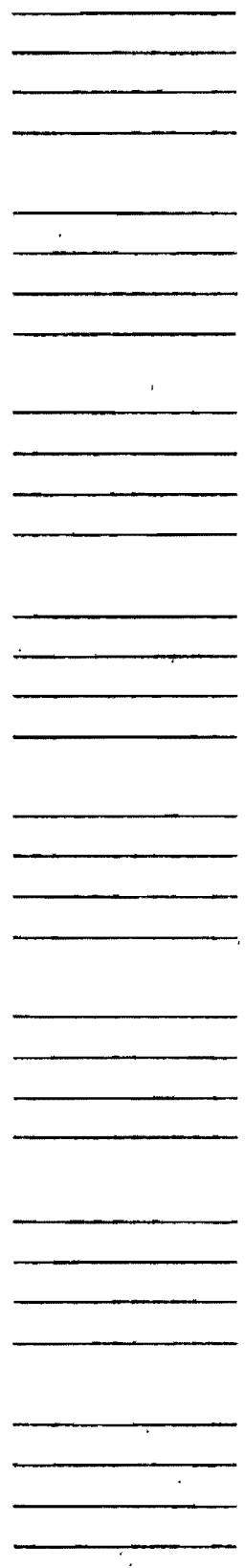
9) My parents check to make sure I understand what they tell me.

10) When I get angry at my parents, they then get angry at me.

11) When I ask my parents a question, they preach at me instead of answering my question.

12) My parents try to make me feel guilty when I have done something they told me not to do.

13) When decisions are made concerning me, my parents ask for my ideas.

14) My parents tell me how I should feel, instead of accepting the way I really feel.

15) When I talk to my parents, they listen calmly and without interruptions.

16) My parents give me messages that they trust me.

17) My parents threaten or ye11 at me when they want me to do something.

18) When I express my fee 7 ings, my parents make fun of me.
Always

often

Seldom

Never

Always

Often

Seldom

Never

Always

Often

Seldom

Never

Always

Often

Seldom

Never

Always

Often

Seldom

Never

Always

often

Seldom

Never

Always

Often

Seldom

Never

Always

Often

Seldom

Never

Always

Often

Seldom

Never

A]ways

often

Seldom

Never
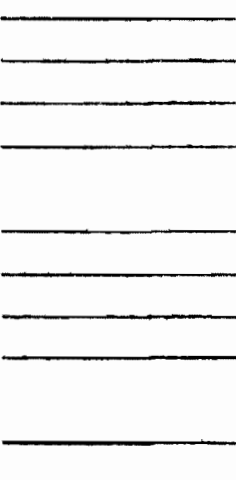

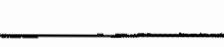
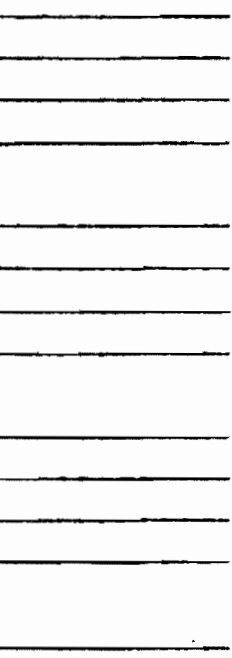

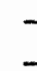
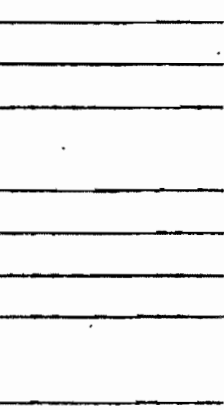

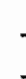
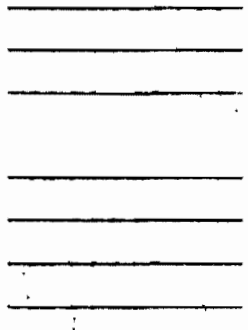
19) When my parents are angry at me, they talk about it calmly with me.

20) My parents respect my opinions even if they don't agree with them.

21) My parents let me blow off steam when I am mad.

22) My parents talk to me as if I were still a little girl.

23) When my parents and I argue, they bring up angry feelings related to other things from the past.

24) My parents listen when I tell them about the things which have made me happy.

25) My parents tel1 me my ideas are dumb.

26) My parents praise and encourage me.
Always

often

Seldom

Never

Always

often

Seldom

Never

Always

often

Seldom

Never

A lways

often

Seldom

Never

Always

often

Seldom

Never

Always

often

Seldom

Never

Always

Often

Seldom

Never

Always

often

Seldom

Never

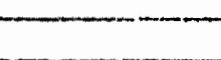
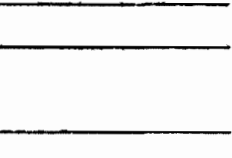

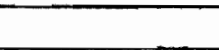
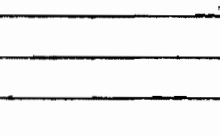

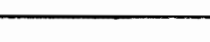
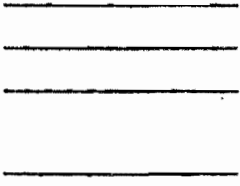

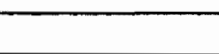
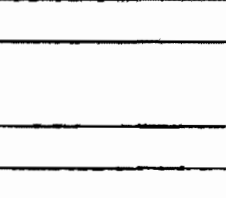

$\longrightarrow$
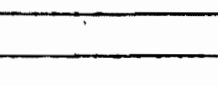

$+2$

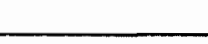

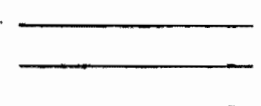


Please answer all the following questions. Place an $X$ next to the answer that best describes how you see other adults. (When you see the word Adults this means adults that you know other than your parents such as teachers., group home staff, counselors.)

Do not think of your parents when you answer these questions.

1) Adults jump to conclusions and don't let me finish what I want to say.

2) It's hard for me to know what adults are feeling.

A]ways

Often

Se 1dom

Never

Aiways

Often

Seldom

Never

3) Adults are willing to explain rules.

Always

Often

Seldom

Never

4) Adults let me blow off steam when I am mad.

ATways

Often

Seldom

Never

5) Adults respect my opinions even if they don't agree with them.

6) Adults check to make sure I understand what they tell me.

7) When I express my feelings, adults make fun of me.

Always

Often

Seldom

Never

A]ways

Often

Seldom

Never

Always

Often

Seldom

Never

8). When I talk to adults, they

ATways

listen calmly and without

Often

Seldom

Never 
9) Adults tell me how I should feel, instead of accepting the way I really feel.

Always

Often

Seldom

Never

10.) When adults are angry at me, they talk about it calmly with me.

Always

Often

Seldom

Never

11) Adults ignore me when I tell them how I feel.

Always

often

Seldom

Never

12) Adults threaten or yell at me when they want me to do something.

Always

often

Seldom

Never

13) Adults give me the "silent treatment" when they are angry at me.

A7ways

Often

Seldom

Never

14) When adults and I argue, they bring up angry feelings related to other things from the past.

15) Adults talk to me as if I were still a little girl.

Always

Often

Seldom

Never

Always

Often

Seldom

Never

16) Adults don't want to hear what I have to say about decisions affecting me.

Always

Often

Seldom

Never

17) Aduits try to understand how I feel.

Always

often

Seldom

Never

18) When I get angry at adults,

Always they then get angry at me.

often

Seldom

Never 
19) Adults give me messages that they trust me.

Always

often

Seldom

Never

20) Adults tell me my ideas are dumb.

Always

often

Seldom

Never

21) Adults listen when I tell them about the things which have made me happy.

Always

Often

Seldom

Never

22) Adults try to make me feel guilty when I have done something they told me not to do.

Always

Often

Seldom

Never

23) When decisions are made concerning me, adults ask for my ideas.

A]ways

Often

Seldom

Never

24) Adults praise and encourage me.

A]ways

often

Seldom

Never

25) When I ask adults a question, they preach at me instead of answering the question.

Always

Often

Seldom

Never

26) Adults do what they say they

Always

Often

Se]dom

Never
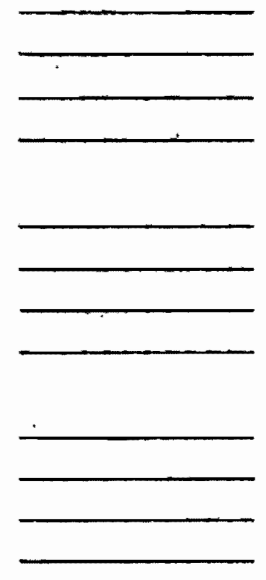
are going to do. 
APPENDIX D

DEFINITIONS OF STATISTICAL MEASURES 


\section{APPENDIX D}

\section{DEFINITIONS OF STATISTICAL MEASURES}

Mann-Whitney U-Test:

The Mann-Whitney U-Test is a nonparametric alternative to the t-test for two independent samples. It is commonly used where the experimenter draws two random samples from the same population, subjects each to a different experimental treatment, and compares the two on a single criterion. It may also be used in the situation in which independent random samples are drawn from two different parent populations and compared on a single criterion to determine whether the two populations differ. The Mann-Whitney U-Test requires data on at least an ordinal scale and is useful with small samples.

In computations for this test, the scores in each sample are ranked. Then $U_{a}$ and $U_{b}$ are determined using the following formulas:

$$
\begin{aligned}
& U_{a}=n_{a} n_{b}+\frac{n_{b}\left(n_{b}+1\right)}{2}-\sum R_{b} \\
& U_{b}=n_{a} n_{b}+\frac{n_{a}\left(n_{a}+1\right)}{2}-\sum R a
\end{aligned}
$$

The calculated $U$ is the smaller of $U_{a}$ and $U_{b}$, and is then compared to the tabled value at the desired level of significance and for the appropriate sample size. When a large number of scores are compared, the following formula is used to transform the $U$ into a $z$ score for comparison to the normal distribution: 


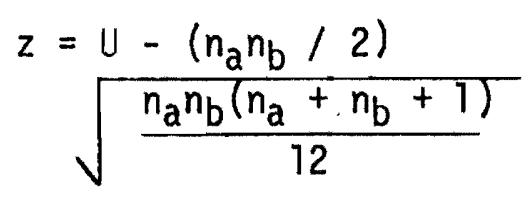

Wilcoxen Matched-Pairs Signed-Ranks Test:

The Wilcoxen Matched-Pairs Signed-Ranks Test is a nonparametric a]ternative to the t-test for two related samples. It may be used in either repeated measurements or matched-pairs types of designs. The Wilcoxen Test requires data on at least an ordinal scale and is used when sample sizes are equal. In this test the differences between the matched scores are ranked. Next, the sum of the ranks of the positive differences and the sum of the ranks of the negative differences are found. The smaller of these sums (s) is then compared to the tabled values at the desired level of significance and for the appropriate value of $N$ (number of differences).

Median:

The median is a measure of central tendency and is a point on the score scale below which one-half of the scores fall. In determining the median, the data is first arranged in a frequency distribution with unit intervals and the following formula is used to compute the median:

$$
\text { median }=X_{u}-\frac{(c f-.5 N)}{f}
$$

where $X_{u}$ is the upper real limit, $f$ the frequency, and $c f$ the cumulative frequency of the median interval.

Chi-Square Median Test:

The Chi-Square Median Test is a nonparametric alternative to the 
t-test for two independent samples when the assumptions underlying both the t-test and the Mann-Whitney U-Test cannot be met. It is an application of the chi-square test of independence in the situation in which the investigator has ordinal data and wishes to determine whether there is a significant difference in the scores of two or more samples. The scores for all samples are arranged in a single ordered series and their common median determined. Then a contingency table is constructed with one column for each sample and with two rows; the top row is for individuals who scored above the median, the bottom for individuals who scored below the median. The chi square statistic is then calculated from the formula and compared to the tabled value for the appropriate degree (s). of freedom:

$$
x^{2}=\sum \sum \frac{(0 i j-E i j)^{2}}{E i j}
$$

Ratio Score:

In determining a ratio score, all responses to the question(s) were totaled. This total was divided by the highest possible score for each question(s) to yield a ratio score. 